\title{
Anais da Oficina do Artigo by Acervo+
}

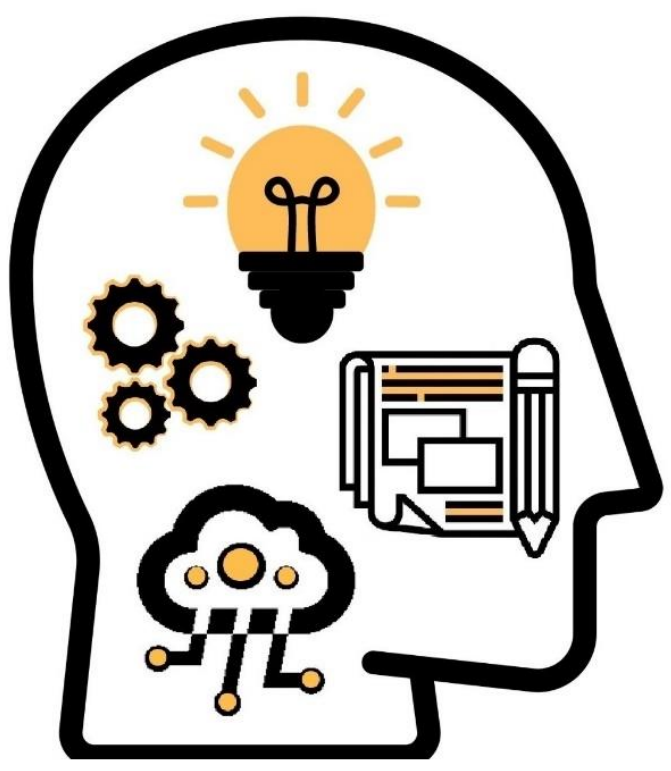

Apoio:

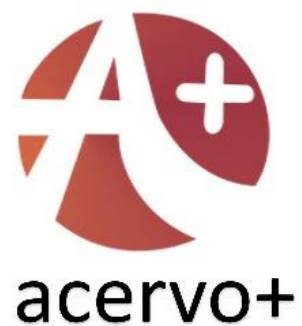
Eventos

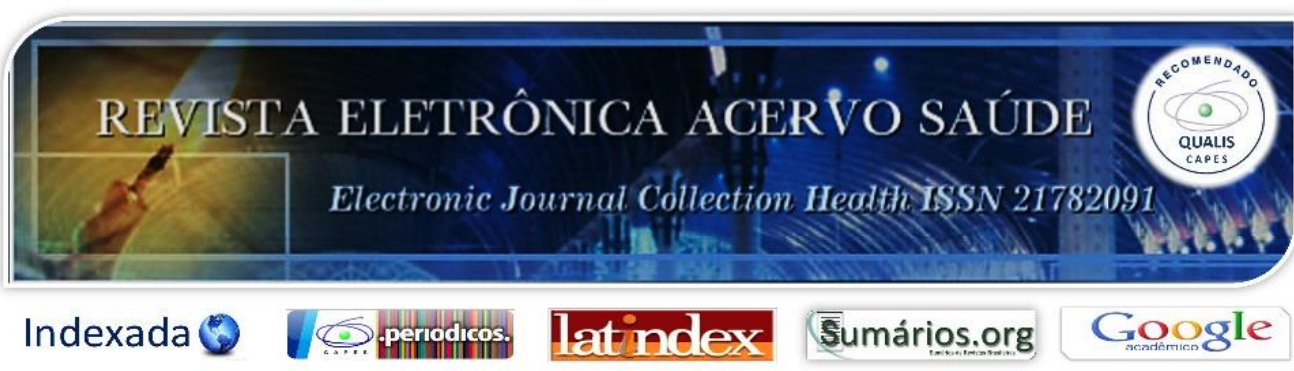




\section{Sumário}

SOBRE O EVENTO.

EDITORIAL

Originais

Mortalidade materna na Região Metropolitana de Belém-Pará, Brasil, entre 2013 e 2017.

Mortalidade por câncer na Região Norte do Brasil na série histórica 2010-2017

Perfil de mulheres grávidas atendidas em uma Estratégia de Saúde da Família no estado do Pará, Brasil 14

Diagnóstico nutricional em pessoas que vivem com HIV/AIDS em terapia antirretroviral atendidos em ambulatório de referência no Nordeste.

Adesão terapêutica à terapia antirretroviral em pessoas que vivem com HIV/AIDS atendidas em ambulatório de referência no Nordeste.

Incremento molecular na acitretina: uma avaliação toxicológica in silico.

Proposta de modificação molecular in silico do bexaroteno: uma análise das propriedades físicoquímicas, farmacocinéticas e toxicológicas.....

Aspectos epidemiológicos dos casos notificados de tentativas de suicídio por intoxicação exógena no

Estado do Piauí

Prevalência de sífilis em gestantes em uma região de saúde no Oeste da Bahia.....

Análise epidemiológica das vítimas de queimaduras através do sistema em informação em saúde DATASUS

Internações por infecções agudas das vias aéreas superiores no Brasil (2019-2020) 30

Levantamento de óbitos por infecções das vias aéreas superiores.

Classificação dos tipos de conteúdos nas fake news em saúde relacionadas ao Coronavírus

Conhecimento de homens universitários quanto ao uso de anticoncepcional de emergência: estudo seccional

Exame de mapeamento enzimático salivar como sinalizador de doença gástrica e prevenção da erosão dental: uma revisão integrativa.

SARS-COV-2 e o impacto odontológico: revisão sistematizada da literatura

Erosão dental em crianças e adolescentes associada ao estilo de vida- revisão sistematizada ......

Acidentes laborais com material biológico ocorridos em um hospital do Rio Grande do Sul

Obesidade, sedentarismo e dieta como fatores de risco para o desenvolvimento de Diabetes Mellitus tipo 2

O perfil dos praticantes de musculação da mesorregião do Centro-Oeste de Minas Gerais

A testagem da albumina na fase aguda da Leishmaniose 


\section{IR PARA O SUMÁRIO}

Identificação de variantes no gene SLC26A9 de acordo com o genótipo da variante rs7512462 em pacientes com fibrose cística (p.Phe508del/p.Phe508del)

Perfil e inatividade física dos docentes do ensino municipal de uma cidade da mesorregião Centro-Oeste

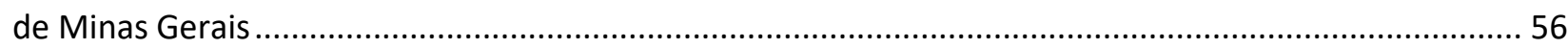

O cuidado em saúde no puerpério sob a perspectiva de usuárias da atenção básica............................... 58

Caracterização estrutural de nanopartículas de ferrita de cobalto dopadas com La ${ }^{3+}$ para aplicação em tratamento de água.

Comunicação dos serviços de um hospital universitário: perspectivas da gestão da clínica.

A invisibilização da depressão pós-parto paterna na Psicologia

Estudo de Caso

Frenectomia lingual em paciente adulto: estudo de caso 66

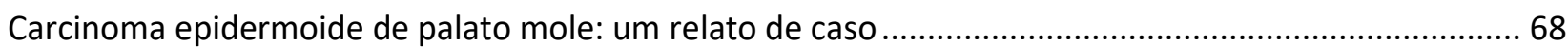

Reabilitação dental pós traumatismo em paciente pediátrico: relato de caso

Cimento de ionômero de vidro modificado por resina para reabilitar dente decíduo acometido por cárierelato de caso

Carcinoma epidermóide de palato mole: um relato de caso......

Relato de Experiência.

Intervenções de enfermagem para promoção do aleitamento materno no alojamento conjunto: relato de experiência

Estimulando a memória de idosos por meio de jogos educativos em período de pandemia por COVID-19: um relato de experiência..

Monitoria de saúde do adulto sob a perspectiva da teoria cognitivista: um relato de experiência 80 Grupo de estudo e pesquisa em enfermagem, cuidado e saúde (GEPEnCS): relato de experiência de docentes e discentes de uma instituição de ensino superior de Brasília.

Ação extensionista de educação em saúde: uma abordagem sobre a fotoeducação no combate ao câncer de pele.

Fale com a parteira: a notoriedade da teleorientação da enfermagem para gestantes e puérperas em tempos de pandemia.

Extensão e educação em saúde: uma abordagem interprofissional sobre o acidente vascular cerebral (AVC)...

Impacto da pandemia causada pela COVID-19 no cotidiano acadêmico de graduandos de enfermagem: relato de experiência.

Olhar acadêmico na assistência à parturientesde um centro de parto normal do nordeste: relato de experiência

Atuação de acadêmicos numa maternidade pública do recife pelo projeto de extensão amor que vem do peito: relato de experiência 
Vivências de um estágio curricular não obrigatório em enfermagem acerca da pandemia do novo coronavírus: um relato de experiência...

Educação em saúde: um relato de experiência sobre a capacitação de leigos em noções básicas de primeiros socorros.

Ações de prevenção do acidente vascular cerebral (AVC) de um projeto de extensão: o homem como figura com pouca participação

Educação em saúde: um relato de experiência sobre higienização das mãos e uso correto de máscaras

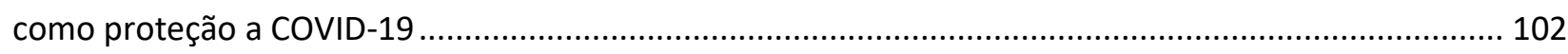

Educação em saúde com estudantes de graduação: um relato de experiência .. 104

Neurotoxoplasmose em pacientes com AIDS: Contribuições da equipe multiprofissional em um Hospital Universitário 106

Revisão Bibliográfica. 108

Abordagem da Síndrome da Dor Miofascial na Atenção Primária 108

A importância clínica da aortite sifilítica: uma revisão de literatura. 110

O despreparo durante a formação médica para a assistência ao paciente surdo 112

Abordagem multiprofissional no tratamento da anquiloglossia em recém-nascidos 114

Neuropatia Autonômica Cardiovascular na Diabetes Mellitus: compreendendo sua fisiopatologia e manifestações clínicas.

Recomendações sobre o aleitamento materno no enfrentamento ao COVID-19. 118

Fakes news em saúde na pandemia de COVID-19: Uma revisão da literatura. 120

As implicações do uso de cigarros eletrônicos no tratamento contra o tabagismo 122

Atuação da enfermagem na assistência em urgência e emergência à motociclistas vítimas de traumatismo cranioencefálico.

Proposta de modelagem molecular da Isotretinoína através de programas de química computacional 126

HIV/AIDS e o público feminino: prevalência em município de referência no Oeste da Bahia..... 128

Os efeitos terapêuticos do Allium sativum (alho) no sistema imunológico: uma revisão da literatura ... 130

Violência interparental e o processo de desenvolvimento infantil.

A Importância da biossegurança na odontologia em tempos do COVID-19 134

O impacto da Síndrome de Burnout em enfermeiros do setor de urgência e emergência: uma revisão integrativa da literatura.

A relevância do exame citopatológico em mulheres lésbicas e bissexuais o conhecimento sobre os riscos das infeç̧ões sexualmente transmissíveis.

Processo de imunização no controle de doenças epidêmicas ............................................................. 140

Epidemiologia da mortalidade por agressões em idosos no município de Juiz de Fora - MG ................. 142 Repercussões do transtorno de déficit de atenção e da hiperatividade sobre o desempenho escolar: uma revisão da literatura 
Acidentes de trabalho com profissionais do ambiente hospitalar. 146

Atuação do enfermeiro na promoção do cuidado humanizado a pacientes na Unidade de Terapia Intensiva 148

Cuidados paliativos: atuação e recursos fisioterapêuticos utilizados para melhora da qualidade de vida do paciente terminal.

O potencial aumento da demência associado ao consumo de benzodiazepínicos na população idosa: uma revisão sistemática .

O impacto do exercício físico no prognóstico dos portadores da doença de Alzheimer: uma revisão sistemática.

Flora intestinal e a modulação no transtorno do espectro autista: uma revisão sistemática .................. 156

Os efeitos do exercício físico aeróbico na melhora cognitiva: uma revisão sistemática 158

As influência de intervenções dietéticas em portadores do transtorno do espectro autista: uma revisão sistemática.

Comorbidades relacionadas ao transtorno do déficit de atenção e hiperatividade: uma revisão sistemática. 162

Avaliação entre microbiota intestinal e transtorno depressivo: uma revisão sistemática 164

Os efeitos da musicoterapia nas funções cognitivas e bem-estar metal de pacientes com doença de alzheimer: uma revisão sistemática 166

Aspectos da candidíase genital em mulheres diabéticas: revisão de literatura 168

A conduta do Cirurgião-Dentista frente as manifestações orais do abuso infantil. 170

A tripla intervenção para o controle do câncer de colo de útero: uma revisão bibliográfica... 172

Presença de manifestações orais associadas ao Lúpus Eritematoso Sistêmico 174

Os efeitos do exercício físico aeróbico na melhora cognitiva: uma revisão sistemática 176

A influência de intervenções dietéticas em portadores do Transtorno do Espectro Autista: uma revisão sistemática.

Comorbidades relacionadas ao Transtorno do Déficit de Atenção e Hiperatividade: uma revisão sistemática. 180

Avaliação entre microbiota intestinal e transtorno depressivo: uma revisão sistemática 182

O impacto do abuso de analgésicos em migranosos: uma revisão sistemática..... 184

Uso do soft laser no controle da dor nas disfunções temporomandibulares 186

Os benefícios da fenestração em pacientes submetidos ao procedimento Fontan: uma revisão sistemática.

Benefícios das rodas de gestantes no ciclo gravídico puerperal: uma revisão integrativa da literatura.. 190 Uso da acupuntura no tratamento da parestesia do nervo alveolar inferior após cirurgia ortognática.. 192

A acupuntura como terapia complementar na clínica odontológica. 194

O acolhimento na rede de atenção primária 196

O impacto da pandemia da COVID-19 na saúde mental..... 198 
Ferramenta tecnológica para a implementação da sistematização da assistência de enfermagem 200

Toxina botulínica como uma ferramenta terapêutica no tratamento da disfunção temporomandibular202

Presença de manifestações orais em pacientes portadores da Síndrome da Imunodeficiência Adquirida 204

Depressão e suicídio na terceira idade: uma revisão de literatura 206

Síndrome do pânico: grupos de risco e aspectos neurofisiológicos. 208

Influência da pandemia de COVID-19 na automedicação 210 


\section{SOBRE O EVENTO}

A Oficina do Artigo é um evento online da Acervo+ que surgiu para educar e tornar acessível a estudantes a produção de conhecimento científico de qualidade. Temos como missão ensinar e contribuir com seus participantes em suas metodologias de pesquisa científica e estratégias de escrita acadêmica.

Em nosso logo, trazemos a lâmpada como o início de sua ideia, o ponto de partida de toda pesquisa. $Q$

As engrenagens representam o meio do processo: 0 ato de pesquisar junto da tarefa de colocar a produção em formato de texto.

Já as nuvens remetem à integração digital de nossas plataformas de ensino e publicação, sistematizadas na Acervo+. As nuvens também simbolizam a tempestade de ideias de impacto que desejamos causar em nossos autores e autoras, incentivando sua produção e desenvolvimento profissional.

O papel e o lápis estampam o final do processo, com a conclusão do artigo científico.

Entretanto, esse resultado não quer dizer final; a partir da conclusão, o autor ou autora tem autonomia completa para seguir na prática da produção de conhecimento. E aí está nosso objetivo: qualificar pesquisadores e pesquisadoras para sua prática e ofício.

"A educação, qualquer que seja ela, é sempre uma teoria do conhecimento posta em prática." Paulo Freire 8

Redação: Rafael Lazzari Smaira Criação \& Arte: Rafael Lazzari Smaira e D. Andreazzi Duarte 


\section{Organização}

- Equipe Editorial Acervo+

- Equipe de Comunicação Acervo+

- Equipe de Estratégia Acervo+

- Equipe Administrativa Acervo+

\section{Comissão Científica}

- Equipe Editorial de Artigos Acervo+

- Equipe Editorial de Anais de Eventos Acervo+

\section{Programação}

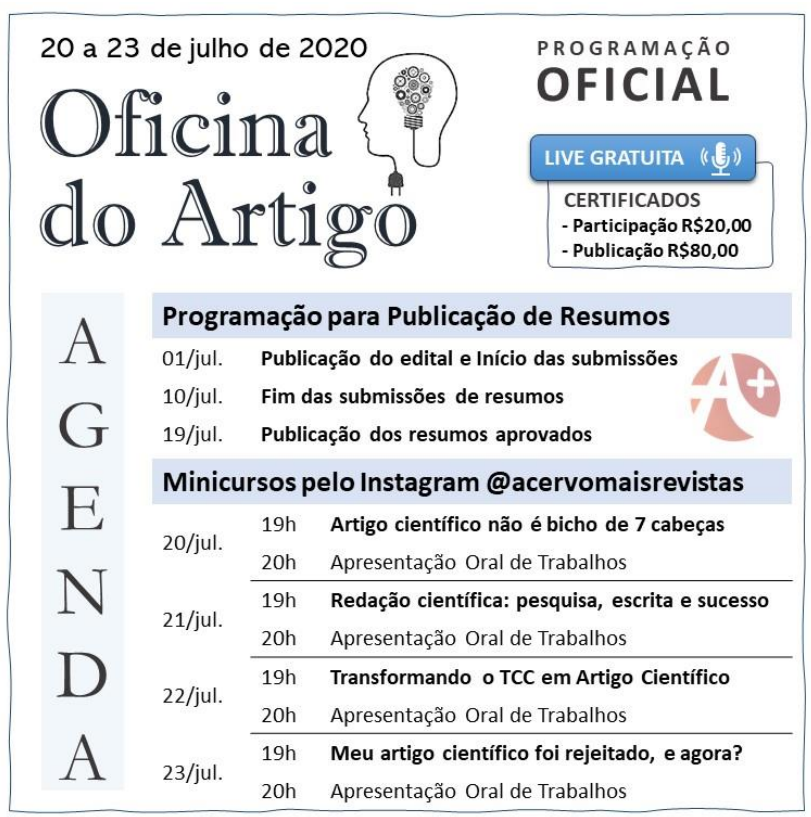

\section{Edital para PUBLICAÇÃO} de RESUMOS

1. Orientações Gerais

Oficina do Artigö

1.1. Serão aceitos RESUMOS SIMPLES entre 300 e 400 palavras.

1.2. Os resumos devem ter no máximo 5 autores/coautores.

1.3. Não há limites de resumos por autor.

2. Submissão dos Resumos

2.1. Período de submissão entre 01 a 10 de julho de 2020.

2.2. Devem seguir as normas e modelo da revista [link na BIO].

2.3. Submeter o resumo e documentos nas normas para o e-mail:

3. Avaliação Científica oficinadoartigo@gmail.com

3.1. Será feita a avaliação pela comissão do evento e editor da revista.

3.2. Envio de resultado da avaliação até o dia 19/jul. de 2020.

3.3. O melhores serão indicados para discussão oral durante o evento.

4. Publicação em Anais

4.1. Os resumos aceitos serão publicados:

- Rev. Acervo Saúde, REAS [resumos da saúde]

- Rev. Acervo Científico, REAC [demais áreas]

5. Certificado de publicação

5.1. Os autores poderão solicitar à Acervot o certificado oficial padrão internacional [verificar valores diretamente com a Acervo+]. 


\section{EDITORIAL}

[...] "Sempre foi um desafio realizar um evento da Acervo+"

Nós sempre sonhamos com veículos de impacto que pudessem vencer as barreiras e levar conhecimento acessível e gratuito a quem precisa, foi assim que surgiu a Acervo+.

Devido ao fato de sermos uma base científica digital e com revistas eletrônicas, não seria diferente que o evento também fosse online, para integrar as pessoas e para que a filosofia da Acervo+ pudesse se fazer presente. Entretanto, sempre nos deparávamos com o preconceito do ensino a distância.

A ciência mostra que todo avanço ocorre diante de um problema, pois bem, o cenário atual trouxeram mudanças que poderiam levar dezenas de anos para ocorrer e, o que antes era uma opção, passou a ser uma necessidade e isso gera a quebra de paradigmas que possibilita a realização de coisa extremamente impactantes para uma sociedade.

Nesse cenário pandêmico caótico, entra em ação a Acervo+ com a sua Oficina do Artigo, atuando como veículo de disseminação que percorre ligeiramente através de fibras óticas para levar o conhecimento científico de forma acessível a todos e deixa claro a que veio, com sua missão de INOVAR em meio ao caos, sua visão em QUALIDADE diante dos preconceito e, sobretudo, com o valor da HONESTIDADE ao ser humano.

Diante disso, apresento a vocês o futuro dos eventos científicos do país. Os trabalhos publicados nesse arquivo de anais de evento totalmente online contém os resultados preliminares de estudos e representam o avanço de um movimento em prol a pesquisa científica cujo seu impacto é incalculável ao olhos de uma sociedade; novos conhecimentos - trabalho em equipe - aprendizado - informação - capacitação e, por fim, o esforço incansável de pessoas tentando contribuir para um mundo de desafios, mas repleto de oportunidades. Parabéns a todos os autores e a equipe da Acervo+!

Finalizo este editorial deixando a mensagem de que, JUNTOS NÓS PODEMOS SER + @Dr.AndreazziDuarte

Editor-líder Acervo+

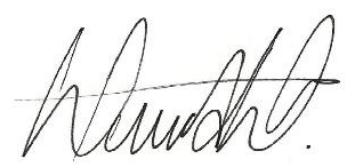




\section{Originais}

001 | RESUMOS SIMPLES: Estudo Original

\section{Mortalidade materna na Região Metropolitana de Belém- Pará, Brasil, entre 2013 e 2017}

Autor/coautores: ${ }^{1}$ Rafael Everton Assunção Ribeiro da Costa, ${ }^{2}$ Ewellyn Natália Assunção Ferreira, ${ }^{3}$ Dandara de Fátima Ribeiro Bendelaque, ${ }^{4}$ Dayara de Nazaré Rosa de Carvalho, ${ }^{5}$ Viviane Ferraz Ferreira de Aguiar.

Instituição: ' ${ }^{1}$ niversidade Estadual do Piauí (UESPI), Teresina-Piauí; ' 2 niversidade da Amazônia (UNAMA), Belém-Pará; ${ }^{3}$ Faculdade Paraense de Ensino (FAPEN), Belém-Pará; ${ }^{4}$ Universidade Estadual do Pará (UEPA), Belém-Pará; ${ }^{2}$ Universidade Federal do Pará (UFPA), Belém-Pará.

Palavras-chave: Mortalidade Materna, Saúde da Mulher, Gravidez.

\section{INTRODUÇÃO}

No Brasil, houve uma redução de aproximadamente $56 \%$ na taxa de mortalidade materna entre 1990 e 2015. Em 2016, foram registrados 1.463 casos, o que representou 16\% de queda em relação ao ano anterior, mas ainda é um número alto quando comparado aos países desenvolvidos (Ministério da Saúde, 2018). As causas da mortalidade materna podem ser diretas: complicações obstétricas na gravidez e período puerperal resultante de lesões, omissões e erros no tratamento ou sequência de eventos em qualquer uma dessas situações, bem como indiretas: aquelas resultantes de doenças pré-existentes ou durante tratamento na gravidez que foram agravadas por seus efeitos fisiológicos (OPAS, 2018).

\section{OBJETIVO}

O presente estudo teve como objetivo identificar os óbitos maternos na Região Metropolitana de Belém do Pará, Brasil, entre os anos de 2013 a 2017, e analisar o perfil clínico-epidemiológico destas mulheres que constituíram os óbitos.

\section{MÉTODO}

Estudo epidemiológico retrospectivo, descritivo, com abordagem quantitativa, realizado em Fevereiro de 2020, com informações de dados secundários do Sistema de Informações sobre 
Mortalidade (SIM) referentes à mortalidade materna na Região Metropolitana de Belém-Pará, Brasil, entre os anos de 2013 e 2017. Devido à natureza dos dados, não houve necessidade de submissão a um Comitê de Ética em Pesquisa (CEP).

\section{RESULTADOS}

Entre 2013 e 2017, foram encontradas 142 mortes maternas na Região Metropolitana de Belém, com o maior número de casos ocorrendo em 2013, com um total de 38 mortes maternas, mostrando uma tendência de queda nos anos seguintes, com 19 casos em 2016; contudo, em 2017, o número de casos voltou a aumentar, alcançando 29 casos. Quanto ao perfil clínico-epidemiológico, houve predomínio da faixa etária entre 20 a 29 anos, raça parda e estado civil solteiro. A maioria das mortes ocorreu durante o puerpério, em ambiente hospitalar e tendo causa de morte intercorrências da gravidez, parto ou puerpério.

\section{CONSIDERAÇÕES FINAIS}

Diante disso, são necessárias ações que promovam a melhoria das condições de vida e assistência às mulheres em idade reprodutiva, tanto em prevenção de gravidezes indesejadas, como de potenciais complicações que podem ocorrer durante o parto, o período de gravidez e o puerpério.

\section{REFERÊNCIAS}

Brasil. Ministério da Saúde. 2018. In: Saúde Brasil 2017: uma análise da situação e os desafios para o alcance dos objetivos de desenvolvimento sustentável. Brasília: Biblioteca Virtual em Saúde.

Organização Pan-Americana da Saúde (OPAS). 2018. In: Saúde Materna. Washington: Organização Pan-Americana da Saúde. 
002 | RESUMOS SIMPLES: Estudo Original

\section{Mortalidade por câncer na Região Norte do Brasil na série histórica 2010-2017}

Autor/coautores: ${ }^{1}$ Rafael Everton Assunção Ribeiro da Costa, ${ }^{2}$ Dayara de Nazaré Rosa de Carvalho, ${ }^{2}$ Jaqueline Dantas Neres Martins, ${ }^{3}$ Dandara de Fátima Ribeiro Bendelaque, ${ }^{4}$ Viviane Ferraz Ferreira de Aguiar.

Instituição: ${ }^{1}$ Universidade Estadual do Piauí (UESPI), Teresina-Piauí; ${ }^{2}$ Universidade Estadual do Pará (UEPA), Belém-Pará; ${ }^{3}$ Faculdade Paraense de Ensino (FAPEN), Belém-Pará; ${ }^{4}$ Universidade Federal do Pará (UFPA), Belém-Pará.

Palavras-chave: Mortalidade, Oncologia, Brasil.

\section{INTRODUÇÃO}

O câncer é caracterizado por uma desordem no crescimento celular, com potencial para invadir tecidos e órgãos à distância (INCA, 2017). Atualmente, é considerado uma das principais causas de mortalidade, afetando populações de todas as regiões e países no mundo (INCA, 2017). A Organização Mundial de Saúde (OMS) estima que o câncer é responsável por 1 a cada 6 mortes mundialmente (OMS, 2018). Mais de 14 milhões de pessoas desenvolvem câncer todo ano, número que chegará a 21 milhões em 2030, sendo que a maior parte das pessoas que desenvolvem esta doença vivem em países que apresentam baixa e média renda (SIEGEL, et al., 2015).

\section{OBJETIVO}

A Região Norte tem um aumento crescente da incidência e mortalidade por câncer, no entanto, estudos nesse sentido são escassos. Assim, este estudo objetivou identificar a mortalidade por câncer na Região Norte do Brasil entre 2010 e 2017.

\section{MÉTODO}

Estudo analítico e descritivo, do tipo retrospectivo e de abordagem quantitativa, realizado em Janeiro de 2020 com dados secundários do Sistema para Informatização dos Dados de Registro Hospitalar de Câncer (SisRHC), referentes à Região Norte na série histórica de 2010 a 2017. Devido à natureza dos dados, não houve necessidade de submissão a um Comitê de Ética em Pesquisa (CEP). 


\section{RESULTADOS}

No período entre 2010 e 2017, 114.085 casos de câncer foram registrados em todos os estados da Região Norte (67.851 no Amazonas [59\%], 21.814 no Pará [19\%], 9.954 em Rondônia [9\%], 8.697 no Tocantins [8\%], 2.595 no Acre [2\%], 2.215 no Amapá [2\%] e 949 casos em Roraima [1\%]). Foram registradas 9.304 mortes, com o maior número de casos no estado do Amazonas, que apresentou um total de 4.264 óbitos (6\%). Quanto aos dados sociodemográficos, houve predomínio de pacientes do sexo masculino (51\%), com idades entre 60 a 69 anos (25\%), pardos (73\%), casados (41\%) e com ensino fundamental incompleto (41\%).

\section{CONSIDERAÇÕES FINAIS}

Houve variações notáveis em alguns estados entre os casos diagnosticados e a taxa de mortalidade, o que pode estar relacionado às distintas conjunturas de organização das redes de atenção à saúde, bem como a diferentes coberturas assistenciais e determinantes sociais de saúde.

\section{REFERÊNCIAS}

Brasil. Instituto Nacional do Câncer (INCA). 2017. In: ABC do Câncer - Abordagens Básicas para o Controle do Câncer. Brasília: Ministério da Saúde.

Organização Mundial da Saúde (OMS). 2018. In: Early cancer diagnosis saves lives, cuts treatment costs. Geneva: Organização Mundial da Saúde.

SIEGEL RL, et al. Cancer statistics, 2015. CA: A Cancer Journal for Clinicians, 2015; 65(1): 5-29. 
003 | RESUMOS SIMPLES: Estudo Original

\title{
Perfil de mulheres grávidas atendidas em uma Estratégia de Saúde da Família no estado do Pará, Brasil
}

\author{
Autor/coautores: ${ }^{1}$ Rafael Everton Assunção Ribeiro da Costa, ${ }^{2}$ Paula Sousa da Silva Rocha, \\ ${ }^{2}$ Aldebaram Mariana Abreu da Silva, ${ }^{2}$ Carlene Leandro Tavares, ${ }^{3}$ Emily Manuelli Mendonça Sena. \\ Instituição: 'Universidade Estadual do Piauí (UESPI), Teresina-Piauí; ${ }^{2}$ Centro Universitário do \\ Pará (CESUPA), Belém-Pará; ${ }^{3}$ Universidade Estadual do Pará (UEPA), Belém-Pará. \\ Palavras-chave: Gestantes, Cuidado Pré-Natal, Perfil de Saúde.
}

\section{INTRODUÇÃO}

A gravidez consiste em um momento importante da vida; em face disso, o Ministério da Saúde instituiu o Programa de Humanização no Pré-Natal e Nascimento pela portaria n 569/2000 (MS, 2011). O pré-natal consiste em um fator chave na proteção e prevenção contra eventos adversos da gravidez, pois permite a identificação, avaliação clínica e gestão de intervenções oportunas em fatores de risco potenciais para mãe e para o feto (LANSKY, et al., 2014). A Estratégia Saúde da Família (ESF), criada em 2006, é um sistema de assistência em atenção primária à saúde, que também é responsável por acolher e acompanhar as grávidas em suas microáreas (MS, 2013).

\section{OBJETIVO}

Diante do exposto, este estudo teve como objetivo traçar o perfil de gestantes atendidas por uma equipe da Estratégia de Saúde da Família de um bairro em uma cidade do estado do Pará, Brasil.

\section{MÉTODO}

Trata-se de uma pesquisa exploratória, retrospectiva, com abordagem quantitativa, realizada em uma ESF do Pará em 2018, que atendia 80 gestantes no programa pré-natal. A amostra foi composta por 74 gestantes, as quais iniciaram o pré-natal em 2018 e não eram casos de doença mental ou gravidez de alto risco. Esta pesquisa foi aprovada pelo Comitê de Ética em Pesquisa (CEP) da Universidade Federal do Pará, sob o CAAE: 57214916.1.0000.0018.

\section{RESULTADOS}

Os resultados mostraram as seguintes características gerais das gestantes: estado civil, família, renda, idade na menarca, número de partos anteriores, histórico familiar e trimestre gestacional de início do pré-natal. No tocante ao estado civil, renda familiar e início do pré-natal, foi evidenciado 
que a maior parte é solteira $(48,6 \%)$, tem renda familiar de até 1 salário $(51,4 \%)$ e iniciaram o prénatal no $1^{\circ}$ trimestre gestacional $(55,4 \%)$. Quanto ao número de partos anteriores, $37,8 \%$ delas não tiveram nenhum parto e $62,2 \%$ tiveram uma ou duas parturições anteriores. A respeito dos resultados da idade da menarca, observou-se que a maioria dos prontuários médicos não coletaram informações $(75,7 \%)$.

\section{CONSIDERAÇÕES FINAIS}

Pode-se concluir que é importante adotar medidas educacionais sobre a importância do prénatal, para que melhorias na saúde das mulheres grávidas possam ser alcançadas a longo prazo, a fim de reduzir as taxas de morbimortalidade materna e infantil. Portanto, os profissionais de saúde precisam abordar as gestantes e a comunidade de maneira acolhedora e humanizada, desenvolvendo atividades focadas na atenção primária e educação em saúde.

\section{REFERÊNCIAS}

Brasil. Ministério da Saúde. 2013. In: Atenção ao pré-natal de baixo risco. Brasília: Cadernos de Atenção Básica, nº 32.

Brasil. Ministério da Saúde. 2011. In: Urgências e emergências maternas: guia para diagnóstico e conduta em situações de risco de morte materna. Brasília: Ministério da Saúde.

LANSKY S, et al. Birth in Brazil survey: neonatal mortality, pregnancy and childbirth quality of care. Cad. Saúde Pública, 2014; 30(supl.1): S1-15. 
004 | RESUMOS SIMPLES: Estudo Original

\section{Diagnóstico nutricional em pessoas que vivem com HIV/AIDS em terapia antirretroviral atendidos em ambulatório de referência no Nordeste}

Autor/coautores: Sofia Oliveira de Souza; Fernanda Carneiro Gomes Ferreira; Érica Priscila Carneiro Ouriques Vasconcelos; Ana Célia Oliveira dos Santos.

Instituição Universidade de Pernambuco (UPE), Recife-Pernambuco.

Financiamento: Trabalho realizado por pesquisadores que receberam bolsas Capes e CNPq.

Palavras-chave: Nutrição, AIDS, Terapia Antirretroviral.

\section{INTRODUÇÃO}

Desde o advento da terapia antirretroviral (TARV), houve o aumento significativo na sobrevida das pessoas que vivem com HIV/Aids (HIPÓLITO RT, et al., 2017). Porém, da mesma forma que atua de modo positivo, a TARV possui efeitos colaterais, sendo os mais comuns a resistência à insulina, dislipidemias, hipertensão arterial e consequentemente maior risco de desenvolver doenças cardiovasculares (GUIMARAES NS, et al., 2017). Apesar de dieta e exercício serem apresentadas como terapias coadjuvantes à TARV, aliado a um monitoramento contínuo por uma equipe multidisciplinar, ainda são prevalentes alterações nutricionais que aumentam os riscos e comprometem a qualidade de vida dessa população (AIRES IO, et al., 2019).

\section{OBJETIVO}

Essa pesquisa tem como objetivo classificar, a partir de análises antropométricas, mais especificamente peso e altura, o estado nutricional de pessoas vivendo com HIV/AIDS atendidos em serviço de referência do Estado de Pernambuco.

\section{MÉTODO}

Estudo transversal, desenvolvido em hospital de referência no Nordeste. População de estudo: adultos de ambos os sexos vivendo com HIV/AIDS, usando a TARV por no mínimo 12 meses. Para avaliação nutricional utilizou-se o Índice de Massa Corporal e foram aferidos peso com balança OMRON e estatura com régua antropométrica WELMY. Para classificação, critérios da World Health Organization de 1997 que divide em magreza, eutrofia, pré-obesidade e obesidade. CAAE: 68068017.0 .3001 .8807$. 


\section{RESULTADOS}

Foram coletados dados de 74 pacientes que se encaixam nos critérios de inclusão, sendo desses, 41 homens e 33 mulheres. Quando classificados de acordo com seu IMC, 2 pacientes $(2,7 \%)$ se classificam em magreza, 20 pacientes (27\%) se classificam como eutróficos, 26 pacientes $(35,13 \%)$ se classificam como pré-obesos, 26 pacientes $(35,05 \%)$ em obesidade. Analisando os sexos de forma isolada, um maior percentual de mulheres se encontra em pré-obesidade, com 12 pacientes $36,3 \%$, e um maior percentual de homens dividem as classificações de eutrofia e préobesidade com 28 pacientes $(68,2 \%)$.

\section{CONSIDERAÇÕES FINAIS}

Apesar de fazer parte do protocolo de tratamento, os resultados mostram dificuldades na manutenção de bons índices de massa corporal, principalmente pela prevalência da pré-obesidade. Explanar acerca da importância da adaptação do estilo de vida, estimulando hábitos saudáveis, a fim de retardar o aparecimento de patologias, atribuindo qualidade à vida dos pacientes em TARV é o perfil necessário para a ressignificação do cuidado com o paciente.

\section{REFERÊNCIAS}

AIRES IO, et al. Aspectos clínicos e nutricionais em pessoas vivendo com HIV/AIDS: uma série de casos. Revista Eletrônica Acervo Saúde, 2019; 28: e1077.

GUIMARÃES NS, et al. Alterações metabólicas e estimativa de risco cardiovascular em pessoas vivendo com HIV/AIDS doze meses após o início da TARV. Rev Med Minas Gerais, 2017; V. 27. HIPOLITO RL, et al. Qualidade de vida de pessoas convivendo com HIV/aids: relação temporal, sociodemográfica e perceptiva da saúde. Revista Latino-Americana de Enfermagem, 2017; v. 25, p. e2874. 
005 | RESUMOS SIMPLES: Estudo Original

\section{Adesão terapêutica à terapia antirretroviral em pessoas que vivem com HIV/AIDS atendidas em ambulatório de referência no Nordeste}

Autor/coautores: Fernanda Carneiro Gomes Ferreira; Sofia Oliveira de Souza; Érica Priscila Carneiro Ouriques Vasconcelos; Ana Célia Oliveira dos Santos.

Instituição: Universidade de Pernambuco (UPE), Recife-Pernambuco.

Financiamento: Conselho Nacional de Desenvolvimento Científico e Tecnológico (CNPq).

Palavras-chave: Adesão terapêutica, AIDS, Terapia Antirretroviral.

\section{INTRODUÇÃO}

O sucesso da terapia antirretroviral (TARV) para o tratamento da infecção pelo vírus da imunodeficiência humana (HIV) depende da manutenção de altas taxas de adesão à terapêutica medicamentosa. A adesão ao tratamento aumenta a sobrevida, reduz o risco de progressão para AIDS e o desenvolvimento de cepas virais resistentes, além de melhorar a qualidade de vida (SANTOS El, et al., 2016). Normalmente existem dificuldades na adesão à mudanças no estilo de vida e à própria medicação, seja pelos efeitos colaterais, pelo caráter estigmatizantes da doença, entre outros fatores que tornam a baixa a adesão ao tratamento um dos mais graves problemas da assistência à saúde (SILVA JAG, et al., 2015).

\section{OBJETIVO}

A pesquisa tem como objetivo avaliar a adesão terapêutica a TARV a partir de questionário validado, analisando critérios específicos que influenciam na mesma, a fim de desenvolver estratégias de melhora na adesão ao tratamento.

\section{MÉTODO}

Estudo transversal, desenvolvido em hospital no Nordeste. População de estudo: adultos de ambos os sexos com diagnóstico de HIV/AIDS, em uso da TARV por no mínimo 12 meses. Foi utilizado como instrumento a adaptação brasileira do "Cuestionario para la Evaluación de la Adhesión al Tratamiento Antiretroviral" publicado pela revista de saúde pública no ano de 2007. A análise preliminar baseou-se em quatro critérios: esforço, detenção de informações sobre 
medicamentos, beneficios e melhora da saúde, avaliados em: nada, pouco, regular, bastante e muito. CAAE:68068017.0.3001.8807.

\section{RESULTADOS}

Foram entrevistados 38 pacientes. Deste total, 21 pacientes (55\%) reportaram se esforçar bastante para seguir com o tratamento, enquanto 7 (18\%) reportaram se esforçar pouco. 24 pacientes (63\%) reportaram ter uma informação regular sobre os medicamentos que toma, enquanto 5 (13\%) relataram não ter nenhuma informação. 30 pacientes (78\%) reportaram como muito o benefício trazido pelo uso dos medicamentos, enquanto $2(5 \%)$ reportaram o benefício como regular. 27 pacientes $(71 \%)$ reportaram ser regular a melhora da saúde desde que começou a tomar os medicamentos, enquanto $5(13 \%)$ reportaram muita melhora da saúde.

\section{CONSIDERAÇÕES FINAIS}

Os resultados preliminares mostram que o principal obstáculo para a adesão ao tratamento antirretroviral é a falta de informação, pois os resultados saltariam para categorias melhores se mais fosse investido na comunicação e educação dos pacientes. Usar de estratégias como fornecer informações acerca do protocolo medicamentoso e explicar os benefícios à saúde do tratamento é importante, pois o sucesso da terapia depende da manutenção de altas taxas de adesão à terapêutica medicamentosa.

\section{REFERÊNCIAS}

SANTOS El, et al. Evidências científicas brasileiras sobre adesão à terapia antirretroviral por pessoas que vivem com HIV/AIDS. Revista Eletrônica Gestão e Saúde, 2016; n. 1, p. 454-470.

SILVA JAG, et al. Factors associated with non-adherence to antiretroviral therapy in adults with AIDS in the first six months of treatment in Salvador, Bahia State, Brazil. Cad Saude Publica, 2015; 31(6):1188-1198. 
006 | RESUMOS SIMPLES: Estudo Original

\section{Incremento molecular na acitretina: uma avaliação toxicológica in silico}

Autor/coautores: Victor Alexandre Cardoso Salazar ${ }^{1}$, Camila Cristina da Silva Miranda², Helena Rayssa Sousa Lima ${ }^{3}$, Gele de Carvalho Araújo Lopes ${ }^{4}$, Cristiano Ribeiro Gonçalves Affonso 5 . Instituição: ${ }^{1234}$ Centro Universitário UniFacid; ${ }^{5}$ Universidade Federal do Piauí (UFPI), Teresina - PI. Palavras-chave: Acitretina, Química computacional, Toxicologia.

\section{INTRODUÇÃO}

A acitretina é um retinóide sintético aromático de $2^{-}$geração que se tornou popular nos últimos anos para o tratamento de dermatoses inflamatórias, mantendo sua eficácia clínica com minimização de efeitos adversos. Sendo apresentada como uma alternativa a falhas na terapia com isotretinoína (TAN MG, et al., 2017). A maioria dos seus efeitos adversos estão ligados a dose, e incluem lábios secos, elevação transitória de enzimas hepáticas, efeitos sobre o colesterol, entre outros (SUBEDI S, et al., 2017). Encontra-se altamente ligado às proteínas plasmáticas e é excretado na mesma proporção por vias renal e hepática. Assim como os outros retinóides sistêmicos, seu uso é associado a elevada teratogenicidade (GUENTHER LC, et al., 2017).

\section{OBJETIVO}

Propor métodos de incremento molecular na acitretina, a fim de otimizar características que influenciem na sua função terapêutica, amenizando efeitos adversos - principalmente a teratogenicidade - utilizando softwares computacionais gratuitos usados no planejamento de novos fármacos.

\section{MÉTODO}

Dentro do incremento molecular, retirou-se ligações simples ou duplas para criação de dois análogos (ACIP1; ACIP2). Para isso, utilizou-se programas gratuitos: ACD/ChemSketch Freeware 14.01, usado para construção da molécula e análogos; Marvin Sketch 6.2.2, empregado para análise de propriedades fisico-químicas; PreADMET 2.0 e Osiris Property Explorer aplicados para verificação de efeitos toxicológicos in silico (testes ames, carcinoma em camundongos, mutagenicidade, teratogenicidade), além do Drug-Score, pontuação geral dos parâmetros do estudo. 


\section{RESULTADOS}

A acitretina apresentou uma massa de 326,18 Daltons, LogP 6,03 e uma relação doadores/aceptores de hidrogênio de 1/3. Esses valores mantiveram-se nos análogos, com destaque para uma dimuinuição do LogP indo para 5,36 no ACIP2. Para os dados do PreADMET, o protótipo mostrou-se mutagênico no teste ames e positivo em causar carcinoma em camundongos (CC); esses dados se mantiveram, com exceção do ACIP1, o qual modificou o CC para negativo. Quanto aos dados avaliados no Osiris, a acitretina exibiu teratogenicidade e sem risco quanto a mutagenicidade, com Drug-Score de 0,21. Os congêneres conseguiram reverter a teratogenicidade, porém, o ACIP2 apresentou mutagenicidade. O Drug-Score foi acentuado no ACIP1.

\section{CONSIDERAÇÕES FINAIS}

Os análogos apresentaram reversão do efeito teratogênico encontrado no protótipo, somado a isso, uma das propostas apresentou aumento no valor de Drug-Score, que se trata de uma pontuação geral dos parâmetros medidos. Ademais, um dos análogos também modificou o CC para negativo. Caracterizando a possibilidade de um dos congêneres serem bons candidatos para otimização. O estudo foi feito in silico e abre portas para novas pesquisas.

\section{REFERÊNCIAS}

GUENTHER LC, et al. Acitretin Use in Dermatology. Journal of Cutaneous Medicine and Surgery, 2017; 21 (3): e2S-12S.

SUBEDI S, et al. Management of pediatric psoriasis with acitretin: A review. Dermatologic Therapy, 2017; 31: e12571.

TAN MG, et al. Acitretin: Monotherapy or Combined Therapy for Hidradenitis Suppurativa?. Journal of Cutaneous Medicine and Surgery, 2017; 21 (1): e48-53. 
007 | RESUMOS SIMPLES: Estudo Original

\section{Proposta de modificação molecular in silico do bexaroteno: uma análise das propriedades físico-químicas, farmacocinéticas e toxicológicas}

Autor/coautores: Victor Alexandre Cardoso Salazar ${ }^{1}$, Helena Rayssa Sousa Lima², Camila Cristina da Silva Miranda ${ }^{3}$, Hyan Ribeiro da Silva ${ }^{4}$, Cristiano Ribeiro Gonçalves Affonso ${ }^{5}$.

Instituição: ${ }^{1234}$ Centro Universitário UniFacid; ${ }^{5}$ Universidade Federal do Piauí (UFPI), Teresina - PI Palavras-chave: Bexaroteno, In silico, Farmacologia.

\section{INTRODUÇÃO}

O bexaroteno é um análogo sintético da vitamina $A$, sendo um dos representantes da 3aㅗ geração dos retinóides sistêmicos, utilizados para disfunções dermatológicas (KHALIL S, et al., 2017). Sua estrutura é semelhante aos compostos dos ácidos retinóides e apresenta ação agonista sobre o receptor X retinóide, é aprovado pela Food And Drug Administration (FDA) para o tratamento de todas as etapas do linfoma cutâneo (MARTÍN-MAESTRO P, et al., 2019). Para pacientes com a pele mais generalizada, é utilizado de forma sistêmica, e pode ocasinar hipotireoidismo por diversos mecanismos. Novos estudos também estão associando o bexaroteno ao tratamento da doença de Alzheimer (KHALIL S, et al., 2017).

\section{OBJETIVO}

Propor modificações moleculares in silico no bexaroteno, a fim de otimizar suas propriedades farmacococinéticas, com ênfase na excreção renal, e analisar os parâmetros físico-químicos e toxicológicos envolvidos entre os análogos e seu protótipo.

\section{MÉTODO}

Para a otimização da molécula, adicionou-se um novo átomo e/ou trocou-se um substituinte, com possível eliminação de dupla ligação, gerando análogos (BXAP1; BXAP2). Utilizou-se programas gratuitos: ACD/ChemSketch Freeware 14.01, usado para confecção do design molecular; Marvin Sketch 6.2.2, empregado para propriedades fisico-químicas; PreADMET 2.0 aplicado para características farmacocinéticas (capacidade em atravessar a barreira hematoencefálica, taxa de absorção do fármaco, excreção) e toxicológicas (teste ames e carcinoma em camundongos) in silico. 


\section{RESULTADOS}

O Bexaroteno apresentou massa de 348,2 Daltons, $\log P$ 6,81 e doadores/aceptores de hidrogênio igual 1/2. Para os análogos, o BXAP2 apresentou maior variação do LogP, indo para 5,61. Quanto a farmacocinética, a molécula protótipo, exibiu BHE (capacidade em atravessar a barreria hematoencefálica) de 1,86, Caco2 (taxa de absorção) de 22.22 e MDCK (taxa de excreção) referente a 0.0077 . Os análogos modificaram alguns parâmetros, como o BHE (BXAP1=3,47; $\mathrm{BXAP2}=0,27$ ) e MDCK (BXAP1=0.070; $\mathrm{BXAP2}=0,35)$. Os testes toxicológicos in silico, para molécula do bexaroteno, identificou efeito mutagênico sobre o teste ames e negativo para carcinoma em camundongos; enquanto para os análogos houve modificação em BXAP1, tornando o teste ames não mutagênico.

\section{CONSIDERAÇÕES FINAIS}

Os congêneres mostraram variação nas características farmacocinéticas e toxicológicas, em relação ao bexaroteno. Apresentando alteração nos valores de entrada na barreira hematoencefálica e taxa de excreção renal, fato que influencia diretamente no efeito terapêutico do fármaco. Com isso, podendo um dos análogos satisfazer o objetivo de otimização do protótipo. Ademais, uma das propostas apresentou melhora em efeitos toxicológicos. Vale destacar que é um estudo in silico que possibilita novas pesquisas.

\section{REFERÊNCIAS}

KHALIL S, et al. Retinoids: a journey from the molecular structures and mechanisms of action to clinical uses in dermatology and adverse effects. J Dermatolog Treat, 2017; 8(28): e684-689.

MARTÍN-MAESTRO P, et al. Autophagy Induction by Bexarotene Promotes Mitophagy in Presenilin 1 Familial Alzheimer's Disease iPSC-Derived Neural Stem Cells. Mol Neurobiol, 2019; 56: e82208236. 
008 | RESUMOS SIMPLES: Estudo Original

\title{
Aspectos epidemiológicos dos casos notificados de tentativas de suicídio por intoxicação exógena no Estado do Piauí
}

\author{
Autor/coautores: Camila Cristina da Silva Miranda', Helena Rayssa Sousa Lima², Victor Alexandre \\ Cardoso Salazar ${ }^{3}$, Josiel de Sousa Ferreira ${ }^{4}$, Jairelda Sousa Rodigues ${ }^{5}$ \\ Instituição: $123{ }^{4}$ Centro Universitário Facid (UNIFACID) Teresina-Piauí; ${ }^{5}$ Universidade Federal do \\ Piauí (UFPI) Teresina-Piauí \\ Palavras-chave: Intoxicação, Suicídio, Piauí.
}

\section{INTRODUÇÃO}

O suicídio e a tentativa de suicídio são fenômenos complexos e multifatoriais que representam um grande problema de saúde pública em todo o mundo (MONTEIRO R, et al., 2015). A intoxicação exógena, por sua vez, se encontra entre os três principais meios utilizados nas tentativas de suicídios (GONDIN APS, et al., 2017). Nesse contexto, o Estado do Piauí mostrou, em um período de 10 anos, um aumento de $221,7 \%$ casos de óbitos por suicídios e apresenta o maior índice da região Nordeste, com sua capital, Teresina, sendo a segunda do país com a maior taxa entre a população jovem (RIBEIRO JF, et al., 2018). Ainda assim, há poucos estudos que abordam suicídios por intoxicação no Brasil.

\section{OBJETIVO}

Caracterizar os aspectos epidemiológicos dos casos notificados de tentativas de suicídio por intoxicação exógena no Estado do Piauí no período de 2013 a 2017, para que seja possível a elaboração de estratégias adequadas de prevenção de suicídio.

\section{MÉTODO}

Trata-se de um delineamento epidemiológico com abordagem quantitativa e qualitativa, com uma pesquisa junto à base de dado Sistema Nacional de Agravos e Notificações (SINAN) dos casos notificados de tentativas de suicídio por intoxicação exógena. Incluiu-se os casos confirmados e disponíveis na base de dados, do período de 2013 a 2017, coletados em dezembro de 2019. Analisou-se: sexo, faixa etária, escolaridade, agente tóxico, tipo de exposição e município de notificação. 


\section{RESULTADOS}

Entre o período estudado, houve 2.346 casos notificados de tentativas de suicídio por intoxicação exógena no Piauí, equivalente a $7,70 \%$ da região nordeste. Dos quais, $74,89 \%$ referiam-se ao sexo feminino e com idade predominante de $20-39$ anos (53,87\% dos casos). Quanto ao agente tóxico, houve predominação do uso de medicamentos, seguido de raticidas - $74,16 \%$ e $8,35 \%$ respectivamente. Outra variável analisada, foi a escolaridade, onde observou-se destaque para

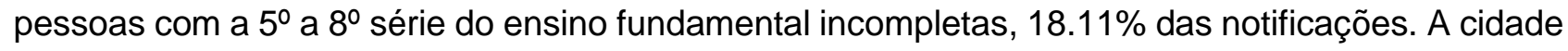
do Estado com maior número de notificações foi a capital Teresina, com 53,96\%, seguida da cidade de Picos com 19,56\%.

\section{CONSIDERAÇÕES FINAIS}

Desse modo, observa-se que as características epidemiológicas predominantes do tema abordado incluem: mulheres, com predomínio de faixa etária dos 20-39 anos, séries finais do ensino fundamental incompletas e residentes da capital Piauiense. Tais dados são de suma importância para o conhecimento profissional e popular sobre a realidade local, para assim aplicar-se estratégias adequadas de promoção à vida.

\section{REFERÊNCIAS}

GONDIM APS, et al. Tentativas de suicídio por exposição à agentes tóxicos registradas em um Centro de Informação e Assistência Toxicológica em Fortaleza, Ceará, 2013. Epidemiol. Serv. Saude, Brasília, 2017; 26(1): e109.

MONTEIRO $R$, et al. Hospitalizações relacionadas a lesões autoprovocadas intencionalmente: Brasil, 2002 a 2013. Ciênc Saúde Coletiva, 2015; 20(3): e689.

RIBEIRO JF, et al. Perfil sociodemogáfico da mortalidade por suicídio. Rev enferm UFPE, Recife, 2018; 12 (1): e44. 
009 | RESUMOS SIMPLES: Estudo Original

\section{Prevalência de sífilis em gestantes em uma região de saúde no Oeste da Bahia}

Autor/coautores: Alialdo Dantas Damascena ${ }^{1}$; Lisiane Cristine Welzel². Instituição: 'Universidade Federal do Oeste da Bahia; '2Universidade Regional do Noroeste do Estado do Rio Grande do Sul.

Palavras-chave: Doenças Sexualmente Transmissíveis, Complicações Infecciosas na Gravidez, Saúde da Mulher.

\section{INTRODUÇÃO}

A sífilis gestacional é uma infecção sexualmente transmissível (IST) causada pela bactéria grampositiva Treponema pallidum e doença de notificação compulsória em território nacional desde o ano de 2005 (SILVA DJ e COSTA OM, 2020), contudo, nos países em desenvolvimento, como o Brasil, a sífilis é considerada uma doença reemergente (SOARES EM, et al, 2020). Durante a gestação, a sífilis pode ocasionar diversos problemas tanto para a mulher quanto para o concepto, entre eles, morte fetal, aborto espontâneo, prematuridade e problemas psicológicos e sociais no recém-nascido (SOUSA FCA, et al, 2020). O presente trabalho se propõe a quantificar os casos de sífilis gestacional num município de referência do Oeste da Bahia.

\section{OBJETIVO}

Analisar a prevalência de casos registrados de sífilis em mulheres gestantes ao longo da última década em um município de referência regional em saúde no oeste do estado da Bahia.

\section{MÉTODO}

As informações foram obtidas a partir dos "Indicadores e Dados Básicos da Sífilis nos Municípios Brasileiros", base de dados pública do Departamento de Doenças de Condições Crônicas e Infecções Sexualmente Transmissíveis do Ministério da Saúde. Foram colhidos dados referentes a um município de referência em saúde para a região Oeste da Bahia -, a fim de analisar a quantidade de casos de sífilis em gestantes nos últimos 10 anos.

\section{RESULTADOS}

Entre os anos de 2010 e 2019, o município-referência contabilizou um total de 211 casos de sífilis em gestantes. Foi possível notar uma tendência não apenas crescente nas infecções, mas também 
de dobrar em determinados períodos de tempo, passando de 5 casos notificados em 2010 para 10 casos em 2013, 22 casos em 2016 e 44 casos em 2018.É necessário avaliar, portanto, a causabase desse aumento, podendo figurar entre eles, uma melhora na forma de notificação, falha na prevenção de ISTs ou ausência de atenção especializada no protocolo pré-natal das unidades de saúde.

\section{CONSIDERAÇÕES FINAIS}

Apesar da notificação compulsória da sífilis e dos programas de prevenção às ISTs, esta doença figura em números altos, especialmente entre as gestantes, causando impactos não somente na vida destas últimas, mas também de suas famílias. É necessária atenção aos protocolos de prénatal existentes e educação continuada em saúde adequada às diferentes populações a fim de evitar uma exacerbação da doença em território nacional e consequências para as gerações futuras.

\section{REFERÊNCIAS}

SILVA DJ, COSTA OM. SIFILIS CONGÊNITA: DIAGNÓSTICO PRECOCE NA GESTAÇÃO. Acervo de Recursos Educacionais em Saúde (Ares) - Universidade Aberta do SUS (UNASUS).

SOARES EM, et al. GESTANTES COM SOROLOGIA POSITIVA PARA A SIFILIS. Revista Eixos Tech, v. 6, n. 1, mar. 2020. ISSN 2359-1269.

SOUSA FCA, et al. Perfil da Sífilis na Gestação no Período de 2007/2016 em Caxias-MA. Revista Enfermagem Atual In Derme, v. 91, n. 29, 6 abr. 2020. 
010 | RESUMOS SIMPLES: Estudo Original

\title{
Análise epidemiológica das vítimas de queimaduras através do sistema em informação em saúde DATASUS
}

\author{
Autor/coautores: Gabriel Santiago da Hora, Viviane da Silva Gomes, Izadora Cristina Bezerra \\ Andrade, Vitoria Maria Carvalho Pereira, Lino Eduardo Farah. \\ Instituição: Centro Universitário Estácio de Sergipe, Aracaju - Sergipe. \\ Palavras-chave: Morbimortalidade, Queimaduras, Urgência.
}

\section{INTRODUÇÃO}

As queimaduras são lesões ocasionada pela ação térmica direta ou indireta sobre o organismo humano, levando a desnaturação proteica e consequentemente, morte celular. Em 2004, a Organização Mundial de Saúde (OMS) definiu queimadura como uma lesão da pele ou outro tecido humano lesionada pela ação do fogo, ou ainda por radiação, eletricidade, fricção ou ainda por agentes químicos e pelo frio (SANCHES PHS, et al, 2016). As queimaduras podem ser divididas em graus: $1^{\circ} 2^{\circ}, 3^{\circ}$ grau (SILVA WP e SANTOS MN, 2019).

\section{OBJETIVO}

Identificar a epidemiologia dos casos de internações e óbitos das vítimas acometidas por queimaduras que tiveram como caráter de atendimento urgência, no Brasil e no Estado de Sergipe.

\section{MÉTODO}

Trata-se de um estudo epidemiológico, de caráter transversal e retrospectivo dos casos morbimortalidade das queimaduras no período de janeiro de 2008 a janeiro de 2019, que tiveram como caráter de atendimento urgência. Os dados foram obtidos através do banco de dados DATASUS e por ser um banco de dados de domínio público, não foi necessário submeter ao comitê de ética e pesquisa.

\section{RESULTADOS}

Neste período, as lesões por queimaduras ocasionaram 228.263 internações e 6.489 casos de óbitos. Os homens representam $62,7 \%$ e as mulheres $37,3 \%$ de todas internações com caráter de atendimento urgência. A faixa etária com mais casos de internações foi entre menores que 1 ano a 9 anos de idade, foram $29,9 \%$, mostrando que a população pediátrica sofre mais com esse tipo de afecção, contudo, seguida da faixa etária de 40 a 69 anos tem presença de 24,9\%. Em relação a 
disseminação desta da afecção pelo país, o Estado com maior número de casos de internações e óbitos respectivamente, foi o Estado de São Paulo com 14,7\% e 19,2\%. Dentre os casos no Brasil, o Estado de Sergipe correspondeu 1,1\% dos casos de internações e 1,4\% dos óbitos, o município de Aracaju foi o que apresentou mais casos foram $96,4 \%$ casos de internações e $100 \%$ dos óbitos do estado de Sergipe.

\section{CONSIDERAÇÕES FINAIS}

Queimaduras representam um grande agravo de saúde pública do Brasil, afeta toda população sem distinção sexo, idade e região. Conhecer a sua epidemiologia é de grande importância para que profissionais da saúde possam se atualizar sobre as queimaduras, podendo assim traçar uma melhor assistência sistematizada para o direcionamento das ações de promoção, prevenção e reabilitação dos pacientes acometidos.

\section{REFERÊNCIAS}

BRASIL. Ministério da Saúde. Departamento de Informática do Sistema Único de Saúde (DATASUS) [online]. Brasília.

SANCHES PHS, et al. Perfil epidemiológico de crianças atendidas em uma Unidade de Tratamento de Queimados no interior de São Paulo. Rev Bras Queimaduras. 2016;15(4):246-50.

SILVA WP, SANTOS MN. Enfermagem no Trauma. 1ํㅡㄹ ed. Porto Alegre: Moriá, 2019. 
011 | RESUMOS SIMPLES: Estudo Original

\section{Internações por infecções agudas das vias aéreas superiores no Brasil (2019-2020)}

Autor/coautores: Evanete Maria de Oliveira, Keilla Barbosa de Souza, Rayane de Oliveira Moura, Thallys Luiz Tavares da Silva, Thais Ranielle Souza de Oliveira.

Instituição: Centro Universitário Unieuro (UNIEURO), Brasília - Distrito Federal.

Palavras-chave: Internações, Morbidade, Epidemiologia.

\section{INTRODUÇÃO}

As infecções que atingem o trato respiratório, principalmente as de vias aéreas superiores, são responsáveis por altas taxas de hospitalizações, redução da qualidade de vida e óbitos de muitos brasileiros anualmente (DIAS FLT, et al., 2020). Como exemplo, doenças relacionadas às infecções das vias aéreas superiores e sua importância relacionada ao atual cenário de pandemia, podemos destacar desde a primeira década do século 21, a gripe aviária (Influenza A H5N1) em 2003, a SRAG em 2002/2003, a Influenza A H1N1 em 2009, apresentando padrões epidêmicos e pandêmicos (LANA RM, et al., 2020). Nesse contexto atual, são importantes estudos que dimensionem as internações por essas morbidades para direcionar ações para prevenção e controle.

\section{OBJETIVO}

Analisar a quantidade de internações por infecções agudas das vias aéreas superiores no Brasil, no período de abril de 2019 a abril de 2020, comparando o número de hospitalizações e a média de casos nas diferentes regiões do país.

\section{MÉTODO}

Estudo de caráter descritivo, quantitativo com dados coletados no site do Ministério da Saúde, no Sistema de Informações Hospitalares do Sistema Único de Saúde (SIH/SUS), fornecidos pela plataforma Tabnet. Foram analisados os números de internações por infecções agudas das vias aéreas superiores no Brasil, do período de abril de 2019 a abril de 2020.

\section{RESULTADOS}

A análise dos dados demonstrou que as hospitalizações no período de 2019 foram superiores às do período de 2020. Ao comparar os dados referentes ao país e a região, observa-se que os 
dados seguem a mesma tendência. Calculando a média de internações de cada mês, é notável que na transição do período de 2019 para 2020 ocorreu declínio de internações referente às infecções das vias aéreas superiores, em contrapartida, no mês de março houve um pico, logo após diminuição. O declínio em abril provavelmente é decorrente do isolamento social, pois ocorreu a restrição da circulação de pessoas, consequentemente de infecções.

\section{CONSIDERAÇÕES FINAIS}

Diante dos dados obtidos, foi observado que as infecções agudas das vias aéreas superiores são doenças de prevalência no território brasileiro. Ficou evidente que no ano de 2019 houve maior taxa de internações que no início de 2020, todavia, em março houve um pico de internações, provavelmente atribuídas ao novo coronavírus.

\section{REFERÊNCIAS}

DIAS FLT, et al. Doenças respiratórias no Triângulo Mineiro: Análise epidemiológica e projetiva com a pandemia de COVID-19. J. Health Biol Sci. 2020; 8(1)1-6.

LANA RM, et al. Emergência do novo coronavírus (SARS-CoV-2) e o papel de uma vigilância nacional em saúde oportuna e efetiva. Cadernos de Saúde Pública, 2020; v. 36, p. e00019620.

Ministério da Saúde - Sistema de Informações Hospitalares do Sistema Único de Saúde (SIH/SUS). Internações por Infecções agudas de vias aéreas superiores. Brasília-DF; 2020. 
012 | RESUMO SIMPLES: Estudo Original

\section{Levantamento de óbitos por infecções das vias aéreas superiores}

Autor/coautores: Gabriella Alves Ferreira, Aila Caterine Almeida de Freitas, Davi Araújo Pinheiro, Gabriela Brito de Souza, Thaís Ranielle Souza de Oliveira.

Instituição: Centro Universitário Euro Americano (UNIEURO), Brasília-Distrito Federal.

Palavras-chave: Mortalidade, Infecção, Vias aéreas superiores.

\section{INTRODUÇÃO}

Abordar a temática de infecções das vias aéreas superiores no Brasil é importante devido a presente pandemia do novo coronavírus. Consta-se que, é uma síndrome respiratória aguda e infecciosa com alta mortalidade, apresentando formas leves, moderadas, graves ou fulminantes. Portanto, traz desafios à vigilância epidemiológica, as políticas públicas e ao autocuidado (RAFAEL RMR, et al., 2020). Essa não foi a primeira pandemia enfrentada pelo Brasil, houve a da H1N1 em 2009. Um estudo mostrou que até 646.000 pessoas morrem de doenças respiratórias relacionadas à gripe sazonal a cada ano (ALVES VRG, et al., 2020). Logo, fazer o levantamento desses dados proporciona estratégias para o controle.

\section{OBJETIVO}

Realizar o levantamento dos óbitos por infecções das vias aéreas superiores por regiões no Brasil durante o mês de abril de 2019 a abril de 2020, através de dados obtidos no Sistema de Informações Hospitalares SIH/SUS.

\section{MÉTODO}

Estudo descritivo, desenvolvido a partir de dados coletados no portal do banco de dados do Ministério da Saúde, incluindo como referência as unidades federativas, calculando o número de óbitos por 100 mil cidadãos por habitantes residentes em determinado espaço geográfico (DATASUS, 2020). As informações utilizadas no estudo estão contidas no Sistema de Informações Hospitalares do Sistema Único de Saúde (SIH-SUS), classificados por regiões mostrando a situação de cada lugar. 


\section{RESULTADOS}

A região Nordeste apresentou a maior taxa média de mortalidade das infecções agudas das vias aéreas superiores de abril de 2019 à abril de 2020, tendo o mês de abril a maior taxa, 6,08\%, fato observado por todas as regiões, ou seja, o mês de abril de 2020 foi o de maior taxa dentro dos meses analisados. O valor médio das taxas de mortalidade no período citado foi de $2,31 \%$ dado obtido pela média dos valores das taxas de mortalidade em todo país. A Região Norte aparece com a menor média de taxa de mortalidade dentre todas as regiões do Brasil.

\section{CONSIDERAÇÕES FINAIS}

O Brasil apresenta grandes diferenças sociais e culturais entre as regiões e isso influencia fortemente os indicadores sociais e de saúde, incluindo a mortalidade. O Nordeste do país é uma região pobre e fatores econômicos como renda per capita e repasse de verbas governamentais em déficit, podem resultar em altas taxas de mortalidade por qualquer infecção.

\section{REFERÊNCIAS}

ALVES VRG, et al. Influenza $\mathrm{A}(\mathrm{H} 1 \mathrm{~N} 1)$ pdm09 infection and viral load analysis in patients with different clinical presentations. Mem. Inst. Oswaldo Cruz, Rio de Janeiro, v. 115, e200009, 2020.

BRASIL. Ministério da Saúde. Sistema de Informações Hospitalares. Brasília, DF, 2020.

RAFAEL RMR, et al. Epidemiologia, políticas públicas e pandemia de covid-19: o que esperar no brasil?. Rev Enferm UERJ, Rio de Janeiro, 2020; 28:e 49570. 
013 | RESUMOS SIMPLES: Estudo Original

\section{Classificação dos tipos de conteúdos nas fake news em saúde relacionadas ao Coronavírus}

Autor/coautores: Mariana Rodrigues Sandes da Silva, Mariana Gomes Leitão de Araújo, Nathália Lima de Pontes, Caroline Barbosa Toledo, Thaís Ranielle Souza Oliveira.

Instituição: Centro Universitário Euro Americano - UNIEURO Brasília-Distrito Federal.

Palavras-chave: Coronavírus, Notícias falsas, Pandemia.

\section{INTRODUÇÃO}

O termo fake news é considerado um artigo noticioso produzido para ser intencionalmente falso e apto a ser verificado como tal, em vista disso pode ludibriar os leitores que tiverem acesso a este material. Desse modo, o impacto destas notícias falsas nas mídias sociais é um problema de saúde pública, pois podem modificar a realidade, levando o indivíduo a comportamentos errôneos (MONARI e FILHO 2019). Diante do enfrentamento da pandemia do covid-19, surgiram inúmeros rumores com a probabilidade de prejudicar o processo saúde-doença. Para minimizar os danos, o Ministério da Saúde segue com o programa "Saúde sem Fake News", que visa checar e informar a população deste cenário (BRASIL, 2020).

\section{OBJETIVO}

Classificar quanto ao tipo de conteúdo nas fake news disseminadas sobre saúde na pandemia de covid-19 checadas pelo programa "Saúde Sem Fake News" uma ação liderada pelo Ministério da Saúde.

\section{MÉTODO}

Trata-se de um estudo descritivo que visou classificar as fake news segundo WARDLE (2017, citado por SOUZA e SALLES, 2020), quanto ao tipo de conteúdo relacionado ao coronavírus através da análise dos dados disponibilizados pelo programa "Saúde sem Fake News" do Ministério da Saúde. Dentro dos critérios do site, foram totalizadas 82 notícias, analisadas 77 e excluídas 5 por serem consideradas verdadeiras, assim não entrando no critério de inclusão.

\section{RESULTADOS}

Identificou-se que 45,5\% das notícias eram de conteúdo enganoso, o qual é considerado como uso enganoso de informações para englobar problemas ou indivíduos; $27,3 \%$ apresentou conteúdo 
fabricado, sendo que esta informação é integralmente falsa podendo causar danos; 13\% demonstrou conteúdo impostor, onde se utilizam informações com referências fontes e pessoas confiáveis; $6,5 \%$ classificaram como manipulação de conteúdo, de modo em que imagens e textos são verdadeiros, mas são formuladas para enganar; 5,2\% apontaram como falsa conexão, onde os títulos, imagens e legendas não condizem com o contexto; e 2,6\% apresentaram como falso contexto, em que imagens ou falas retiradas do contexto são produzidas.

\section{CONSIDERAÇÕES FINAIS}

Nota-se a importância de programas que visam desmistificar as fake news, como o programa "Saúde sem Fake News", onde a população tem acesso à informação de forma gratuita e de fácil acesso, evitando problemas mais graves no âmbito da saúde pública e assim contribuindo para com a diminuição da propagação de notícias falsas o que pode acarretar danos à população.

\section{REFERÊNCIAS}

BRASIL. Ministério da Saúde. Saúde sem Fake News: Coronavírus. 2020.

MONARI ACP, FILHO CB. Saúde sem Fake News: Estudo e Caracterização das Informações Falsas Divulgadas no Canal de Informações e checagem de Fake News do Ministério da Saúde. v. 13, n. 1, p. 160-186. abr. 2019.

SOUZA KAP, SALLES MM. Ecossistema da Desinformação: Tipos de Conteúdos Fraudulentos nas Eleições Presidenciais de 2018. Jornalismo do XXIV Congresso de Ciências da Comunicação na Região Sudeste. 2018. 
014 | RESUMOS SIMPLES: Estudo Original

\section{Conhecimento de homens universitários quanto ao uso de anticoncepcional de emergência: estudo seccional}

Autor/coautores: Laryssa Bezerra Silva, Nathália Lima de Pontes, Graziani Izidoro Ferreira, Fernanda Souza e Silva Garcia

Instituição: Centro Universitário Euro-Americano (UNIEURO), Distrito Federal, Brasília

Financiamento: Fundação de Apoio à Pesquisa do Distrito Federal (FAPDF)

Palavras-chave: Anticoncepção pós-coito, Comportamento contraceptivo, Estudantes.

\section{INTRODUÇÃO}

A anticoncepção hormonal de emergência (AHE) corresponde ao método que pode ser utilizado nos dias após o intercurso sexual desprotegido, em casos de falhas de outros métodos contraceptivos ou violência sexual para prevenção da gravidez indesejada (VARGAS AC, et al., 2017). É observado na literatura que a visão masculina ainda é limitada quanto ao conhecimento sobre anticoncepção, saúde sexual e reprodutiva, o que leva os homens a exercerem papel dominante, deixando essa questão sob a responsabilidade da mulher, em decorrência de uma construção histórica de gênero, social e cultural que impõe à mulher a decisão pela contracepção (NOGUEIRA IL, et al., 2018).

\section{OBJETIVO}

Analisar o conhecimento sobre a prática do uso do anticoncepcional hormonal de emergência e o ciclo reprodutivo feminino por estudantes universitários do sexo masculino em uma Instituição de Ensino Superior.

\section{MÉTODO}

Estudo seccional, com 111 universitários do sexo masculino, idade igual ou superior à 18 anos de uma instituição privada do Distrito Federal. A coleta de dados ocorreu entre agosto 2019 e março de 2020 por um questionário autoaplicável. As análises de frequência simples, dispersão e desvio padrão foram feitas no software SPSS® versão 20.0. Projeto aprovado pelo Comitê de Ética em Pesquisa sob no 3.487 .552 . 


\section{RESULTADOS}

A média da frequência do uso pela parceira variou de 1-4 vezes ao ano, o principal motivo foi a relação sexual desprotegida com $63 \%(n=34), 16 \%(n=17)$ acreditam que AHE deve ser utilizada antes da relação sexual, $0,9 \%(n=01)$ afirmou que o prazo máximo é de $120 \mathrm{~h}$ ou $5^{\circ}$ dia, $27 \%(n=28)$ desconhecem que a frequência do uso do contraceptivo diminui sua eficácia, $15 \%(n=16)$ acreditam que o contraceptivo provoca aborto, $65 \%(n=69)$ desconhecem os agravos. Ao ciclo reprodutor feminino a frequência de acertos foi de apenas $22 \%(n=15)$ para menstruação, $20 \%(n=13)$ ovulação, já $75 \%(n=58)$ conheciam sobre fertilidade.

\section{CONSIDERAÇÕES FINAIS}

O conhecimento dos universitários é deficiente e a prática do uso do AHE por suas respectivas parceiras sexuais é frequente. A falta de conhecimento sobre o uso adequado do AHE pode colocar a saúde da mulher em risco e é preocupante o comportamento dos universitários em suas relações sexuais sem o uso do preservativo, o que contribui para o comportamento de risco, gravidez indesejada e infecções sexualmente transmissíveis.

\section{REFERÊNCIAS}

NOGUEIRA IL, et al. Participação do homem no planejamento reprodutivo: revisão integrativa. J. res: fundam. care. online, 2018; 10 (1); e242247.

VARGAS AC, et al. Uso indiscriminado de contraceptivo de emergência por universitárias no Norte do Paraná. Brazilian Journal of Surgery and Clinical Research (BJSCR), 2017; 20 (1); e6571. 
015 | RESUMOS SIMPLES: Estudo Original

\section{Exame de mapeamento enzimático salivar como sinalizador de doença gástrica e prevenção da erosão dental: uma revisão integrativa}

Auto/coautores: Aurélio de Oliveira Rocha ${ }^{1}$, Lucas Menezes dos Anjos ${ }^{2}$, Ingrid de Melo Silva ${ }^{1}$, Denílson Oliveira Correia da Silva ${ }^{1}$, Thayanne Monteiro Ramos Oliveira'

Instituição: ${ }^{1}$ Universidade Tiradentes (UNIT), Aracaju - SE; '2Universidade Federal de Sergipe (UFS), Aracaju - SE.

Palavras-chave: Exame bucal, Refluxo esofágico, Erosão dentária.

\section{INTRODUÇÃO}

A erosão dental é definida como uma perda progressiva e irreversível da estrutura dental por processo químico não bacteriano. Pesquisas apontam sua ocorrência frequente em pacientes portadores da doença do refluxo gastroesofágico (DRGE) (WARSI I, et al., 2019; SARATH KKS, et al., 2018). Um sintoma clássico da DRGE é a regurgitação caracterizada pelo retorno involuntário do conteúdo gastroduodenal para o esôfago, podendo alcançar a cavidade oral, causando ou acelerando a degradação de colágeno dentinário exposto por conter agentes agressores como ácido clorídrico, sais biliares, enzimas pancreáticas, pepsina e tripsina. O diagnóstico precoce desta patologia pode reduzir significativamente seus efeitos no organismo (FRIESEN LR, et al., 2017).

\section{OBJETIVO}

Conhecer a fisiologia da Doença de Refluxo Gastroesofágico, compreender os efeitos negativos desta condição na cavidade oral, abordar sintomas e aspectos relacionados ao seu diagnóstico.

\section{MÉTODOS}

Foi realizada uma busca por estudos recentes na base de dado PubMed, utilizando os descritores "Diagnosis, Oral and Gastroesophageal Reflux and Tooth Erosion". Inseridos na plataforma onde foram cruzados com a expressão booleana AND. Dos 15 artigos identificados e selecionados para análise, 12 foram excluídos por não apresentar texto completo disponível e não serem estudos recentes. Portanto, três artigos foram qualificados para inclusão nesta revisão.

\section{RESULTADOS}


A DRGE afeta a orofaringe de maneira visível e precoce, assim, o dentista é considerado um profissional fundamental para evidenciar sua instalação (WARSI I, et al., 2019). A saliva é um fator biológico relevante para prevenir erosão, devido capacidade tampão, além de ser componente principal para realização do exame de mapeamento enzimático salivar (SARATH KKS, et al., 2018). Tal exame é solicitado pelo dentista e consiste na coleta da saliva pelo paciente e encaminhamento a um laboratório, onde este evidenciará a presença de enzimas gástricas na cavidade bucal. Caso o resultado seja positivo o paciente deve ser encaminhado para atendimento médico (FRIESEN LR, et al., 2017).

\section{CONSIDERAÇÕES FINAIS}

Dentre os exames disponíveis, o exame laboratorial de Mapeamento Enzimático vem se destacando na Odontologia por auxiliar o dentista na determinação do risco ao paciente para o desenvolvimento ou progressão das lesões de erosão. Assim, o conhecimento da DRGE pelo cirurgião-dentista é importante o para seu diagnóstico precoce, evitando danos irreversíveis aos tecidos duros dentais.

\section{REFERÊNCIAS}

FRIESEN LR, et al. Is histologic esophagitis associated with dental erosion: a cross-sectional observational study?. BMC Oral Health. 2017;17(1):116.

SARATH KKS, et al. Oral manifestations of gastroesophageal reflux disease in children: A preliminary observational study. J Indian Soc Pedod Prev Dent. 2018;36(2):125-129.

WARSI I, et al. Risk factors associated with oral manifestations and oral health impact of gastrooesophageal reflux disease: a multicentre, cross-sectional study in Pakistan. BMJ Open. 2019;9(3):e021458. 
016 | RESUMOS SIMPLES: Estudo Original

\section{SARS-COV-2 e o impacto odontológico: revisão sistematizada da literatura}

Autor/coautores: Aurélio de Oliveira Rocha ${ }^{1}$, Thaine Oliveira Lima1', Lucas Menezes dos Anjos², Ingrid de Melo Silva ${ }^{1}$, Denílson Oliveira Correia da Silva ${ }^{1}$.

Instituição: 'Universidade Tiradentes (UNIT), Aracaju - SE; ${ }^{2}$ Universidade Federal de Sergipe (UFS), Aracaju - SE

Palavras-chave: Odontologia Comunitária, Infecções por Coronavírus, Equipe de Saúde Aliada.

\section{INTRODUÇÃO}

O surto do vírus Sars-coV-2 mudou fundamentalmente os países e, consequentemente, está mudando a realidade dos profissionais da Odontologia. Essa pandemia está criando profundas mudanças nos governos, na economia global e nos sistemas de saúde (HAINES A, et al., 2020). A classe da saúde odontológica tem buscado alternativas e traçado estratégias em defesa da segurança dos pacientes e profissionais. Dentre essas mudanças podemos destacar a suspensão temporária de atendimentos eletivos e somente realização de atendimento clínico em caso de urgência e emergência, buscando sempre interagir com o paciente que na maioria dos casos se encontram estressados e ansiosos devido a situação esgotante causada pela pandemia (SABINOSILVA R, et al., 2020).

\section{OBJETIVO}

O Presente estudo tem como intuito investigar como profissionais da odontologia tem cuidado e orientado seus pacientes frente a pandemia do Coronavírus, a fim de reduzir os riscos de contaminação durante atendimento clínico.

\section{MÉTODO}

Foi realizada uma busca completa por estudos na base de dado PubMed, utilizando os descritores "Community Dentistry, Coronavírus infections, Allied Health personnel". Inseridos na plataforma de maneira cruzada utilizando a expressão booleana and. Dos 13 artigos identificados e selecionados para análise, 11 foram excluídos por não apresentar texto completo disponível e não condizer com o assunto estudado. Assim, 02 artigos foram qualificados para inclusão nesta revisão. 


\section{RESULTADOS}

Segundo Haines A et al. (2020), os profissionais estão em busca de maneiras para contornar os desafios do afastamento social e promover saúde para seus pacientes. Para Sabino-Silva R, et al. (2020) especialistas tem buscado formas de redução do contato social garantindo o estado de saúde por meio da adoção de medidas de higiene nos ambientes de atendimento através de métodos de desinfecção, esterilização e utilização de equipamentos de proteção individual. Além disso, sempre reforçando, incentivando e orientando em relação aos cuidados preventivos por meio do uso de máscara em todos os ambientes por parte da população, lavagem das mãos com água e sabão (HAINES A, et al., 2020).

\section{CONSIDERAÇÕES FINAIS}

Aos profissionais da área odontológica cabe orientar aos pacientes de cuidados essenciais para prevenção do contágio de doenças como o coronavírus, através das mudanças necessárias ao ambiente clínico no pré, trans e pós intervenção garantindo aos mesmos, atendimento seguro e de qualidade.

\section{REFERÊNCIAS}

HAINES A, et al. National UK programme of community health workers for COVID-19 response. Lancet. 2020;395(10231):1173-1175.

SABINO-SILVA R, et al. Coronavirus COVID-19 impacts to dentistry and potential salivary diagnosis. Clin Oral Investig. 2020;24(4):1619-1621. 
017 | RESUMOS SIMPLES: Estudo Original

\section{Erosão dental em crianças e adolescentes associada ao estilo de vida- revisão sistematizada}

Autor/coautores: Aurélio de Oliveira Rocha ${ }^{1}$, Thaine Oliveira Lima ${ }^{1}$, Lucas Menezes dos Anjos², Ingrid de Melo Silva1', Denílson Oliveira Correia da Silva'.

Instituição: ' ${ }^{1}$ niversidade Tiradentes (UNIT), Aracaju - SE; ${ }^{2}$ Universidade Federal de Sergipe (UFS), Aracaju - SE.

Palavras-chave: Erosão Dentária, Criança, Qualidade de Vida.

\section{INTRODUÇÃO}

O aumento da presença de desgastes dentais patológicos associados a mudanças no estilo de vida em crianças e adolescentes tem se tornado frequente nos atendimentos odontológicos. Dentre essas alterações podemos destacar a erosão dental (SANTANA NMS, et al., 2018). Essa patologia possui etiologia complexa e multifatorial causada pela queda brusca do $\mathrm{pH}$ bucal, seu mecanismo consiste na dissolução química dos tecidos dentários duros por ácidos de origem não bacteriana, provocando perda superficial e irreversível dos tecidos dentais (MANASWINI YH, et al., 2020). Este problema tem se tornado uma preocupação, pois pode causar hipersensibilidade dentária, oclusão alterada, dificuldades alimentares, estética deficiente, exposição pulpar e abscessos dentários (ALDLAIGAN YH, et al., 2017).

\section{OBJETIVO}

O presente trabalho tem como objetivo analisar a relação entre estilo de vida e erosão dental em crianças e jovens e a repercussão negativa física e psicológica dessa condição nas funções diárias.

\section{MÉTODO}

Foi realizada uma busca por estudos recentes nas bases de dados Lilacs e PubMed, utilizando os descritores "Tooth Erosion, Child and Quality of Life". Inseridos na plataforma onde foram cruzados com a expressão booleana AND. Dos 18 artigos identificados e selecionados para análise, 15 foram excluídos por não apresentar texto completo disponível e não serem estudos recentes. Portanto, três artigos foram qualificados para inclusão nesta revisão. 


\section{RESULTADOS}

Segundo Santana NMS, et al. (2018), uma complicação vinculada ao paciente infantil se dá ao consumo de doces extremamente ácidos e que estão cada vez mais populares nesta faixa etária. Além disso, esses alimentos ficam retidos na boca durante algum tempo o que intensifica o tempo de interação entre a solução e a superfície do dente, aumentando o risco de dissolução dos tecidos duros principalmente dentes decíduos que são mais vulneráveis aos desgastes erosivos que os dentes permanentes devido as diferenças estruturais entre eles, gerando consequências físicas e psicológicas ao indivíduo (AL-DLAIGAN YH, et al., 2017; MANASWINI YH, et al., 2020). Devido complexidade dessa patologia estudos duradouros são necessários.

\section{CONSIDERAÇÕES FINAIS}

Desgastes dentais precoces possuem etiologia complexa, onde os fatores associados encontram-se interligados na maioria dos casos. Devido aumento significativo desta condição na população adulta e infantil é de suma importância que profissionais busquem conhecer essa doença garantindo diagnóstico, prevenção e tratamento corretos para seus pacientes.

\section{REFERÊNCIAS}

AL-DLAIGAN YH, et al. The influence of frequently consumed beverages and snacks on dental erosion among preschool children in Saudi Arabia. Nutr J. 2017;16(1):80.

MANASWINI YH, et al. Impact of Calcium Glycerophosphate-supplemented Carbonated Beverages in Reducing Mineral Loss from the Enamel Surface. Int J Clin Pediatr Dent. 2020;13(1):1-5.

SANTANA NMS, et al. Prevalência de erosão dentária e fatores associados em uma população de escolares. Revista de Odontologia da UNESP. 2018; 47(3): 155-160. 
018 | RESUMOS SIMPLES: Estudo Original

\section{Acidentes laborais com material biológico ocorridos em um hospital do Rio Grande do Sul}

Autor/coautores: Cryshna Leticia Kirchesch.

Instituição: Universidade Federal de Pelotas (UFPel), Pelotas - Rio Grande do Sul.

Palavras-chave: Acidentes de trabalho, Saúde ocupacional, Hospital.

\section{INTRODUÇÃO}

No Brasil, os dados do anuário estatístico da Previdência Social, mostram que ocorreram um total de 450.613 mil acidentes de trabalho no ano de 2017 , sendo 340.229 casos de acidentes típicos, 100.684 de trajeto e 9.700 de doenças de trabalho. Do montante total 46.736 mil ocorreram no Estado do Rio Grande do Sul (BRASIL, 2017). Quanto aos acidentes de trabalho envolvendo material biológico, os trabalhadores da área hospitalar são os mais acometidos, visto que sua atividade os expõe rotineiramente ao manuseio com materiais perfurocortantes e fluidos potencialmente contaminados (NEVES JPG e MOURA RCM, 2018).

\section{OBJETIVO}

Descrever o perfil dos acidentes de trabalho hospitalar envolvendo materiais biológicos. Os dados poderão ser úteis na elaboração de novas pesquisas contribuindo para minimizar a carência da produção científica sobre a temática.

\section{MÉTODO}

Estudo quantitativo, com base em dados secundários. Incluíram-se registros de acidentes de trabalho no período de maio de 2017 a maio de 2019. Realizou-se o levantamento de 97 fichas. A análise estatística deu-se a partir do Statistical Analysis System. Utilizou-se estatística descritiva simples com cálculo de frequências e percentual de cada variável. A pesquisa foi aprovada pelo Comitê de Ética em Pesquisa em Seres Humanos (CEP) sob parecer 3.266.057.

\section{RESULTADOS}

Grande parte dos acidentados sofreram exposição percutânea $(60,5 \%)$, tendo como material orgânico de maior potencial de risco contaminante, o sangue, presente em 63 ocorrências (86,0\%). O bloco cirúrgico foi o setor hospitalar onde 33\% dos acidentes ocorridos geraram notificação de agravos, compondo praticamente um terço da amostra, sendo o procedimento cirúrgico (30,3\%) a 
atividade que se demonstrou mais suscetível aos acidentes. Em relação à ocupação, diversas categorias apresentaram notificações de acidentes com destaque para técnicos de enfermagem $(28,9 \%)$, enfermeiros (19,6\%) e médicos (13,4\%). A equipe de enfermagem compõe quase metade dos casos de profissionais acometidos pelos acidentes de trabalho.

\section{CONSIDERAÇÕES FINAIS}

Considera-se importante descrever o perfil dos acidentes de trabalho, para que sejam fomentados os programas e ações educativas para todos os trabalhadores do âmbito hospitalar, visando o controle de acidentes. Logo, esse estudo serve como fonte de informações para que gestores e profissionais que atuam no âmbito hospitalar reforcem essas estratégias para redução da exposição aos riscos laborais.

\section{REFERÊNCIAS}

BRASIL. Ministério da Economia. Secretaria de Previdência Social. Anuário Estatístico de Acidentes de Trabalho. Brasil. 2017. Disponível em: http://sa.previdencia.gov.br/site/2018/09/AEAT-2017.pdf. NEVES JPG, MOURA RCM. Acidentes com perfurocortantes em profissionais de enfermagem. Rev. Hum. Ser - UNIFACEX, 2018;3(1):33-46. 
019 | RESUMOS SIMPLES: Estudo Original

\section{Obesidade, sedentarismo e dieta como fatores de risco para o desenvolvimento de Diabetes Mellitus tipo 2}

Autor/coautores: Emilly Emanuella Oliveira Santos/Stéfanne Rodrigues Rezende/Dhullya Eduarda Resende Santos/Hanstter Hallison Alves Rezende.

Instituição: Universidade Federal de Jataí (UFJ), Jataí-Goiás.

Palavras-chave: Diabetes Mellitus tipo 2, Saúde, Estilo de vida.

\section{INTRODUÇÃO}

O Diabetes Mellitus (DM) é uma doença crônica não transmissível (DCNT). Podendo ocorrer por produção insuficiente ou má absorção de insulina, hormônio que regula a glicose no sangue e garante energia para o organismo (FREITAS RM, et al., 2020). No DM tipo 2 observa-se a perda funcional das células $\beta$, devido a diminuição da produção de insulina, ocasionando resistência à insulina. Esse tipo de diabetes está diretamente relacionado a hipertensão, hábitos alimentares e sedentarismo (SALIN AB, et al., 2019). A sua prevalência vem crescendo significativamente devido ao processo de industrialização, a urbanização, dietas hipercalóricas, inatividade física, histórico familiar, obesidade e aumento da expectativa de vida (SILVA AOB, et al., 2018).

\section{OBJETIVO}

O presente trabalho tem por objetivo reconhecer a importância de que a detecção precoce dos fatores de risco para DM tipo 2 possa minimizar ou reduzir a exposição das pessoas a essa DCNT.

\section{MÉTODO}

Trata-se de um estudo bibliográfico, baseado em textos de artigos científicos selecionados nas bases de dados do Google Acadêmico, Scielo, IBGE e Acervo+. A busca e seleção foi realizada através dos descritores: diabetes mellitus, fatores de risco, saúde pública. Na busca, 5 artigos foram selecionados, entre os anos de 2015 a 2020.

\section{RESULTADOS}

Em 2013, a Pesquisa Nacional de Saúde - PNS (IBGE) estimou que no Brasil 6,2\% da população de 18 anos ou mais de idade referiram diagnóstico médico de diabetes, cerca de 9,1 milhões de pessoas. As mulheres (7,0\%) apresentaram maior proporção de relato de diagnóstico de diabetes que os homens $(5,4 \%)$. Em relação aos grupos de idade, quanto maior a faixa etária, maior o 
percentual, que variou de 0,6\%, para aqueles de 18 a 29 anos de idade, a 19,9\%, para as pessoas de 65 a 74 anos de idade. Para aqueles que tinham 75 anos ou mais de idade, o percentual foi de $19,6 \%$.

\section{CONSIDERAÇÕES FINAIS}

O diabetes é atribuído a uma combinação de diferenças genéticas e fatores ambientais. Maus hábitos alimentares, estilo de vida sedentário, são apontados como os principais fatores etiológicos do aumento da prevalência da obesidade no mundo. Há evidências bem fundamentadas da relação entre a qualidade da alimentação e os riscos de desenvolver DM.

\section{REFERÊNCIAS}

FREITAS RM, et al. Avaliação do perfil clínico e prática de atividades físicas em idosos diabéticos, cadastrados na Estratégia Saúde da Família. Revista Eletrônica Acervo Saúde, 2020; 48: e2159.

IBGE. Pesquisa nacional de saúde: percepção do estado de saúde, estilos de vida e doenças crônicas. Rio de Janeiro, 2013. p. 155-164.

SALIN AB, et al. Diabetes Mellitus tipo 2: perfil populacional e fatores associados à adesão terapêutica em Unidades Básicas de Saúde em Porto Velho-RO. Revista Eletrônica Acervo Saúde, 2019; 33: e1257.

SILVA AOB, et al. Relação da alimentação com surgimento precoce da obesidade e diabetes mellitus tipo 2 em crianças e adolescentes. Revista Eletrônica Acervo Saúde, 2018; 18: e90. 
020 | RESUMOS SIMPLES: Estudo Original

\section{O perfil dos praticantes de musculação da mesorregião do Centro-Oeste de Minas Gerais}

Autor/coautores: Gleison Silva Morais, Cíntia Aparecida Santos, Júlia Vieira Salgado Silva, Lucas Rios Drummond, José Vítor Vieira Salgado.

Instituição: Universidade do Estado de Minas Gerais (UEMG), Divinópolis-Minas Gerais.

Financiamento: Financiamento Próprio.

Palavras-chave: Atividade Física, Academias, Descrição.

\section{INTRODUÇÃO}

A musculação é o termo mais utilizado para designar o treinamento contra-resistido, ou seja, movimentos realizados pelo corpo contra algum tipo de resistência (DUTRA PTB, et al., 2019). Essa não é uma modalidade esportiva, mas uma forma de treinamento físico e devido as suas qualidades passaram a ocupar lugar de destaque nas academias (RODRIGUES ALP, 2017). Além disso os exercícios contra-resistidos constituem a base do treinamento de atletas de diversas modalidades (RODRIGUES FP, 2018).

\section{OBJETIVO}

O objetivo do estudo é caracterizar o perfil dos praticantes de musculação de uma cidade da mesorregião do Centro-Oeste de Minas Gerais.

\section{MÉTODOS}

O estudo é de natureza quantitativa descritiva exploratória, através da aplicação de questionário estruturado, para caracterização da rotina de treinamento e hábitos pessoais. Os critérios de seleção foram: idade mínima de 18 anos; não apresentar déficit cognitivo impedindo responder o questionário; e praticar musculação regularmente (ao menos três meses contínuos e ininterruptos). O estudo foi aprovado pelo Comitê de Ética em Pesquisa pelo parecer 2.580.837. Para análise dos dados, foi utilizada estatística descritiva, média e desvio padrão. A normalidade foi atestada pelo teste Shapiro Wilk, para análise dos resultados foi utilizando o pacote estatístico SPSS 20.0 para nível de significância 5\%. 


\section{RESULTADOS}

Participaram do estudo 184 indivíduos sendo 48\% ( $n=88)$ homens e 52\% ( $n=96)$ mulheres. Os dados apresentaram distribuição normal, do total 119 indivíduos fazem somente musculação e 65 praticam também outras atividades como natação, crossfit entre outras. A média de idade dos praticantes foi de 36 anos $( \pm 10,75)$ para homens e 43,64 anos $( \pm 10,89)$ para mulheres. $O$ Índice de Massa Corporal (IMC) para homens foi de 24,91 $( \pm 3,1)$ e $23,28( \pm 3,8)$ para mulheres. Quanto a orientação profissional para realização do treinamento $86 \%(n=158)$ dos indivíduos responderam possuir acompanhamento e 14\% ( $n=26)$ não possuir. Quando questionados se realizaram exames e/ou avaliação física antes de iniciar a prática da atividade $80 \%(n=148)$ dos indivíduos realizaram, enquanto $20 \%$ ( $n=36)$ não o fizeram. No que se refere à utilização de suplementos alimentares, $33 \%(n=60)$ eram usuários e $67 \%(n=124)$ não fizeram o uso. Referente a rotina de treinamento os indivíduos treinam em média 3,5 vezes por semana, 72 minutos dia, em média 47 meses de prática geral.

\section{CONSIDERAÇÕES FINAIS}

Considera-se que o perfil dos praticantes de musculação apresenta singularidade referente ao sexo e composição corpórea, os resultados obtidos contribuem para o planejamento de ferramentas que consigam, de forma coesa, superintender, auxiliar projetos e programas através da caracterização realizada.

\section{REFERÊNCIAS}

DUTRA PTB, et al. Efeitos do Treinamento Resistido em Obesos: uma revisão integrativa. Revista Eletrônica Acervo Saúde, n. 21, p. e831-e831, 2019.

RODRIGUES ALP. Caracterização do perfil e dos hábitos de suplementação alimentar de praticantes de musculação em uma academia do município de Fortaleza-CE. Revista Brasileira de Nutrição Esportiva, v. 11, n. 66, p. 662-668, 2017.

RODRIGUES FP. Perfil dos usuários de anabolizantes praticantes de musculação na região do alto tietê. Revista Científica UMC, v. 3, n. 3, 2018. 
021 | RESUMO SIMPLES: Estudo Original

\section{A testagem da albumina na fase aguda da Leishmaniose}

Autor/coautores: Regina Célia da Silva.

Instituição: Universidade Federal do Piauí, Teresina - Piauí.

Palavras-chave: Albumina, Fase aguda, Leishmaniose.

\section{INTRODUÇÃO}

A Leishmaniose visceral é uma doença inflamatória considerada como emergente, e está entre as seis mais importantes doenças tropicais, segundo a Organização Mundial de Saúde (SILVA, et al., 2019).

O paciente quando diagnosticado com ela apresenta infecção aguda, que pode se tornar crônica, levando ao óbito. Essa fase se caracteriza a princípio por febre e alterações na permeabilidade vascular, juntamente com profundas mudanças nos valores das proteínas da fase aguda, como a Albumina. A diminuição em sua síntese é característica de um processo inflamatório. Visto isso, tem-se que a dosagem dessa proteína agiliza o diagnóstico da doença (SALES ET, et al., 2017).

\section{OBJETIVO}

Demonstrar a importância da mensuração da albumina para o diagnóstico dos pacientes com leishmaniose na fase aguda, em comparação com os parâmetros do Hemograma.

\section{MÉTODO}

Utilizou-se $1 \mathrm{ml}$ de plasmas de 59 pacientes com Leishmaniose em 2018 do Hospital, congelados por até 3 anos $\left(-20^{\circ} \mathrm{C}\right)$ com o kit ALB2 Albumin Gen.2-cobas, Roche Diagnóstica Brasil Ltda, por 30 min, método colorimétrico. Estudo transversal, com coorte aberta seguida de análise quantitativa com descrição das variáveis na população estudada. A pesquisa foi aprovada pelo Comitê de Ética na região norte do Piauí com parecer CAAE: 74411417.9.0000.5214.

\section{RESULTADOS}

$73 \%$ dos pacientes são homens na faixa etária de 18 a 50 anos (22\%), com $38 \%$ de probabilidade de morte e valores de albumina de $2,5 \mathrm{~g} / \mathrm{dL}$ para hematócritos $(\%) \geq 25 \%$; albuminas de $2,6 \mathrm{~g} / \mathrm{dL}$ para leucócitos $(\mu / \mathrm{l})>$ de 2000; albumina de 2,3g/dL para neutrófilos $(\mu / \mathrm{l})>500$ e albumina de $2,5 \mathrm{~g} / \mathrm{DI}$ para plaquetas $(\mu / \mathrm{l})<100.000$. 


\section{IR PARA O SUMÁRIO}

O decréscimo da albumina, que é de origem proteica, ocorre na fase aguda da doença. As alterações na sua concentração podem impactar na farmacocinética e farmacodinâmica de drogas ligadas às proteínas (CONNER, 2017) e ocorrem em situações médicas específicas, como a hiperalbuminemia em situações de desidratação, e a hipoalbuminemia em processos inflamatórios.

\section{CONSIDERAÇÕES FINAIS}

Constatou-se que a Albumina se manteve com valores baixos nas amostras, o que evidencia que todos os pacientes estavam na fase aguda. Quando há diagnóstico tardio da doença os pacientes tendem a óbito na maioria dos casos. Visto isso, notou-se que caso a dosagem de Albumina fizesse parte do protocolo da doença a detecção do nível de inflamação e dos pacientes na fase aguda seria mais efetiva.

\section{REFERÊNCIAS}

CONNER BJ. Treating Hypoalbuminemia. Revista The Veterinary Clinics of North America: Small Animal Practice, 2017; 47.

SALES ET, et al. Neutrofilia e hipoalbuminemia em sangue periférico de cães naturalmente infectados por Leishmania Infantum. Revista Ciência Animal, 2017; 27.

SILVA $M$, et al. Performance evaluation of anti-fixed Leishmania infantum promastigotes immunoglobulin $\mathrm{G}(\mathrm{lgG})$ detected by flow cytometry as a diagnostic tool for visceral Leishmaniasis. Revista Journal of Immunological Methods, 2019; 469. 
022 | RESUMOS SIMPLES: Estudo Original

\section{Descrição epidemiológica de fissuras labiopalatais em centro de referência}

Autor/coautores: Aline Debs Diniz, Giovana Rezende Fernandes Costa, Salmo Raskin. Instituição: Universidade Positivo (UP), Curitiba-Paraná; Pontifícia Universidade Católica do Paraná (PUCPR), Curitiba-Paraná.

Palavras-chave: Fissura labiopalatal, Epidemiologia, Herança familiar.

\section{INTRODUÇÃO}

As fissuras labiopalatais (FLP) estão entre as anomalias craniofaciais mais frequentemente diagnosticadas, sendo essas caracterizadas por disjunções nas regiões do lábio e/ou palato, decorrente de embriogênese inadequada (BUTALI A, et al., 2017). Os pacientes portadores de tais alterações necessitam de apoio multidisciplinar especializado, para que a doença seja manejada de forma adequada e esses tenham melhor reabilitação funcional. (JIN LJ, et al., 2016). Uma combinação entre fatores genéticos, hereditários e ambientais pode contribuir para formação das FLP, sendo a descrição de sua epidemiologia essencial para o diagnóstico, investigação etiológica, tratamento e auxílio na criação de políticas públicas de saúde que atendam a este público (WORLEY ML, et al., 2018).

\section{OBJETIVO}

Analisar e descrever as características epidemiológicas de pacientes atendidos em centro de referência e comparar frequências dos tipos de FLP descritas em dois grupos de pacientes com e sem irmãos fissurados.

\section{MÉTODO}

Estudo observacional retrospectivo, que analisou 2194 prontuários de pacientes com FLP atendidos no centro de referência. Os dados qualitativos foram expressos em frequência relativa. As fendas foram descritas usando a Classificação Spina modificada e compararam-se as frequências dos seus tipos em grupos de pacientes que possuem irmãos com e sem FLP ( $\mathrm{A}$ e $B$ ). Análise comparativa feita pelo teste de Fisher com $p<0,05$. Aprovado no Comitê de Ética em Pesquisa ( $n^{0}$ 1.349.674). 


\section{RESULTADOS}

Identificou-se 1110 casos de parentes com FLP (50,59\%) sendo: 38 mães, 36 pais, 28 avós, 120 irmãos e 888 demais parentes. Referente aos tipos de FLP, detectou-se: $34,86 \%$ fendas transforame unilateral, $16,54 \%$ fendas transforame bilateral $14,44 \%$ fendas pré-forame unilateral incompleta, 10,8\% fendas pós-forame incompleta, 7,56\% fendas pós-forame completa, 7,56\% fendas pré-forame unilateral completa, $1,59 \%$ fendas pré-forame bilateral incompleta, $1,27 \%$ fendas pré-forame bilateral completa, 2,87\% associações entre fendas pré e pós-forame e 2,5\% fendas atípicas. Quando comparados tipos de fissuras entre grupos que tinham irmãos com e sem FLP, houve diferença significante entre as frequências de fendas transforame unilateral, com 38 casos no grupo $A$ e 727 casos no $B(p<0,0001)$.

\section{CONSIDERAÇÕES FINAIS}

Foram descritas, parcialmente, as características epidemiológicas dos pacientes portadores de FLP. Quanto à frequência dos padrões de fenda, houve diferença significante apenas nos casos de fissuras transforame unilaterais, mais frequentes naqueles cujos irmãos não eram portadores FLP. Os resultados obtidos auxiliarão no estudo de fatores etiológicos, bem como no melhor entendimento do perfil da doença e direcionamento de ações públicas preventivas e terapêuticas.

\section{REFERÊNCIAS}

WORLEY ML, et al. Cleft Lip and Palate. Clinics in perinatology, 2018; 45(4):661-678.

BUTALI A, et al. Descriptive epidemiology of orofacial clefts in Africa using data from 46,502 Smile Train surgeries. Journal of Public Health and Epidemiology, 2017; 9(5):114-121.

JIN LJ, et al. Global burden of oral diseases: emerging concepts, management and interplay with systemic health. Oral diseases, 2016; 22(7):609-19. 
023 | RESUMOS SIMPLES: Estudo Original

\section{Identificação de variantes no gene $S L C 26 A 9$ de acordo com o genótipo da variante rs7512462 em pacientes com fibrose cística (p.Phe508del/p.Phe508del)}

Autor/coautores: Luana Gavioli dos Santos; Stéphanie Villa-Nova Pereira; Luciana Cardoso Bonadia; Carmem Silvia Bertuzzo; Fernando Augusto Lima Marson.

Instituição: Universidade Estadual de Campinas (UNICAMP), Campinas - São Paulo.

Palavras-chave: Fibrose cística, SLC26A9, Variantes de nucleotídeo único.

\section{INTRODUÇÃO}

A busca por novos fármacos vem sendo utilizada para elaborar um tratamento personalizado para pacientes com fibrose cística (FC; OMIM: 219700), doença genética autossômica recessiva causada por variantes patogênicas no gene Cystic Fibrosis Transmembrane Regulator (CFTR) (Marson FAL, et al., 2017). Sabe-se que os genes modificadores atuam não apenas na diferenciação da manifestação clínica destes pacientes, mas também em suas respostas aos tratamentos. Dentre eles, a variante benigna rs7512462 presente no gene SLC26A9 (Solute Carrier Family 26 Member 9 - família de transportadores de ânions) parece estar modulando a resposta ao fármaco Orkambi (Kmit A, et al., 2019).

\section{OBJETIVO}

Identificar pelo uso do sequenciamento do tipo Sanger, outras variantes presentes no gene SLC26A9 que, juntamente com a variante rs7512462, possam estar associadas às diferentes respostas ao medicamento Orkambi em pacientes FC e homozigotos para a variante patogênica p.Phe508del.

\section{MÉTODO}

O diagnóstico de FC foi determinada pela rotina laboratorial e a identificação do genótipo para a variante rs7512462 foi realizada por PCR em tempo real. Após a seleção dos 3 possíveis genótipos de rs7512462, o sequenciamento dos 21 exons do SLC26A9 foi realizado pelo método de Sanger. Finalmente, as variantes elencadas foram avaliadas in silico por numerosos preditores. Possuindo para tal pesquisa a aprovação do Comitê de Ética em Pesquisa (CAAE: 38162914.3.0000.5404). 


\section{RESULTADOS}

Foram incluídos 3 pacientes com FC com o genótipo p.Phe508del/p.Phe508del para o gene CFTR, com genótipos diferentes para a variante rs7512462 e que apresentaram respostas diferenciadas ao tratamento com Orkambi, droga associada a medicina de precisão e personalizada para a FC. Foram identificadas ao todo 15 variantes de nucleotídeos únicos sendo nenhuma considerada como patogênica. A variante missense p.Pro606Leu (rs74146719) com MAF de 0,03 ocorreu em heterozigose em um paciente. As demais variantes ocorreram em homozigose ou heterozigose e eram de regiões intrônicas. As predições in silico foram realizadas, apontando alterações ou criações de sítios tanto de silenciadores quanto de aprimoradores de splicing.

\section{CONSIDERAÇÕES FINAIS}

Apesar da ausência de patogenicidade nas variantes encontradas no gene SLC26A9 pelas análises de preditores, possivelmente, há outras variantes além da rs7512462 que podem estar associadas, isoladamente ou em conjunto, com a resposta desses pacientes aos fármacos utilizados pela medicina de precisão e personalizada.

\section{REFERÊNCIAS}

KMIT A, et al. Extent of rescue of F508del-CFTR function by VX-809 and VX-770 in human nasal epithelial cells correlates with SNP rs7512462 in SLC26A9 gene in F508del/F508del Cystic Fibrosis patients. Biochimica et Biophysica Acta (BBA) - Molecular Basis of Disease. 1 de junho de 2019.

MARSON FAL, et al. Personalized or Precision Medicine? The Example of Cystic Fibrosis. Front. Pharmacol., 20 junho de 2017. 
024 | RESUMOS SIMPLES: Estudo Original

\section{Perfil e inatividade física dos docentes do ensino municipal de uma cidade da mesorregião Centro-Oeste de Minas Gerais}

Autor/coautores: Gleison Silva Morais, Eneder Donizete Rosa, Karen Cristine Rodrigues Alves. Instituição: Universidade do Estado de Minas Gerais (UEMG), Divinópolis-Minas Gerais.

Financiamento: Financiamento Próprio.

Palavras-chave: Absenteísmo, Professores, Atividade física.

\section{INTRODUÇÃO}

A atividade física tem sido relacionada como um importante agente de proteção para a saúde desde a década de 50 (SANTANA JO e PEIXOTO SV, 2017). O Brasil, em 2015, aplicou mais de um bilhão de reais em prerrogativas de auxílio-doença previdenciário, cobrindo afastamentos dos trabalhadores de morbidade declarada e no serviço público federal, as aposentadorias precoces e os afastamentos no mesmo ano orçaram mais de 300 milhões de reais (LEÃO ALM, et al., 2015). Assim sendo, este estudo permitiu analisar a relação entre os níveis de atividade física e complementar informações sobre o perfil docente da rede municipal de ensino (SILVA DMR, et al., 2018).

\section{OBJETIVO}

O estudo busca identificar e analisar a inatividade física dos docentes da rede municipal de uma cidade na mesorregião do Centro-Oeste de Minas Gerais, bem como complementar a caracterização da amostra em estudo.

\section{MÉTODOS}

Este é um estudo transversal do tipo survey, com caráter qualitativo-quantitativo, aplicado em 12 escolas e 08 Centros Municipais de Educação Infantil (CMEl's). O estudo foi aprovado pelo Comitê de Ética em Pesquisa (CAAE 14043619.30000.5115 / Número 3.599.966). Para verificar o nível de atividade física em docentes da rede municipal utiliza-se uma versão curta do Questionário Internacional de Atividade Física (IPAQ-versão curta). E, para complementar o perfil e compreender melhor o contexto social em que estão inseridos, foi aplicado aos docentes, um questionário sociodemográfico. 


\section{RESULTADOS}

Um total de 90 professores responderam aos questionários, sendo que $96 \%$ dos docentes são mulheres ( $n=86$ ), com idade geral de 44 ( \pm 9 anos). Com relação ao nível de ensino em que atuam, $53 \%$ dos entrevistados $(n=48)$ atuam no ensino fundamental $I$. A maior parte dos professores $91,1 \%$ $(n=82)$, é concursada para o cargo. Quanto à formação acadêmica, $78 \%(n=70)$ possuem especialização na área. A partir dos dados do IPAQ-versão curta, e, analisadas as proporções de sujeitos ativos nos domínios da atividade física, encontra-se um total de $46 \%$ dos docentes ( $n=41$ ) em estado sedentário, o que por sua vez pode estar associado com o tempo médio informado, em minutos por semana em que passam sentados (207 minutos semanais $( \pm 181)$ ).

\section{CONSIDERAÇÕES FINAIS}

Os docentes são em sua maioria do sexo feminino, com predominância de faixa etária acima de 40 anos, com formação acadêmica em nível de especialização. A princípio, supõe-se que os baixos níveis de atividade física e que o perfil e a rotina dos professores no exercício da profissão os tornam irregularmente ativos.

\section{REFERÊNCIAS}

SANTANA JO, PEIXOTO SV. Inatividade física e comportamentos adversos para a saúde entre professores universitários. Revista Brasileira de Medicina do Esporte, v. 23, n. 2, p. 103-108, 2017. LEÃO ALM, et al. Absenteísmo-doença no serviço público municipal de Goiânia: Absenteísmodoença no serviço público municipal de Goiânia. Revista Brasileira de Epidemiologia, [s.I.], v. 18, n. 1, p.262-277, mar. 2015. FapUNIFESP.

SILVA DMR, et al. Condições de trabalho e estresse em professores de Escolas Públicas Estaduais de Divinópolis-MG. Educação em Revista, Marília, v.19, n.2, p. 129-142, Jul.-Dez., 2018. 
025 | RESUMOS SIMPLES: Estudo Original

\title{
O cuidado em saúde no puerpério sob a perspectiva de usuárias da atenção básica
}

\author{
Autor/coautores: Sayonara de Souza Ferreira, Kalyane Kelly Duarte de Oliveira' Maria Valéria \\ Chaves de Lima, Thaina Jacome Andrade de Lima, Ilza Iris dos Santos. \\ Instituição: Faculdade Nova Esperança de Mossoró (FACENE/RN); Universidade do Estado do \\ Rio Grande do Norte (UERN/ Pau dos Ferros/RN); Universidade Potiguar (UnP/Mossoró/RN). \\ Palavras-chave: Puerpério, Cuidados, Atenção Básica.
}

\section{INTRODUÇÃO}

O puerpério inicia-se logo após o parto, ocorrendo involuções múltiplas de natureza hormonal, psíquica e metabólica, sendo consideradas como necessárias para a promoção dos ajustes fisiológicos (GOMES GF e SANTOS APV, 2017). Sabendo da vulnerabilidade a diversas complicações que podem acometer a puérpera, detectou-se o seguinte problema: nesta fase as atenções voltam-se para o recém-nascido e a mulher recebe menos atenção pela equipe de saúde. Assim, defende-se a visita puerperal como ferramenta imprescindível para a qualidade de vida ao binômio mãe-filho, pois possibilita identificar problemas que interferem na vida de ambos, pode ser realizada de forma simples, dinâmica e econômica, acontecendo por meio das orientações educativas. O estudo é relevante por enfatizar a importância da assistência ao puerpério e as possíveis causas da deficiência dela (GOMES GF e SANTOS APV, 2017).

\section{OBJETIVO}

Investigar o cuidado dispensada as puérperas na atenção básica.

\section{MÉTODO}

Trata-se de uma pesquisa descritiva, de abordagem qualitativa, desenvolvida com 20 puérperas cadastradas em 5 unidades básicas de saúde em um município do interior do estado do RN. A coleta de dados aconteceu em visita domiciliar com aplicação de entrevista em outubro de 2019. Os dados foram analisados com Bardin (2009). O projeto pautou-se na resolução 466/12, sendo aprovado pelo Comitê de Ética em Pesquisa da FACENE/PB com parecer ㄲo 1.877.405/2016. 


\section{RESULTADOS}

Verifica-se que das 20 participantes, 14 puérperas têm idade entre 20 a 29 anos, 10 vivem com companheiro, 8 tem ensino médio, 11 não trabalham. Dos dados obstétricos, 8 são primíparas, todas realizaram pré-natal, 13 realizaram pelo SUS, 3 tiveram complicações na gestação como préeclâmpsia. Sobre os profissionais participantes das consultas citaram enfermeiros, médicos e técnicos de enfermagem. Sobre os dados puerperais: 14 tiveram parto cesárea, 11 receberam visita puerperal, 8 apresentaram sintomas que interferiu na qualidade de vida, todas amamentam. As orientações recebidas na visita puerperal foram sobre: aleitamento materno, cuidados com o recémnascido, suplementação de vitamina A e ferro, exame Papanicolau, anticoncepção, vacinas puerperais e do $\mathrm{RN}$, testes de triagem neonatal.

\section{CONSIDERAÇÕES FINAIS}

A avaliação dos resultados mostrou deficiência nas ações dispensadas ao período puerperal, restringindo-se ao pré-natal e parto, diante disto, confirma-se a pouca atenção destinada a puérpera. As participantes demostraram pouco conhecimento sobre como realizar os cuidados adequados com o bebê e autocuidado, deixando prevalecer os cuidados adquiridos por conhecimento popular. A pesquisa evidenciou a importância das ações educativas, da interação entre profissional e usuário e o trabalho em equipe.

\section{REFERÊNCIAS}

BARDIN L. Análise de Conteúdo. Ed.70. Lisboa, Portugal, LDA, 2009.

GOMES GF, SANTOS APV. Assistência de enfermagem no puerpério. Rev. Enf. Contemp, v. 6, n. 2, p. 211-220, 2017. 
026 | RESUMOS SIMPLES: Estudo Original

\section{Caracterização estrutural de nanopartículas de ferrita de cobalto dopadas com $\mathrm{La}^{3+}$ para aplicação em tratamento de água}

Autor/coautores: Rafael Leal da Silva.

Instituição: Secretaria de Educação e da Ciência e Tecnologia da Paraíba (SEECT-Paraíba).

Financiamento: Conselho Nacional de Desenvolvimento Científico e Tecnológico (CNPq).

Palavras-chave: Ferrita de cobalto, Caracterização magnética, Terra rara.

\section{INTRODUÇÃO}

Existe vários métodos de síntese de ferritas de cobalto relatadas na literatura, entre eles, estão sol-gel, solvotermal, micelas inversas, técnicas de combustão, sonoquímico e hidrotérmica. A dopagem das feritas de cobalto com íons das terras raras Lantâneo $\left(\mathrm{La}^{3+}\right)$, tem sido estudada e mostra que esse incremento causa modificações nas propriedades magnéticas desse material, possibilitando um novo espectro de aplicações nos mais variados ramos, principalmente na biomedicina. Em especial, a dopagem com $\mathrm{La}^{3+}$ tem sido estudada para modificação das propriedades dielétricas, mostrando-se efetiva para os melhoramentos dessas características, assim como as magnéticas e estruturais e tamanho das partículas (MARIOSI FR, et al., 2020; WU X, et al., 2016).

\section{OBJETIVO}

Caracterizar estrutural e magneticamente nanopartículas de CoFe2O4 doparas com íons de $\mathrm{La}^{3+}$; investigar aplicação ambiental em tratamento de água.

\section{MÉTODO}

Nanopartículas de $\mathrm{CoFe}_{2-\mathrm{x}} \mathrm{La}_{\mathrm{x}} \mathrm{O}_{4}$ com $0.10<\mathrm{x}<0.40$ foram preparadas pelo método de reação por coordenação iônica usando o biopolímero quitosana. As partículas foram produzidas à temperatura de $600{ }^{\circ} \mathrm{C}$ por $2 \mathrm{~h}$. Os tamanhos médios de cristalito foram calculados pelo método Rietveld nos difratogramas de raios-X. A morfologia, tamanho e aglomeração foram analisadas por microscopia eletrônica de transmissão e as propriedades magnéticas, analisadas por intermédio de medidas de magnetometria de amostra vibrante. 


\section{RESULTADOS}

Os tamanhos médios de cristalito foram calculados pelo método Rietveld nos difratogramas de raios-X e variaram entrem 9,7 - 5,2 nm, diminuído com o aumento da dopagem de íons de $\mathrm{La}^{3+}$. As análises de raio-X também evidenciam a formação de fase única. As nanopartículas são esféricas, formando grandes aglomerados confirmado pela medida de microscopia eletrônica de transmissão. A magnetização de saturação das nanopartículas em temperatura ambiente foi de 43,10 emu/g (para $x=0,10$ ) e, quando a concentração foi aumentando, a magnetização seguiu a tendência de uma queda linear. O menor valor de saturação foi de $14,90 \mathrm{meu} / \mathrm{g}$ (para $\mathrm{x}=0,40$ ). A coercitividade, remanência e anisotropia cristalina também diminuíram.

\section{CONSIDERAÇÕES FINAIS}

A substituição de íons de $\mathrm{Fe}^{3+}$ por $\mathrm{La}^{3+}$ causa drásticas modificações nas propriedades magnéticas da ferrita de cobalto. O tamanho das partículas depende fortemente da dopagem, reduzindo o tamanho e levando as partículas ao domínio simples. Os átomos de $\mathrm{La}^{3+}$ foram incorporados dentro da estrutura da ferrita de cobalto e não foi observado fases secundárias. Os resultados parciais indicam a possibilidade de aplicação em tratamento de água (MARIOSI FR, et al., 2020).

\section{REFERÊNCIAS}

MARIOSI FR, et al. Lanthanum-doped spinel cobalt ferrite (CoFe2O4) nanoparticles for environmental applications. Ceramics International, 2020; 46(3): 2772-2779.

WU X, et al. Effect of the rare-earth substitution on the structural, magnetic and adsorption properties in cobalt ferrite nanoparticles. Ceramics International, 2016; 42(3): 4246-4255. 
027 | RESUMOS SIMPLES: Estudo Original

\section{Comunicação dos serviços de um hospital universitário: perspectivas da gestão da clínica}

Autor/coautores: Pâmela Camile Silva Benevenuto Rodrigues; Johanna Michelle Arias Barrionuevo; Michelly Kim Oliveira Rosa Guimarães; Gímerson Erick Ferreira; Mara Regina Rosa Ribeiro.

Instituição: Universidade Federal de Mato Grosso (UFMT) e Hospital Universitário Júlio Muller (HUJM), Cuiabá - Mato Grosso.

Palavras-chave: Gestão, Comunicação, Marketing.

\section{INTRODUÇÃO}

Para comunicar-se com alguém é importante que a informação, o objetivo e o resultado esperado sejam claros. Logo, a comunicação se refere à troca de informações, no qual existe um processo dialógico, cujo conteúdo é compreendido e convertido em resultados (OLIVEIRA AV, et al., 2018). A gestão da clínica envolve o gerenciamento da transparência expressando o compromisso com as diretrizes do sistema de saúde na perspectiva e na promoção do controle social, trabalhando em os meios da comunicação interna e externa para favorecer o fácil acesso às informações dos serviços hospitalares (PADILHA RQ, et al., 2018).

\section{OBJETIVO}

Conhecer os aspectos da comunicação institucional (comunicação interna e externa), as maneiras de integrar as comunicações adotadas nos setores do hospital e os principais desafios da comunicação em um serviço hospitalar público.

\section{MÉTODO}

Pesquisa descritiva, de análise documental, com abordagem qualitativa. Foram utilizados como fonte de dados: o Plano Diretor Estratégico (PDE) dos anos 2016-2017 / 2018-2019, o SITE e a INTRANET de um Hospital Universitário do Centro-Oeste, realizada de dezembro de 2019 à março de 2020. A organização dos dados seguiu a proposta de análise temática. A pesquisa faz parte de um projeto matricial com aprovação no Comitê de Ética/HUJM no 3.285.978/2019. 


\section{RESULTADOS}

Identificou-se que as informações do PDE de 2016- 2017 estão mais completas quando comparado ao PDE de 2018-2019, onde as informações são escassas. O acesso à intranet é exclusivo do servidor, e algumas ações só podem ser realizadas com nome de usuário e senhas pessoais, como solicitações via site e acesso a documentos/protocolos. Também, foi possível identificar que não há um espaço dedicado para a ferramenta Gestão à Vista, na intranet do hospital. Quanto ao SITE, não há divulgação de todas as certificações/premiações conquistados pelo hospital, é possível visualizar apenas algumas certificações na página principal, e ainda os projetos de pesquisa realizados no hospital não são atualizados desde 2016.

\section{CONSIDERAÇÕES FINAIS}

A gestão da clínica articula-se com a comunicação interna e externa, sendo importante ao visualizar a projeção de melhorias para hospital, interagir com processos apropriados de que a instituição necessita, trabalhando de maneira eficaz e eficiente em todos os setores da instituição. Devendo assim, trabalhar melhor suas projeções de longo prazo sem descuidar os meios da comunicação, pois é parte essencial da disseminação de informações para o profissional e usuário.

\section{REFERÊNCIAS}

OLIVEIRA AV, et al. Comunicação organizacional como estratégia de gestão. Revista Científica da AJES, 2018; 7: 1-10.

PADILHA RQ, et al. Princípios para a gestão da clínica: conectando gestão, atenção à saúde e educação na saúde. Ciência \& Saúde Coletiva, 2018; 23 (12): 4249-57. 
028 | RESUMOS SIMPLES: Estudo Original

\section{A invisibilização da depressão pós-parto paterna na Psicologia}

Autor/coautores: Raissa Rodrigues Falcão; Lúcia Talita Santos de Lima; Tuany Lorena Ferreira. Instituição: Faculdade de Ciências Humanas (ESUDA), Recife-Pernambuco. Centro Universitário Estácio do Recife (Estácio), Recife-Pernambuco.

Palavras-chave: Depressão pós-parto paterna, Invisibilização, Saúde do homem.

\section{INTRODUÇÃO}

Este estudo foca na depressão pós-parto paterna, um tema que ainda não é suficientemente discutido pela Psicologia. A saúde mental é engendrada por questões relativas às dinâmicas de gênero que nos subjetivam de forma binária, nas quais a depressão entre homens é, em geral, subdiagnosticada (ZANELLO V, et al., 2015). Assim, muitas vezes, isentamos de responsabilização e de reconhecimento o exercício da paternidade e sobrecarregamos de obrigações e expectativas o exercício da maternidade. Diante de um lugar coadjuvante e des(a)creditado, o homem pai pode apresentar sintomas como o aumento da impulsividade, irritabilidade, agressividade e uso de drogas (BRITES TJC, 2016), desenvolvendo um quadro que pode ser nomeado como depressão pós-parto paterna.

\section{OBJETIVO}

Este estudo tem como objetivo geral compreender as possíveis relações entre as dinâmicas de gênero e poder na sociedade e a invisibilização da depressão pós-parto paterna nos estudos de Psicologia.

\section{MÉTODO}

Trata-se de uma pesquisa qualitativa e bibliográfica que analisou o fenômeno da invisibilização da depressão pós-parto paterna na Psicologia. As buscas foram realizadas através das palavras chaves: "depressão pós-parto paterna"; "paternidade"; "saúde do homem" nas plataformas PePSIC e SciELO. Em ambas, foi utilizado o filtro de pesquisas apenas em português e publicadas nos últimos 5 anos. Foram escolhidos os artigos de títulos que mais se aproximavam do tema.

\section{RESULTADOS}

Foram selecionados oito artigos, além do Guia do Pré Natal do Parceiro e a Política Nacional de Atenção Integral a Saúde do Homem (PNAISH). Foi observado que a depressão pós-parto paterna 
ainda não é discutida em nenhum dos referidos documentos. No geral, as pesquisas consideram que a depressão pós-parto paterna tem impactos na relação mãe-bebê e na relação conjugal, e que os sintomas depressivos incluem sobretudo irritabilidade e afastamento emocional. Um estudo evidenciou, por exemplo, que 94\% dos homens no Brasil gostariam de ser inseridos nas consultas de pré-natal e participar dos momentos que incluem os cuidados com a saúde da mulher e do bebê (ARAÚJO F, et al., 2017).

\section{CONSIDERAÇÕES FINAIS}

As condições necessárias para os homens buscarem o cuidado com sua saúde mental estão diretamente ligadas às mudanças de concepções das dinâmicas de gênero pelos profissionais da saúde. A Psicologia deve trabalhar para promover a subversão das atribuições antagônicas que ainda marcam as concepções sobre maternidade e paternidade. Ou seja, é preciso compreender a paternidade como algo constitutivo, e não anexo, de uma relação de cuidado com uma criança.

\section{REFERÊNCIAS}

ARAÚJO F, et al. Pré-natal masculino: a inclusão na saúde do homem. Revista de Trabalhos Acadêmicos UNIVERSO São Gonçalo. 2017; 2(3).

BRITES TJC. Depressão pós-parto paterna: família em risco. Repositório Científico da Universidade de Coimbra, 2016; 58.

ZANELLO V, et al. Saúde mental e gênero: facetas gendradas do sofrimento psíquico. Revista de Psicologia, 2015; 27: 238-246. 


\section{Estudo de Caso}

029 | RESUMOS SIMPLES: Estudo de Caso

\section{Frenectomia lingual em paciente adulto: estudo de caso}

Autor/coautores: Leticia Monteiro Rocha; Maria Antônia Duarte Silva; Larissa Maria Alves dos Santos; Eduarda Larissa Soares Silva, Sandra Hipólito Cavalcanti.

Instituição: Faculdade Pernambucana de Saúde (FPS), Recife-PE; UNISÃOMIGUEL, Recife-PE;

Palavras-chave: Anquiloglosia, Freio lingual, Cirurgia.

\section{INTRODUÇÃO}

A anquiloglossia é uma anomalia congênita do frênulo lingual, e que pode causar alterações nas funções orofaciais, caso esta alteração não seja diagnósticada e tratada precocemente, pode afetar negativamente o desenvolvimento da língua, fala, mastigação, deglutição, entre outros problemas que no futuro podem implicar em constrangimento social (PENHA ES DA, et al., 2019).

O protocolo de avaliação do freio lingual tem a finalidade de avaliar aspectos anatômicos e funcionais da língua, e tornou-se obrigatório a sua realização em todos os hospitais e maternidades do Brasil através da lei número 13.002 de 20 de junho de 2014, em que um dos tratamentos mais indicados é a frenectomia (ARAUJO MCM, et al., 2020).

\section{OBJETIVO}

Relatar o caso clínico de frenectomia lingual em um adulto com anquiloglossia, visando sua restituição fono-motricial.

\section{ESTUDO DE CASO}

Para esse estudo, foi avaliado um paciente adulto saudável, do gênero feminino, com 20 anos de idade. Segundo relato da própria paciente, esta revelou ter dificuldades na dicção, além do comprometimento para articular algumas palavras e fonemas, informa também que quando criança apresentou dificuldades para realizar movimentos de mastigação e revela que não foi amamentada exclusivamente no seio até os seis meses de vida. 
O diagnóstico de anquiloglossia foi confirmado por meio da aplicação do Protocolo de Avaliação do Frênulo Lingual de Marchesan, que considera frênulo alterado quando a soma das provas gerais for igual ou maior que 3, o qual a paciente apresentou na soma total dos escores 4. Após a confirmação do diagnóstico, como conduta terapêutica, optou-se por a realização da intervenção cirúrgica, através da frenectomia e acompanhamento fonoaudiológico. Após 1 mês de cirurgia o protocolo foi reaplicado, resultando no escore de 0 , com melhora nos movimentos da língua e na dicção.

\section{CONSIDERAÇÕES FINAIS}

A frenectomia em um freio lingual curto, tardiamente diagnosticado, é uma técnica cirúrgica de fácil execução, com potencial para restabelecer as funções matriciais da língua. Além disso, para um melhor resultado, enfatiza-se a importância da abordagem multiprofissional, associando a avaliação diagnóstica por um profissional da área de saúde habilitado, a frenectomia realizada por um especialista em saúde bucal e a terapia fonoaudiológica, contribuindo positivamente na reinserção social do paciente (ARAUJO MCM, et al., 2020).

\section{REFERÊNCIAS}

PENHA ES, et al. Teste da linguinha: as gestantes sabem do que se trata?. Revista Eletrônica Acervo Saúde, 2019; 2: e957.

ARAUJO MCM, et al., Evaluation of the lingual frenulum in newborns using two protocols and its association with breastfeeding. J. Pediatr, 2020; 1: 379-385.

COTA ALS, et al. Frenectomia para restituição fono-motricial da língua. Revista Eletrônica Acervo Saúde, 2019; 2: e1457. 
030 | RESUMOS SIMPLES: Estudo de Caso

\section{Carcinoma epidermoide de palato mole: um relato de caso}

Autor/coautores: Lucas Menezes dos Anjos ${ }^{1}$, Marcos Antônio Lima dos Santos ${ }^{1}$, Aurélio de Oliveira Rocha², Ingrid de Melo Silva², Denílson Oliveira Correia da Silva².

Instituição: Universidade Federal de Sergipe (UFS) ${ }^{1}$, Aracaju - SE; Universidade Tiradentes, Aracaju - SE ${ }^{2}$.

Palavras-chave: Carcinoma de células escamosas, Diagnóstico bucal, Neoplasias bucais.

\section{INTRODUÇÃO}

Mais de $90 \%$ dos casos de câncer que ocorrem na cavidade bucal são do tipo carcinoma epidermoide, sendo um tumor que se manifesta em diferentes graus de malignidade, tendo como características mais predominantes anaplasia, crescimento rápido, destruição do tecido local e capacidade de metástase (MENDES IER, et al., 2019). O carcinoma epidermoide corresponde a cerca $15 \%$ dos tumores da orofaringe, já sua ocorrência no palato mole e pouco documentada na literatura devido sua baixa prevalência. Acomete homens e mulheres de elevada faixa etária em uma proporção de 3:1 (PASSARELLI DHC, et al., 2017).

\section{OBJETIVO}

Descrever e discutir um relato de caso clínico de carcinoma epidermóide localizado em palato mole extenso e com alto grau de agressividade, de rápida evolução e prognóstico desfavorável em paciente idoso.

\section{ESTUDO DE CASO}

Para realização do estudo o paciente assinou o Termo de Consentimento Livre e Esclarecido (TCLE) permitindo que suas imagens fossem documentadas e usada para fins acadêmicos. Paciente do sexo masculino, 61 anos, melanoderma, tabagista e etilista crônico, procurou atendimento odontológico por apresentar lesão tumoral, ulcerada e sangrante em palato mole com evolução de seis meses. O mesmo relatava sintomatologia dolorosa associada a lesão, além de dificuldade de deglutição e limitação de abertura bucal. Baseado na anamnese e nas características físicas da lesão, foram propostas três hipóteses diagnósticas, sendo elas carcinoma espinocelular, líquen plano e eritroplasia. Realizou-se a biópsia incisional para confirmação do diagnóstico, onde o material coletado foi conduzido para análise histopatológica no laboratório. O laudo histopatológico confirmou a presença de carcinoma epdermoide, pois a organização celular do 
tecido exibia presença de infiltrado celular inflamatório, mitoses atípicas, presença de pérolas de queratina, além de vascularização por angiogene recente.

\section{CONSIDERAÇÕES FINAIS}

Relatar casos de menor prevalência na literatura auxilia os profissionais na identificação e diagnostico de patologias de caráter agressivo, como é o caso do carcinoma epidermóide associado ao palato mole, que quando diagnosticado precocemente apresenta prognostico favorável, levando a maior sobrevida do paciente.

\section{REFERÊNCIAS}

MENDES IER, et al. Diagnóstico tardio de um carcinoma epidermoide: um relato de caso. Unimontes Científica, p. 42-48, 2019.

PASSARELLI DHC, et al. A interdisciplinaridade no diagnóstico de carcinoma epidermóide. Revista de Odontologia da Universidade Cidade de São Paulo, v. 23, n. 3, p. 273-277, 2017. 
031 | RESUMOS SIMPLES: Estudo de caso

\section{Reabilitação dental pós traumatismo em paciente pediátrico: relato de caso}

Autor/coautores: Aurélio de Oliveira Rocha', Thaísla Santana de Aquino', Lucas Menezes dos Anjos $^{2}$, Ingrid de Melo Silva ${ }^{1}$, Thaine Oliveira Lima ${ }^{1}$.

Instituição: ${ }^{1}$ Universidade Tiradentes (UNIT), Aracaju - SE, ${ }^{2}$ Universidade Federal de Sergipe (UFS), Aracaju - SE.

Palavras-chave: Traumatismo dentário, Criança, Odontologia.

\section{INTRODUÇÃO}

O traumatismo facial que resulta em dentes fraturados, deslocados ou perdidos, pode apresentar efeitos negativos consideráveis sobre os aspectos funcionais, estéticos e psicológicos da criança (GONÇALVES BM, et al., 2017). Devido a diversos fatores predisponentes e sua localização na arcada dentária, os incisivos centrais superiores são os dentes mais atingidos pelo trauma dental (CAMPOS V, et al., 2017). Fatores como oclusão anormal, overjet acentuado, inadequado selamento labial e respiração bucal são algumas das características que aumentam significativamente a susceptibilidade dos indivíduos a lesões traumáticas na dentição permanente (CUNHA LM, et al., 2017).

\section{OBJETIVO}

Relatar um caso clínico de fratura dental devido trauma físico em ambiente domiciliar envolvendo esmalte e dentina, compreender as principais causas de fratura dental e ressaltar a importância da prevenção.

\section{ESTUDO DE CASO}

Paciente 6 anos de idade, sexo feminino, 24kg, ASA I, procurou atendimento em clínica odontológica acompanhada do avô que relatou que a criança apresentava desconforto em dente anterior fraturado devido traumatismo dental por queda enquanto brincava em casa. Ao exame clínico intraoral foi observado fratura de borda incisal da unidade $61 \mathrm{com}$ envolvimento de dentina e esmalte. Ao exame radiográfico não foi observada nenhuma alteração digna de nota. Clinicamente ainda foi possível observar que a criança apresentava mordida aberta, respiração bucal, projeção dos incisivos superiores, palato profundo e falta de selamento labial, características que intensificam risco de fratura dental durante traumatismo. Foi proposto para o determinado caso reabilitação 
dental da unidade 61 com resina composta cor A2 de dentina e A1 de esmalte. Além disso, a paciente foi encaminhada para tratamento médico com otorrinolaringologista, fonoaudiologista e tratamento dental com ortodontista, devido alterações miofuncionais. Para realização do referente estudo o responsável pelo paciente assinou Termo de Consentimento Livre e Esclarecido (TCLE).

\section{CONSIDERAÇÕES FINAIS}

O traumatismo dentário é uma ocorrência cada vez mais crescente em crianças devido exposição durante brincadeiras e características orofaciais. É de suma importância adoção de medidas de proteção como capacetes e protetores bucais durante essas atividades. A decisão de tratamento ocorre através do comprometimento dental e grau de acometimento dos tecidos. O cirurgiãodentista deve estar atento as complicações associadas a essa condição para proporcionar tratamento integral ao paciente.

\section{REFERÊNCIAS}

CAMPOS V, et al. Traumatismo nos dentes decíduos anteriores: Estudo retrospectivo do Projeto de Extensão em Traumatologia Dentária da Faculdade de Odontologia da Universidade Estadual do Rio de Janeiro. Interagir: pensando a extensão, 2017; 22: 46-60.

CUNHA LM, et al. Sequelas imediatas e tardias do trauma dentário em dentes decíduos. Jornada Odontológica dos Acadêmicos da Católica, 2017; 3(1).

GONÇALVES BM, et al. O impacto do traumatismo dental e do comprometimento estético na qualidade de vida de pré-escolares. Revista Paulista de Pediatria, 2017; 35(4): 448-455. 
032 | RESUMOS SIMPLES: Estudo de caso

\section{Cimento de ionômero de vidro modificado por resina para reabilitar dente decíduo acometido por cárie- relato de caso}

Autore/coautores: Aurélio de Oliveira Rocha ${ }^{1}$, Thaísla Santana de Aquino ${ }^{1}$, Lucas Menezes dos Anjos $^{2}$, Thaine Oliveira Lima1', Denílson Oliveira Correia da Silva'. Instituição: 'Universidade Tiradentes (UNIT), Aracaju - SE; ${ }^{2}$ Universidade Federal de Sergipe (UFS), Aracaju - SE.

Palavras-chave: Cárie dentária, Ionômero, Dente decíduo.

\section{INTRODUÇÃO}

Morfologia dentária do hospedeiro, dieta cariogênica, microorganismos da cavidade bucal, período de tempo, fatores socioeconômicos, aspectos comportamentais, essas expressões não só explicitam os fatores determinantes que influenciam no desenvolvimento da doença cárie, mas também demonstram a multifatorialidade da doença crônica infecciosa que alcança alta incidência durante a infância e a adolescência (FELDENS CA, et al., 2018). O aumento na utilização dos Cimentos de ionômero de vidro modificado por resina é decorrente de suas características vantajosas, tais como: liberação de flúor, adesão às estruturas dentárias, coeficiente de expansão térmica similar ao da estrutura dentária e biocompatibilidade (SAMPAIO C, et al., 2018).

\section{OBJETIVO}

Relatar um caso clínico de um paciente infantil com cavidade por cárie na unidade 84 e reabilitação do mesmo com cimento de ionômero de vidro modificado por resina e discutir acerca desse material na odontopediatria.

\section{ESTUDO DE CASO}

Para realização do referente estudo o responsável pelo paciente assinou o Termo de Consentimento Livre e Esclarecido (TCLE). Paciente 5 anos de idade, sexo masculino, 28kg, ASA I, procurou atendimento em clínica odontológica acompanhado do responsável para atendimento de rotina. Ao exame clínico intraoral foi observado cavidade acometendo a face oclusal e distal da unidade 84 devido presença de lesão cariosa. Ao exame radiográfico foi observado que a lesão comprometia esmalte e metade superficial da dentina. Foi preenchido o diário alimentar onde foi notado alto consumo de doces por parte de criança, assim foi realizada orientação referente a alimentação, bem como orientação e motivação de higiene oral, além de escovação supervisionada. 
Para unidade que apresentava lesão de cárie foi proposto reabilitação com cimento de ionômero de vidro modificado por resina, tendo em vista as vantajosas propriedades desse cimento para a dentição infantil.

\section{CONSIDERAÇÕES FINAIS}

A cárie é uma doença complexa e multifatorial que acomete principalmente crianças, para seu controle é indispensável realização da higiene oral satisfatória. O cimento de ionômero de vidro modificado por resina apresenta características que o confere como uma excelente alternativa nos procedimentos restauradores na dentição decídua. O profissional de saúde deve estar apto para orientar e motivar a criança quanto a uma alimentação saudável e eficiente escovação dental.

\section{REFERÊNCIAS}

FELDENS CA, et al. Feeding frequency in infancy and dental caries in childhood: a prospective cohort study. Int Dent J. 2018;68(2):113-121.

SAMPAIO C, et al. Cimento de ionômero de vidro é melhor que resina composta para restaurações classe II em molares decíduos? Uma revisão sistemática e metanálise. Archives of health investigation,2018; 6 . 
033 | RESUMOS SIMPLES: Estudo de Caso

\section{Carcinoma epidermóide de palato mole: um relato de caso}

Autor/coautores: Lucas Menezes dos Anjos ${ }^{1}$, Marcos Antônio Lima dos Santos ${ }^{1}$, Aurélio de Oliveira Rocha², Ingrid de Melo Silva², Denílson Oliveira Correia da Silva².

Instituição: Universidade Federal de Sergipe (UFS), Aracaju-SE'; Universidade Tiradentes, Aracaju-SE2.

Palavras-chave: Carcinoma de células escamosas, Diagnóstico bucal, Neoplasias bucais.

\section{INTRODUÇÃO}

Mais de $90 \%$ dos casos de câncer que ocorrem na cavidade bucal são do tipo carcinoma epidermóide, sendo um tumor que se manifesta em diferentes graus de malignidade, tendo como características mais predominantes anaplasia, crescimento rápido, destruição do tecido local e capacidade de metástase (MENDES IER, et al., 2019). O carcinoma epidermóide corresponde a cerca $15 \%$ dos tumores da orofaringe, já sua ocorrência no palato mole e pouco documentada na literatura devido sua baixa prevalência acomete homens e mulheres de elevada faixa etária em uma proporção de 3:1 (PASSARELLI DHC, et al., 2017).

\section{OBJETIVO}

Descrever e discutir um relato de caso clínico de carcinoma epidermóide localizado em palato mole extenso e com alto grau de agressividade, de rápida evolução e prognóstico desfavorável em paciente idoso.

\section{ESTUDO DE CASO}

Para realização do estudo o paciente assinou o Termo de Consentimento Livre e Esclarecido (TCLE). Paciente do sexo masculino, 61 anos, melanoderma, tabagista e etilista crônico, procurou atendimento odontológico por apresentar lesão tumoral, ulcerada e sangrante em palato mole com evolução de seis meses. O mesmo relatava sintomatologia dolorosa associada a lesão, além de dificuldade de deglutição e limitação de abertura bucal. Baseado na anamnese e nas características físicas da lesão, foram propostas três hipóteses diagnósticas, sendo elas carcinoma espinocelular, líquen plano e eritroplasia. Realizou-se a biópsia incisional para confirmação do diagnóstico, onde o material coletado foi conduzido para análise histopatológica no laboratorial. O laudo histopatológico confirmou a presença de carcinoma epidermóide, pois a organização celular do 
tecido exibia presença de infiltrado celular inflamatório, mitoses atípicas, presença de pérolas de queratina, além de vascularização por angiogênese recente.

\section{CONSIDERAÇÕES FINAIS}

Relatar casos de menor prevalência na literatura auxilia os profissionais na identificação e diagnóstico de patologias de caráter agressivo, como é o caso do carcinoma epidermóide associado ao palato mole, que quando diagnosticado precocemente apresenta prognóstico favorável, levando a maior sobrevida do paciente.

\section{REFERÊNCIAS}

MENDES IER, et al. Diagnóstico tardio de um carcinoma epidermoide: um relato de caso. Unimontes Científica, 2019; 42-48.

PASSARELLI DHC, et al. A interdisciplinaridade no diagnóstico de carcinoma epidermóide. Revista de Odontologia da Universidade Cidade de São Paulo, 2017; 23(3): 273-277. 


\title{
Relato de Experiência
}

034 | RESUMOS SIMPLES: Relato de Experiência

\section{Intervenções de enfermagem para promoção do aleitamento materno no alojamento conjunto: relato de experiência}

\author{
Autor/coautores: Raila Gonçalves dos Santos; Tuanny Caroline Pereira de Santana; Maria \\ Eduarda da Silva Valentino Ferreira; Maria Beatriz Falcão; Sandra Hipolito Cavalcanti. \\ Instituição: Faculdade Pernambucana de Saúde (FPS), Recife-Pernambuco. \\ Palavras-chave: Alojamento Conjunto, Enfermagem, Aleitamento Materno.
}

\section{INTRODUÇÃO}

O Alojamento Conjunto (AC) é um estabelecimento de apoio integral a mãe e bebê após o nascimento 24 horas por dia. É considerado um setor que estimula o aleitamento materno (AM), propiciando o vínculo do binômio mãe-bebê e família, além de fortalecer o autocuidado e participação ativa nos cuidados com o filho (RODRIGUES CF, 2020). Neste contexto, torna-se um espaço propicio a educação e promoção da saúde executada pelo profissional, desenvolvendo maior habilidade e segurança da mãe, desmistificando crenças, mitos e tabus sobre a prática de amamentar. Enfim, proporciona o sucesso da amamentação e reduz a morbimortalidade infantil (DUARTE DA, 2019).

\section{OBJETIVO}

Relatar a experiência das intervenções de enfermagem para promoção do aleitamento materno no alojamento conjunto, realizado durante o ensino teórico-prático do rodízio em Saúde da Mulher em um Hospital Escola de Pernambuco.

\section{RELATO DE EXPERIÊNCIA}

A vivência prática aconteceu numa entidade filantrópica, que atua nas áreas de assistência médico-social, ensino, pesquisa e extensão comunitária, voltado para o atendimento da população carente pernambucana. As atividades foram supervisionadas pela docente responsável pelo estágio. Os cuidados e orientações somente eram realizados após o consentimento das mães. 
IR PARA O SUMÁRIO

As atividades teórico-práticas foram realizadas no AC durante o período de fevereiro a março de 2020. No alojamento percebeu-se que as mães eram carentes de conhecimento sobre o $\mathrm{AM}$, tinham muitas dúvidas sobre o assunto. E para minimizar esse déficit, foram desenvolvidas atividades educativas, com o objetivo de ampliar o conhecimento das mães sobre a temática vivenciada.

Elaborou-se ações diárias, na qual esclareciam as dúvidas sobre a amamentação, os benefícios e o manejo da lactação, bem como evitar fissuras, posicionamento e pega adequada do bebê, ordenha e além do apoio a puérpera após a alta. Salienta-se que todas as abordagens com as mães eram feitas individualmente ou em rodas de conversas, a fim de incentivar a troca de experiências, selar um vínculo com elas e proporcionar maior segurança no ato de amamentar.

\section{CONSIDERAÇÕES FINAIS}

O Alojamento Conjunto é um local onde se realiza a educação em saúde e o aleitamento materno é um dos principais assuntos a serem abordados e trabalhados. Considerando as questões socioculturais e emocionais referente ao puerpério, durante a experiência vivenciada notou-se o quanto é importante a assistência profissional, pois as orientações fornecidas durante a prática contribuíram para o conhecimento das mães e apoiaram sobremaneira para o sucesso da amamentação.

\section{REFERÊNCIAS}

DUARTE DA. Benefícios da Amamentação. Revista Eletrônica Acervo Enfermagem, 2019; 1, 001. JÚNIOR AMF, et al. Atuação do enfermeiro no puerpério imediato em um hospital maternidade no Pará. Revista Eletrônica Acervo Saúde, 2020; 12(3): e2508.

RODRIGUES CF. Práticas atuais de amamentação na primeira hora de vida em uma maternidade de risco habitual. Revista Eletrônica Acervo Saúde, 2020; 12(1): e1826. 
035 | RESUMOS SIMPLES: Relato de Experiência

\section{Estimulando a memória de idosos por meio de jogos educativos em período de pandemia por COVID-19: um relato de experiência}

Autor/coautores: Ana Carolina Vidigal Vieira Ferreira, Michelle Souza Nascimento, Andyara do Carmo Pinto Coelho Paiva, Adélia Dayane Guimarães Fonseca, Thaís Vasconselos Amorim. Instituição: Universidade Federal de Juiz de Fora (UFJF), Juiz de Fora- Minas Gerais.

Palavras-chave: Idoso, Memória, Jogos educativos.

\section{INTRODUÇÃO}

A institucionalização de pessoas idosas provoca mudanças em sua vida e rotina. Além da mudança de ambiente, as alterações incluem a convivência com pessoas desconhecidas e a necessidade de se adequar às normas (SOUZA FGM, et al., 2020). Estudos apontam que o desenvolvimento de atividades lúdicas com idosos proporciona melhora na qualidade de vida e estimula o convívio social, facilitando o desenvolvimento de estratégias de promoção da saúde (MIRANDA SA, et.al, 2020). Dessa forma, o desenvolvimento de oficinas lúdico-pedagógicas, que tem boa adesão dos residentes, possibilitam a preservação da cognição dos idosos (MUNHOZ OL, et al., 2016).

\section{OBJETIVO}

Relatar a experiência da construção de cartelas de bingo para utilizar com os idosos de uma instituição de longa permanência, como forma de estimular a cognição por meio de jogos educativos.

\section{RELATO DE EXPERIÊNCIA}

A partir da necessidade de encontrar atividades alternativas a serem desenvolvidas com 28 idosos institucionalizados no interior de Minas Gerais, no período de pandemia pelo Covid-19, discentes e docentes de um projeto de extensão elaboraram o planejamento de um bingo. Durante o desenvolvimento da proposta, foram construídas por meio de um programa computacional, cartelas compostas por figuras coloridas e de fácil identificação, para garantir que o momento de encontro fosse o mais inclusivo possível e conferisse a adesão da maioria dos idosos. Com o auxílio do aplicativo CANVA, construímos um total de 60 cartelas de bingo com desenhos de partes do 
corpo humano de fácil identificação, objetos diversos, animais, frutas e alimentos em geral. O objetivo da oficina é proporcionar uma atividade lúdica em um momento de pandemia, que traz repercussões físicas, psicológicas e sociais, principalmente para os idosos por constituírem o grupo de risco, e estimular a memória dos idosos para promover melhor qualidade de vida. Para minimizar os riscos de uma contaminação, a atividade será executada por profissionais que já estão envolvidos nos cuidados.

\section{CONSIDERAÇÕES FINAIS}

Para estimular a cognição da pessoa em processo de envelhecimento, é fundamental o uso de métodos que despertem seu interesse e estimulem a sua participação. Ressalta-se que, além de promover o exercício mental, as atividades lúdicas permitem a socialização entre os residentes. Acredita-se que a utilização de jogos educativos em tempos de pandemia pelo Covid-19, contribui para diminuir o impacto psicológico provocado pelo isolamento social.

\section{REFERÊNCIAS}

MIRANDA SA, et al. Aplicabilidade de atividades lúdicas como parâmetro na recognição do Alzheimer precoce na atenção básica de saúde. Revista Eletrônica Acervo Saúde, 2020; (44): e2250.

MUNHOZ OL, et al. Oficina bingo da saúde: uma experiência de educação em saúde com grupos de idosos. Revista Mineira de Enfermagem. 2016; 20:e968.

SOUZA FJM, et al. Percepção dos idosos institucionalizados acerca da qualidade de vida. Revista Eletrônica Acervo Saúde, 2020; 12 (7): e3310. 
036 | RESUMOS SIMPLES: Relato de Experiência

\section{Monitoria de saúde do adulto sob a perspectiva da teoria cognitivista: um relato de experiência}

Autor/coautores: Daniele Gonçalves Pedroso, Nathália Lima de Pontes, Thaís de Souza Misquita, Andréia Guedes Oliva Fernandes, Talita de Cassia Raminelli da Silva Instituição: Centro Universitário Euro Americano (UNIEURO), Brasília - Distrito Federal. Palavras-chave: Ensino, Monitoria,Teoria cognitivista.

\section{INTRODUÇÃO}

A monitoria se configura numa atividade de ensino e pesquisa que possibilita a aproximação do discente com a prática docente, o que fortalece a associação da teoria com a prática, estimula o raciocínio, a criatividade, o pensamento e a expressão do aluno (LIMA HF, et al., 2018). Dentre as abordagens de ensino que desafiam o discente, está a cognitivista, a qual enfatiza que o aprendizado acontece através dos processos de organização do conhecimento mediante a realização de atividades cooperativas, de modo a levar o estudante a racionalizar e então desenvolver o pensamento crítico-reflexivo (MIZUKAMI, 1986 citado por ROSA JIJ, 2020).

\section{OBJETIVO}

Relatar a experiência de discentes do curso de enfermagem na monitoria da disciplina de Saúde do Adulto sob a perspectiva da abordagem cognitivista em uma Instituição de Ensino Superior privada do Distrito Federal.

\section{RELATO DE EXPERIÊNCIA}

A monitoria aconteceu no segundo semestre de 2019 e diferentes instrumentos didáticos, como jogos, foram utilizados. Na perspectiva da abordagem de ensino cognitivista, a utilização de jogos contribui para a criação de ambientes que facilitam a troca de experiência e de cooperação entre os estudantes. Estes aprendem por meio dos desafios propostos e são estimulados a pesquisarem, racionalizarem e solucionarem os problemas de maneira lúdica, de forma a compartilharem ideias e conhecimentos (LEÃO MF e DUTRA MM, 2018; ROSA JIJ, 2020).

Estudos dirigidos e casos clínicos também foram utilizados como recursos didáticos. Compreende-se que, o uso do estudo dirigido e caso clínico, possibilitou aos discentes realizarem associação dos conhecimentos prévios adquiridos, em diversas disciplinas do curso de 
Enfermagem, com o conteúdo abordado em Saúde do Adulto. De acordo com a teoria cognitivista, o conhecimento se dá a partir de experiências prévias, que somadas aos estímulos ambientais e novos conteúdos, resultam em reestruturação das estruturas cognitivas. Por meio de assimilação e adaptação dos conteúdos, novos conceitos são adquiridos pelos estudantes no processo de ensinoaprendizagem (MIZUKAMI, 1986 citado por ROSA, 2020; LEÃO MF e DUTRA MM, 2018).

\section{CONSIDERAÇÕES FINAIS}

Acredita-se que o uso da abordagem cognitivista na monitoria de Saúde do Adulto, bem como em outras disciplinas do curso de Enfermagem, pode contribuir no processo de ensinoaprendizagem, ao proporcionar ao estudante, a autonomia e a associação do conhecimento teórico e prático.

\section{REFERÊNCIAS}

LEÃO MF, DUTRA MM. Influências do comportamentalismo, cognitivismo e humanismo na prática pedagógica de alguns professores de ciências da região do Baixo Araguaia. Educação em Debate, Fortaleza, 2018; ano 40; (76); e146162.

LIMA HF, et al. Aplicação da metodologia ativa na monitoria acadêmica da enfermagem cirúrgica: relato de experiência. Encontro de Extensão, Docência e Iniciação Científica. Quixadá, 2018; 5 (1); e12.

OSA JIJ. As condições necessárias para a aplicação do método de ensino temático-reflexivo na disciplina de filosofia. Revista Enciclopédia de Filosofia, 2020; 7; e111125. 
037 | RESUMOS SIMPLES: Relato de Experiência

\section{Grupo de estudo e pesquisa em enfermagem, cuidado e saúde (GEPEnCS): relato de experiência de docentes e discentes de uma instituição de ensino superior de Brasília}

Autor/coautores: Monnik Helles Pereira Correia Higino, Thaís de Souza Misquita, Talita de Cassia Raminelli da Silva, Andréia Guedes Oliva Fernandes, Graziani Izidoro Ferreira.

Instituição: Centro Universitário Euro Americano (UNIEURO), Brasília - Distrito Federal.

Palavras-chave: Grupo de Pesquisa, Enfermagem, Educação.

\section{INTRODUÇÃO}

A produção científica no campo da enfermagem é a base para o desenvolvimento da prática clínica baseada em evidências, firmando, valorizando e reconhecendo a enfermagem como ciência. Grupos de pesquisas nas Instituições de Ensino Superior (IES) configuram-se como importantes meios de ensino e aprendizagem, pois permitem aos docentes e discentes a ampliação de conhecimentos, a promoção de produção científica e o progresso da ciência. A pesquisa exerce forte influência no processo de formação do profissional de enfermagem ao construir habilidades e competências no pensar crítico e reflexivo do acadêmico (OLIVEIRA MP, et al., 2016; ERDMANN AL, et. al., 2017).

\section{OBJETIVO}

Relatar a experiência da participação de discentes e docentes em um grupo de pesquisa em enfermagem, cuidado e saúde, em uma IES de Brasília desde sua implantação em 2017 até o ano de 2019.

\section{RELATO DE EXPERIÊNCIA}

O grupo de pesquisa denominado GEPEnCS, iniciou em 2017, com objetivo de inserção dos universitários no meio científico, incentivo à pesquisa, produção e difusão de conhecimento, sendo aberto para toda a IES. Atualmente, participam do grupo 9 docentes e 23 discentes dos cursos de enfermagem, nutrição, farmácia e psicologia. Os encontros ocorrem mensalmente e os conteúdos abordados são estruturados no início dos semestres através de cronograma elaborado pelos membros. 
Constata-se o crescimento do grupo, quanto às diferentes habilidades cognitivas, procedimentais e atitudinais conquistadas e observa-se melhor desempenho dos estudantes nas disciplinas de metodologia científica, trabalho de conclusão de curso, na elaboração e apresentação dos trabalhos acadêmicos propostos nas diversas disciplinas dos cursos da IES.

Dentre as dificuldades relatadas pelos discentes, estão a escrita científica, que exige esforços para se adequar à comunidade científica e a instabilidade na frequência de alguns participantes que interfere no desenvolvimento das atividades grupais. Para os docentes, as dificuldades estão relacionadas a conciliação com diversas atividades na IES e o ensino das diversas metodologias científicas para o desenvolvimento dos estudos.

\section{CONSIDERAÇÕES FINAIS}

Acredita-se que o grupo de pesquisa é essencial para o progresso dos estudantes e dos professores no que concerne à produção científica, troca de experiências e de conhecimentos entre os integrantes das diferentes áreas do saber. Diante disso, é importante refletir sobre a inserção dos acadêmicos na área científica desde os períodos iniciais do curso, a fim de estimular o pensamento crítico e reflexivo, bem como aprimorar o currículo dos docentes e dos discentes.

\section{REFERÊNCIAS}

ERDMANN AL, et. al. Grupos de pesquisa em enfermagem no Brasil: comparação dos perfis de 2006 e 2016. Revista Gaúcha de Enfermagem, 2017; 38(2): e5169.

OLIVEIRA MP, et al. Scientific research on the Nursing graduation: an integrative review. Revista Práxis, 2016; 4(16): e116121. 
038 | RESUMOS SIMPLES: Relato de Experiência

\title{
Ação extensionista de educação em saúde: uma abordagem sobre a fotoeducação no combate ao câncer de pele
}

\author{
Autor/coautores: Raila Gonçalves dos Santos; Lorena Ribeiro de Carvalho; Leticia Monteiro \\ Rocha; Tuanny Caroline de Santana; Ítala Morgânia Farias da Nóbrega. \\ Instituição: Faculdade Pernambucana de Saúde (FPS), Recife-Pernambuco. \\ Palavras-chave: Extensão, Educação em Saúde, Câncer de Pele.
}

\section{INTRODUÇÃO}

O câncer de pele é a neoplasia de maior incidência no Brasil, estudos mostram que existe uma relação entre a radiação ultravioleta (UV) e os casos de câncer de pele (URASAKI MBM, et al., 2016). O câncer de pele é evitável, através de estratégias de prevenção primária, que atua na redução de fatores de risco, por meio de modificações ambientais e comportamentais (IMANICHI D, et al., 2017). Ações educativas e de orientação sobre proteção ao sol pode contribuir de modo significativo para minimizar o aparecimento de tipos de câncer de pele e outros agravos (LOPEZ AT, et al., 2018).

\section{OBJETIVO}

Relatar a experiência de estudantes de Enfermagem durante ações de orientação sobre a Fotoeducação, atividades desenvolvidas pelo projeto de extensão "Uso Racional de Medicamentos: a informação é o melhor remédio!" de uma faculdade de Pernambuco.

\section{RELATO DE EXPERIÊNCIA}

Inicialmente a equipe do projeto de extensão realizaram capacitações com o grupo de estudantes do projeto para uniformizar as temáticas de fotoproteção a serem abordadas nas orientações e preparação do material educativo a ser disponibilizado ao longo das ações, enfatizando quanto ao uso correto de protetores solares e cuidados com a pele.

As atividades aconteceram entre novembro e dezembro de 2019, pela manhã e tarde. No primeiro momento, foi utilizado nas capacitações recurso audiovisual, sendo apresentados as estatísticas sobre a incidência do câncer de pele e os conceitos de fotoproteção. Em um segundo momento foram realizadas as ações educativas em parceria com a Campanha Nacional de Prevenção ao Câncer de Pele, remetendo ao dezembro laranja. 
Por conter um público-alvo diverso, o maior desafio encontrado foi a capitação de alguns usuários e a adequação a linguagem formal de saúde, de modo que todos pudessem entender o objetivo da ação. Para tornar a interação mais proveitosa, foi instigado a troca de experiência e o conhecimento prévio que esse público tinha, a fim de estreitar a relação de confiança e garantir assimilação das atividades.

\section{CONSIDERAÇÕES FINAIS}

A excelente receptividade, a necessidade de informações da população trouxe a percepção de que as atividades de fotoeducação não podem ser pontuais. As ações contribuíram para uma melhor compreensão do público-alvo no que se refere ao câncer de pele e fotoproteção, desmostrando também que esses conhecimentos foram incorporados nas suas rotinas e foram capazes de incentivar amigos e familiares, que igualmente apresentam mudanças de hábitos no que diz respeito aos cuidados em relação aos raios solares.

\section{REFERÊNCIAS}

IMANICHI D, et al. Fatores de risco do câncer de pele não melanoma em idosos no Brasil. Diagnóstico e Tratamento, v.22, n.1, 2017.

LOPEZ A, et al. Secondary Prevention Strategies for Nonmelanoma Skin Cancer. Oncology (Williston Park). 2018;32(4):195-200.

URASAKI M, et al. Práticas de exposição e proteção solar de jovens universitários. Rev. Bras. Enferm. [online]. 2016, vol.69, n.1 [cited 2020-07-04], pp.126-133. 
039 | RESUMO SIMPLES: Relato de Experiência

\section{Fale com a parteira: a notoriedade da teleorientação da enfermagem para gestantes e puérperas em tempos de pandemia}

Autor/coautores: Milena da Silva ${ }^{1}$, Tuanny Caroline Pereira de Santana ${ }^{1}$, Tatianne Cavalcanti Frank $^{2}$, Joanna Francyne Silva de Barros ${ }^{3}$.

Instituição: 'Discente do curso de Enfermagem da Faculdade Pernambucana de Saúde, Recife-

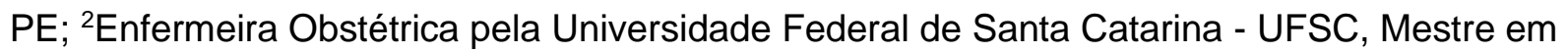
enfermagem pela Universidade Estadual de Maringá. Pesquisadora do Grupo de Pesquisa Narrativas do Nascer- UFPE. Docente de pós-graduações Lato Sensu, Recife-PE. ${ }^{3}$ Docente do curso de Enfermagem da Faculdade Pernambucana de Saúde, Recife-PE Palavras-chave: Teleorientação, Enfermagem Obstétrica, Pandemia.

\section{INTRODUÇÃO}

A COVID-19 é considerada uma emergência de saúde pública em consequência ao aumento dos casos e mortes (ABDOLLAHPUOR S e KHADIVZADEN T, 2020). No dia 11 de março de 2020, a Organização Mundial de Saúde declarou que o mundo se encontrava em um cenário de pandemia (CHAWLA D, et al., 2020). Assim, a teleorientação tornou-se um aliado promovendo menor exposição dos indivíduos (SETO E, et al., 2020). No intuito de evitar idas desnecessárias aos hospitais, surge o projeto "Fale com a Parteira Pernambuco", como objetivo de orientar as gestantes, conforme diretrizes estabelecidas pelo Ministério da Saúde e Órgãos de Saúde, ajudando-as a identificar sinais de gravidade do COVID-19 (COFEN, 2020).

\section{RELATO DE EXPERIÊNCIA}

O projeto pioneiro "Fale com a Pateira Pernambuco" é uma iniciativa voluntária de teleorientação da enfermagem para gestantes e puérperas em tempos de pandemia, realizado por meio de plantões de 24 horas, online e gratuitos. Recebeu a chancela da Comissão Nacional de Saúde da Mulher do COFEN (COFEN, 2020). O projeto, já conta com iniciativas similares em vários estados do Brasil. Tem o suporte de 52 enfermeiras obstetras e 30 reguladoras (Enfermeiras e Acadêmicas de Enfermagem) que no período de 22 de março a 30 de junho de 2020 realizaram cerca de 2.300 atendimentos. 
O fluxo de atendimento é realizado pelo o acesso ao link disponível na página principal do Instagram @falecomaparteira, que permite a entrada das mulheres ao grupo de WhatsApp. Antes de iniciar o atendimento a enfermeira responsável informa o nome e número de registro do COREN e solicita o preenchimento do termo de consentimento informado para teleorientação de enfermagem. O projeto "Fale com a Parteira Pernambuco" realiza educação em saúde estimulando a autonomia da mulher com embasamento científico e avalia a necessidade de deslocamento a maternidade. Tendo a finalidade de sanar dúvidas relacionadas à pandemia da COVID-19, fisiologia da gestação, alterações obstétricas, e trabalho de parto, parto e puerpério, tornando-se uma rede de apoio para estas mulheres.

\section{CONSIDERAÇÕES FINAIS}

O dinamismo da teleorientação em tempos de pandemia apresenta-se como uma estratégia eficaz na redução do fluxo de usuários nos serviços de saúde, uma vez que os atendimentos estão suspensos mediante o isolamento social, evitando exposições desnecessárias aos serviços de saúde, mantendo a continuidade do pré-natal, a detecção precoce de intercorrências gestacionais e neonatais, orientações relacionadas ao processo de trabalho de parto e parto, e os cuidados contra a COVID-19.

\section{REFERÊNCIAS}

ABDOLLAHPUOR S, KHADIVZADEN T. Improving the quality of care in pregnancy and childbirth with coronavirus (COVID-19): a system article view. The Journal of Maternal-Fetal \& Neonatal Medicine, 2020; 1(9).

CHAWLA D, et al. Perinatal-Neonatal Management of COVID-19 Infection - Guidelines of the Federation of Obstetric and Gynecological Societies of India (FOGSI), National Neonatology Forum of India (NNF), and Indian Academy of Pediatrics (IAP). Indian Pediatr, 2020;57(6):536-548.

SETO E, et al. Opportunities and Challenges of Telehealth in Remote Communities: Case Study of the Yukon Telehealth System. JMIR Med Inform, 2019; 7(4): e11353. 
040 | RESUMO SIMPLES: Relato de Experiência

\section{Extensão e educação em saúde: uma abordagem interprofissional sobre o acidente vascular cerebral (AVC)}

Autor/coautores: Camila Teixeira Neves; Raila Gonçalves dos Santos; Ana Carolina de Godoy Araújo; Lícia Luele Pires da Silva; Priscila Tamar Alves Nogueira.

Instituição: Faculdade Pernambucana de Saúde (FPS), Recife-Pernambuco.

Palavras-chave: Acidente Vascular Cerebral, Educação em Saúde, Extensão Comunitária.

\section{INTRODUÇÃO}

O Acidente Vascular Cerebral (AVC), é uma das doenças mais incidentes na população brasileira e mundial, sendo a segunda causa de morte no mundo e a primeira de incapacidade (BRASIL, 2018). A prevenção, o reconhecimento dos sinais e o tratamento nas primeiras $24 \mathrm{~h}$ são imprescindíveis para melhorar o prognóstico (BENSENOR IM, et al., 2015).

Desta forma, o projeto Pense Bem AVC FPS visa trabalhar com a população sobre o tema, à luz da educação popular em saúde, a fim de possibilitar a identificação precoce e conduta correta na ocorrência de um AVC, bem como, na adoção de práticas e cuidados de saúde, visando prevenir o AVC e suas complicações.

\section{OBJETIVO}

Relatar a experiência a partir da percepção de estudantes de Enfermagem, Fisioterapia e Medicina, sobre realização de ações do projeto de extensão Pense Bem AVC FPS em Unidade de Saúde da Família (USF) da região metropolitana do Recife (RMR), Pernambuco.

\section{RELATO DE EXPERIÊNCIA}

O projeto de extensão Pense Bem AVC FPS desenvolve ações educativas acerca do AVC. Nós, estudantes extensionistas, realizávamos palestras sobre o tema AVC para os usuários que se encontravam na USF a espera de atendimento (na maioria adultos e idosos), abordando os sinais, sintomas, prevenção e, em caso de socorro, quais os hospitais seriam referências na RMR. Após as palestras, promovíamos rodas de conversas, onde os usuários nos relatavam suas experiências e esclareciam suas dúvidas.

Realizávamos as ações às quintas-feiras, de maio a novembro de 2019. A equipe extensionista observou que, muitas vezes, a população não é instruída sobre temas importantes como o AVC, 
pois eles possuíam muitas lacunas sobre o assunto, principalmente sobre como podem se prevenir. Assim essa temática era o centro das abordagens durante as intervenções.

O maior desafio foi adequar a linguagem formal de saúde, de modo que todos os pacientes pudessem entender a doença. Nesse contexto, utilizamos linguagens coloquiais como "derrame" e comparamos o AVC isquêmico a um "cano entupido", o que se mostrou positivo para vencer as barreiras de linguagem.

\section{CONSIDERAÇÕES FINAIS}

Foi percebido que, no geral, a população não tem acesso a espaços que abordem temas importantes como o AVC, sendo boa parte do conhecimento adquirido por meio da história oral, repassada por familiares e experiências próprias.

A partir dos relatos dos participantes, percebeu-se que a atuação foi muito apreciada, pois a população almeja conhecer sobre temas que afetam diretamente suas vidas, de seus familiares e da comunidade como um todo.

\section{REFERÊNCIAS}

ALMEIDA UTFH, et al. O conhecimento dos acadêmicos de medicina das instituições particulares de Belém sobre o acidente vascular encefálico. Revista Eletrônica Acervo Saúde. 2019; n35, p. e1430: 1-9.

BENSENOR IM, et al. Prevalência de acidente vascular cerebral e de incapacidade associada no Brasil: Pesquisa Nacional de Saúde. Arquivos de Neuro-psiquiatria. 2015; 73(9): 746-750.

BRASIL. MINISTÉRIO DA SAÚDE. Manual de rotinas para atenção ao AVC. Brasília: Ministério da Saúde, 2013. 54 p. 
041 | RESUMO SIMPLES: Relato de Experiência

\section{Impacto da pandemia causada pela COVID-19 no cotidiano acadêmico de graduandos de enfermagem: relato de experiência}

Autor/coautores: Myllena Ferreira Rabelo1, Jonas de Jesus Carvalho', Kaique Vinicius da Cruz Santos Aguiar ${ }^{1}$, Daniella de Medeiros Lopes Lobo².

Instituição: ' ${ }^{1}$ Graduando de enfermagem da Faculdade Pitágoras de Feira de Santaa, Feira de Santana- Bahia; ${ }^{2}$ Mestre em Enfermagem na subarea Saúde da Mulher. Especialista em Estratégia de Saúde da Família com ênfase em Saúde coletiva, Feira de Santana-Bahia. Palavras-chave: Pandemia, Covid-19, Relato de experiência.

\section{INTRODUÇÃO}

A COVID-19 é uma doença causada pelo coronavírus SARS-CoV-2, onde a sintomatologia varia de infecções assintomáticas a quadros respiratórios graves (BRASIL, 2020). Esta patologia gerou uma pandemia mundial, obrigando a tomada de decisões para frear a velocidade de contaminação na população, e uma delas foi distanciamento social, que requer o isolamento das pessoas com o seu meio social, como ambiente de trabalho, escolas e faculdades, causando impacto na economia e na saúde mental da sociedade. (MEDEIROS EAS, 2020). A vida acadêmica sofrera influência desse fenômeno, onde estratégias de estudos foram elaboradas, impactando a vida de muitos estudantes.

\section{OBJETIVO}

Relatar a experiência do impacto da pandemia causada pelo COVID-19 na vida acadêmica de graduandos de enfermagem de uma faculdade privada, em uma cidade do interior do Estado da Bahia.

\section{RELATO DE EXPERIÊNCIA}

A pandemia causada pela COVID-19, o novo coronavírus, é um fenômeno que surpreendeu a todos, pois nenhum dos estudantes estavam preparados para as proporções que chegou. Onde os mesmos tiveram que readaptar a rotina, aderindo à aula online, como método de continuidade das aulas teóricas, método o qual não estava disponível para todos, criando um obstáculo no aprendizado, pontuando também sobre o distanciamento entre os colegas, docentes e funcionários. 
Foi relatado sobre o desafio de elaborar e apresentar o Trabalho de Conclusão de Curso (TCC) de forma online, onde houve união entre graduandos e docentes, elaborando a melhor forma para que todos pudessem apresentar. A preocupação em relação aos estágios supervisionados, critério essencial para a graduação, que foram suspensos e não há prazo para retorno, gera incerteza da formação no período estimado. Outro ponto importante é sobre a busca de novas formas de conhecimento, onde antes eram utilizados livros da biblioteca da instituição, palestras e cursos presenciais, atualmente os estudantes aderiram a materiais, congressos e simpósios online, assistindo também a Lives com especialistas da área.

\section{CONSIDERAÇÕES FINAIS}

O impacto gerado na vida acadêmica gera preocupação para os graduandos, devido às dificuldades enfrentadas para alcançar a graduação, onde é necessário readaptar a sua rotina e empregar novos métodos para aprimorar seus conhecimentos, ficando refém de um meio que não está disponível para todos. Os estudantes vivenciaram a experiência do se "reinventar" e assumiram maior autonomia na construção do saber, em união com Instituições de ensino, docentes e colegas.

\section{REFERÊNCIAS}

BRASIL. Coronavírus. Ministério da Saúde. Publicado em 2020.

MEDEIROS, EAS. Desafios para o enfrentamento da pandemia COVID-19 em hospitais universitários. Rev. paul. Pediatr. Vol 38 São Paulo 2020 Epub Apr 22,2020 
042 | RESUMO SIMPLES: Relato de Experiência

\section{Olhar acadêmico na assistência à parturientesde um centro de parto normal do nordeste: relato de experiência}

Autor/coautores: Milena da Silva ${ }^{1}$, Joanna Francyne Silva de Barros ${ }^{2}$, Geyslane Pereira Melo de Albuquerque ${ }^{2}$. Viviane Maria Gomes de Araújo $^{3}$.

Instituição: ${ }^{1}$ Acadêmica de Enfermagem da Faculdade Pernambucana de Saúde (FPS); ${ }^{2}$ Docente de Enfermagem da Faculdade Pernambucana de Saúde (FPS); ${ }^{3}$ Enfermeira Obstetra e Mestre em Hebiatria pela UPE.

Palavras-chaves: Assistência de Enfermagem, Parto e Trabalho de Parto.

\section{INTRODUÇÃO}

A atenção ao parto e nascimento vem se transformando cada vez mais em uma assistência humanizada, dando atenção integral mulher (MALHEIROS PA, et al., 2012). É um processo fisiológico que necessita de respeito, para que se tenha uma experiência positiva, confortável e segura (YOULIANG OU, et al., 2018). A fim de garantir atenção humanizada dentro de uma experiência pessoal, surge o Centro de Parto Normal (CPN) regulamentado pela portaria ㄲo11 de 7 de Janeiro de 2015, uma unidade de assistência ao parto normal de risco habitual, assistida por enfermeiros obstetras que pela lei 7.498 de 25 de junho de 1986, o autoriza a prestar assistência ao período perinatal e ao recém-nascido, como também identificar distociais, fundamentado no respeito e embasamento cientifico (MINISTÉRIO DA SAÚDE, 2015).

\section{RELATO DE EXPERIÊNCIA}

A área de saúde da mulher é um desafio enorme e mais especificamente quando voltada a parturição, o estágio no CPN no nordeste do Brasil em uma maternidade de referencia, trouxe uma imensidão de sentimentos. As atividades eram voltadas a assistência as gestantes, puérperas e aos recém-nascidos de acordo com demanda do serviço, estas mulheres eram adimitidas, evoluídas e acompanhadas através da abertura de partograma, utilizavam metodos não farmacologicos de alívo da dor se desejassem, além de conseguir proporciona-las uma experiencia fisiolagica e natural incentivando sempre seu protagonismo dentro do processo de trabalho de parto e parto.

Prestar assistência ao parto é uma das sensções mais extraodinárias, tudo que a mulher está sentindo naquele momento é transferido no ambiente, é possivél sentir toda essa emoção a cada vez que recepciona um bebê, é uma experiência única e incrivelmente subjetiva. A assistência ao 
parto é mais do que uma contração ou dilatação, não é apenas um procedimento, naquele momento somos apenas coadjuvantes e é uma honra vivenciar cada segundo e cada parto.

\section{CONSIDERAÇÕESFINAIS}

Vivenciar a humanização do parto de forma atenciosa, autônoma e ao mesmo tempo coadjuvante e ainda conseguir partilhar com aquelas mulheres as sensações e sentimentos, mesmo que por pouco tempo é uma dádiva, sempre com respeito e profissionalismo, reconhecendo a necessidade de intervir e estimulando o protagonismo da mulher. Recepcionaruma nova vida, um novo amor, uma nova mulher, uma nova família é a mais honrosa das experiências.

\section{REFERÊNCIAS}

MALHEIROS PA, et al. Parto E Nascimento: Saberes E Práticas Humanizadas, 2012.

Portaria nº11 de 07 de janeiro de 2015, Ministério da Saúde.

YOULIANG OU, et al. Effect of Obstetric Fine Nursing on Pain during Natural Childbirth and Postpartum Recovery, 2018. 
043 | RESUMOS SIMPLES: Relato de Experiência

\section{Atuação de acadêmicos numa maternidade pública do recife pelo projeto de extensão amor que vem do peito: relato de experiência}

Autor/coautores: Milena da Silva1', Sandra Hipolito Cavalcanti².

Instituição: ${ }^{1}$ Discente do curso de Enfermagem da Faculdade Pernambucana de Saúde (FPS)

${ }^{2}$ Docente do curso de Enfermagem da Faculdade Pernambucana de Saúde (FPS).

Palavras-chave: Amamentação, Aleitamento materno, Rede de Apoio.

\section{INTRODUÇÃO}

Evidências científicas comprovam a superioridade do aleitamento materno exclusivo frente ao uso de outras formas de alimentos fornecidos a crianças. Mas, apesar de todos os esforços ainda é difícil manter a lactação como fator predominante. Diante disto, evidencia-se que o profissional de saúde tem papel fundamental na reversão desse quadro, como rede de apoio ao aleitamento materno (MINISTÉRIO DA SAÚDE, 2015). Para manter sua efetividade surge como estratégia o alojamento conjunto, peça essencial à saúde materno-infantil (MINISTÉRIO DA SAÚDE, 2017). No intuito de aumentar o apoio à amamentação surge o Projeto "Amor que Vem do Peito" com o objetivo de estimular, sensibilizar, disseminar entre profissionais de saúde, estudantes, mães e familiares (FPS, 2019).

\section{RELATO DE EXPERIÊNCIA}

Trata-se de um estudo do tipo relato de experiência pelo projeto "Amor que vem do peito" no ano de 2019 de uma instituição de ensino superior com estudantes da área de saúde onde as atividades eram desenvolvidas em uma maternidade pública do Recife.

Muitas das mães que estavam internadas nos alojamentos eram multíparas, como também se encontravam mães vivenciando essa experiência pela primeira vez. Nessa tangencia, observou-se a necessidade de analisar essas mulheres, enfatizando suas experiências e dúvidas sobre a amamentação. A ação extensionista foi desenvolvida de forma simples, com uma roda de conversa que as deixassem confortáveis e acolhidas para relatar as suas experiências e expondo suas dúvidas, assim tornando um momento descontraído e rico de histórias e situações vividas. 
Amamentar é um assunto delicado, devido às questões culturais inseridas neste contexto. Mediante a este fator, nem sempre essas mulheres acolhiam de forma positiva estas informações e na grande maioria era difícil propor novos conhecimentos, porém praticando habilidades de comunicação e perseverança, a informação era repassada com sucesso.

\section{CONSIDERAÇÕES FINAIS}

Por mais atual que sejam os assuntos relacionados à amamentação ou por mais informadas que as mulheres estejam hoje, ainda existem informações errôneas. É um assunto que necessita estar presente, ser falado e defendido sempre e é com este objetivo que o Projeto "Amor que vem do peito" se estrutura, de modo a apoiar e tornar esta experiência a mais confortável e única possível para lactante, ao ponto de inseri-la como protagonista deste momento.

\section{REFERÊNCIAS}

FPS. Faculdade Pernambucana de Saúde. Edital de Processo Seletivo do Projeto de extensão “Amor que Vem do Peito", 2019, 1ª edição.

BRASIL. Ministério da saúde, Caderno de Atenção Básica, Saúde da criança, Aleitamento Materno e Alimentação Complementar, 2015, 2ª Edição.

BRASIL Ministério da Saúde, Bases para discussão da Política Nacional de Promoção, Proteção e Apoio ao Aleitamento Materno, 2017. 
044 | RESUMOS SIMPLES: Relato de Experiência

\section{Vivências de um estágio curricular não obrigatório em enfermagem acerca da pandemia do novo coronavírus: um relato de experiência}

Autor/coautores: Juan Victor da Silva, Cacilda Maria dos Santos Leal.

Instituição: Universidade Estadual do Piauí (UESPI), Floriano - Piauí. Unidade Mista de Saúde Jurandi Mendes (UMSJM), Angical do Piauí - Piauí.

Palavras-chave: Enfermagem, Estágio, COVID-19.

\section{INTRODUÇÃO}

O mundo está passando por mais uma grave crise de saúde provocada por uma doença infecciosa causada por um novo tipo do coronavírus (SARS-CoV-02), a doença chamada COVID19 é potencialmente fatal e representa o mais importante problema mundial de saúde pública dos últimos 100 anos (MEDEIROS EA, 2020). Em um cenário imprevisível como o atual, é importante que se tenha uma equipe multiprofissional fortalecida pelo conhecimento. Assim, o estágio não obrigatório se torna um apoio para os profissionais e a equipe propicia novas experiências ao estagiário, visto que o estágio acadêmico é uma troca de informações, ideias e experiências entre acadêmicos e profissionais da instituição (RODRIGUES GL, et al., 2016).

\section{OBJETIVO}

Relatar a experiência de um estágio de enfermagem acerca da pandemia do novo coronavírus.

\section{RELATO DE EXPERIÊNCIA}

No decorrer do estágio não obrigatório, foi possível observar a rotina do hospital, além da dinâmica adotada pelos profissionais em enfrentamento à COVID-19, baseando-se nos protocolos da Organização Mundial da Saúde (OMS) e do Ministério da Saúde (MS), além da Secretaria de Saúde do Estado do Piauí (SESAPI).

Inicialmente, o estágio foi marcado pela apresentação dos setores, e respectivamente dos profissionais. Posteriormente, o acervo e sistematização da assistência foram evidenciados. Foi notório observar que os meios de intervenção estavam sendo executados conforme atualizações, além de medidas conhecidas como procedimentos operacionais padrão, que englobavam uma assistência ainda maior por parte da equipe multiprofissional. No que tange ao trabalho executado 
pela equipe de enfermagem, conceitua-se em um trabalho essencial, da triagem à assistência ao paciente em estado mais avançado, sempre com a prática baseada em evidências.

Profissionais de enfermagem bem preparados e pautados na ética. Os cuidados prestados aos pacientes ajudaram no aprimoramento do conhecimento prático. Além do que, o acompanhamento aos pacientes ajudou na construção do pensamento crítico e reflexivo para uma formação com fortes pilares em enfermagem.

\section{CONSIDERAÇÕES FINAIS}

Diante do exposto, conclui-se que o estágio permitiu a observação da dinâmica e funcionamento de uma instituição de saúde em meio a uma pandemia, principalmente no que se refere a atuação da equipe de enfermagem, e de como esses profissionais fazem uso da sua atribuição técnicocientifico para tratar e cuidar de pacientes acometidos pelo vírus, levando em conta as necessidades básicas de cada ser humano.

\section{REFERÊNCIAS}

MEDEIROS EA. A luta dos profissionais de saúde no enfrentamento da COVID-19. Acta Paul Enferm. 2020;33:e-EDT20200003.

RODRUIGUES GL, et al. A vivência no campo de estágio: Relato de experiência. Rev. esc. enferm. USP, 2016;2:e20160005. 
045 | RESUMOS SIMPLES: Relato de Experiência

\section{Educação em saúde: um relato de experiência sobre a capacitação de leigos em noções básicas de primeiros socorros}

Autor/coautores: Esther Portela Sandes, Gabriela Menezes Cavalcante, Kézia Porto Lima, Mayana Morais da Luz, Vitória Pereira Carvalho.

Instituição: Faculdade Carajás, Marabá-Pará.

Palavras-chave: Primeiros socorros, Educação em saúde, Enfermagem.

\section{INTRODUÇÃO}

O enfermeiro exerce constantemente o papel de educador em saúde. Dessa forma, ainda no decurso do seu trajeto acadêmico deve desenvolver práticas educativas em saúde voltadas à população, contribuindo para a formação de um perfil educador. A educação em saúde é um instrumento fundamental para a promoção, prevenção e reabilitação à saúde, pois fomenta a autonomia dos indivíduos no que tange às questões de saúde coletiva. $\mathrm{O}$ atendimento inicial às urgências e emergências está diretamente relacionado as chances de sobrevida da vítima, portanto a capacitação de leigos em primeiros socorros mostra-se favorável (BERTOLDO C, et al., 2019; OLIVEIRA M, et al., 2015).

\section{OBJETIVO}

Relatar a experiência dos acadêmicos do $7^{0}$ semestre de Enfermagem referente a ação de ensino em saúde sobre primeiros socorros aos seus familiares.

\section{RELATO DE EXPERIÊNCIA}

A atividade de educação em saúde foi direcionada a leigos e desenvolvida por discentes do $7^{\circ}$ período do curso de Enfermagem de uma instituição de ensino superior localizada no Sudeste do Pará, em maio de 2020. A ação integrava a disciplina de Assistência de Enfermagem em Urgência e Emergência, intitulada "Primeiros Socorros na Comunidade", porém devido a medidas de prevenção impostas pela pandemia do COVID-19, o ensino foi ministrado pelos acadêmicos por videoconferência, tendo como público-alvo os seus próprios familiares, os quais participaram de suas respectivas residências.

Para o embasamento teórico, utilizou-se da literatura que compõe a disciplina mencionada. Foram apresentados slides, vídeos demonstrativos e simulação prática das manobras e ações 
corretas no atendimento inicial a uma urgência e/ou emergência. Durante a capacitação foram abordadas temáticas relevantes para o público-alvo relacionadas a incidência de casos na região, tais como: suporte básico de vida em reanimação cardiopulmonar, manobra de Heimlich, acidentes por animais peçonhentos, controle de hemorragias, escala de Cincinnati e medidas protetivas ao paciente convulsivo.

\section{CONSIDERAÇÕES FINAIS}

Nota-se que a educação em saúde proposta teve impacto benéfico no público-alvo, pois desmistificou-se condutas baseadas no senso comum, orientando-os a práticas baseadas em evidências científicas através de linguagem acessível, resultando na capacitação de indivíduos leigos para o suporte adequado em primeiros socorros, possibilitando assim, em situações de urgência e/ou emergência, o aumento da sobrevida do indivíduo até a chegada do atendimento especializado e a redução de mortes não assistidas.

\section{REFERÊNCIAS}

BERTOLDO C, et al. Noções básicas de primeiros socorros: relato de experiência de um projeto de extensão rural. Rev Bras Promoç Saúde, 2019; 32: e8255.

OLIVEIRA M, et al. Concepção de graduandos de enfermagem sobre a prática de educação em saúde em primeiros socorros. Rev Rene. 2015 mar-abr; 16 (2): 150-8. 
046 | RESUMO SIMPLES: Relato de Experiência

\section{Ações de prevenção do acidente vascular cerebral (AVC) de um projeto de extensão: o homem como figura com pouca participação}

Autor/coautores: Lícia Luele Pires da Silva; Vitória Marion Costa Silva; Talita Candeias do Rêgo; Nicole Helen Freitas Tavares; Marina Alves Caminha.

Instituição: Faculdade Pernambucana de Saúde (FPS), Recife-Pernambuco.

Palavras-chave: Saúde do homem, Educação em saúde, Acidente Vascular Cerebral.

\section{INTRODUÇÃO}

O Acidente Vascular Cerebral (AVC) é uma das doenças que mais incapacita os indivíduos, deixando-os na maioria dos casos com sequelas, tornando-os dependentes nas suas atividades diárias. No Brasil, a doença se mostra muito frequente, com altos números de casos a cada ano, sendo a prevenção a melhor forma para que esta realidade seja modificada (BOTELHO TS, et al., 2016; DA SILVA DN, et al., 2019).

O projeto de extensão Pense Bem AVC da Faculdade Pernambucana de Saúde (FPS) tem como principal função fornecer educação em saúde sobre o tema AVC, com foco em medidas preventivas, sendo constatado durante as ações na Unidade de Saúde da Família (USF), um grande déficit na quantidade de homens presentes.

\section{OBJETIVO}

Este relato de experiência objetiva trazer uma abordagem reflexiva acerca da menor participação dos homens nas atividades do projeto de extensão, podendo este fato estar aliado com a baixa procura destes pelos serviços de saúde.

\section{RELATO DE EXPERIÊNCIA}

Durante as três práticas extensionistas realizadas em uma USF de uma cidade do estado de Pernambuco foi identificado que a população masculina representava uma parcela que variava de $8 \%$ a $27 \%$ dos presentes nas ações, e ainda assim, os poucos que compareciam apresentavam uma resistência para participar da discussão sobre os diferentes temas que eram abordados pelos integrantes do projeto. Diferente do público feminino, as quais eram maioria e demonstravam grande interesse na condução da ação, trocando experiências e esclarecendo dúvidas. 
A população masculina ainda mantém bloqueios que impedem o reconhecimento de suas necessidades de saúde, sendo considerados como um grupo de difícil acesso, o que impede que seja realizado um trabalho preventivo de maneira eficiente. Os homens, ainda são considerados como o mantenedor do sustento da casa, onde muitas vezes, não prezam pela sua saúde, transferindo esse cuidado para algum ente da família, geralmente uma figura feminina. Diante dessas condições, acabam apresentando uma menor expectativa de vida quando comparados com as mulheres (BIDINOTTO DNPB, et al., 2016).

\section{CONSIDERAÇÕES FINAIS}

São necessários estudos que avaliem quais são as dificuldades que interferem no trabalho de prevenção com os homens, da mesma forma, deve-se enfatizar a importância do estímulo a figura masculina no que concerne cuidados integrais a saúde e a sua importância como propagadores de informações educativas.

\section{REFERÊNCIAS}

BIDINOTTO DNPB, et al. Men's health: non-communicable chronic diseases and social vulnerability. Revista Latino-Am. Enfermagem, 2016; 24: e2756.

BOTELHO TS, et al. Epidemiologia do acidente vascular cerebral no Brasil. Temas em saúde, João Pessoa, 2016.

DA SILVA DN, et al. Cuidados de enfermagem à vítima de acidente vascular cerebral (AVC): Revisão integrativa. Revista Eletrônica Acervo Saúde, 2019; 36: e2156. 
047 | RESUMOS SIMPLES: Relato de Experiência

\section{Educação em saúde: um relato de experiência sobre higienização das mãos e uso correto de máscaras como proteção a COVID-19}

Autor/coautores: Isabela Rocha Jucá, Katryane Oliveira Santos, Kézia Porto Lima, Mateus Barbosa Lima, Sarah Beatriz Cavalcante Ribeiro.

Instituição: Faculdade Carajás, Marabá-Pará.

Palavras-chave: Lavagem de mãos, Equipamento de proteção individual, COVID-19.

\section{INTRODUÇÃO}

Devido acelerada proporção de infectados pelo vírus COVID-19, foi oficialmente declarada pela Organização Mundial de Saúde (OMS) uma Pandemia e os casos evidenciaram uma emergência de saúde pública (OPAS, 2020). O Ministério da Saúde (MS) emitiu uma série de orientações sobre medidas de prevenção durante a rotina, a fim de minimizar a exposição ao vírus respiratórios, como por exemplo, a higienização adequada das mãos. Somada a utilização das máscaras, etiqueta correta ao tossir ou espirrar e distanciamento social, tal situação pode ser considerada um fenômeno de mudança aos hábitos e rotina de higiene (GARCIA LP, 2020).

\section{OBJETIVO}

Relatar a experiência da orientação dos acadêmicos de Enfermagem do $5^{\circ}$ semestre aos seus familiares sobre a técnica de higienização das mãos e uso correto de máscara facial para a proteção contra o COVID-19.

\section{RELATO DE EXPERIÊNCIA}

Trata-se de uma intervenção de ensino em saúde, voltada a familiares de acadêmicos do 5ำ semestre do curso de Enfermagem, tal ação compõe a disciplina de Práticas Educativas de Saúde na Amazônia. Diante da situação de distanciamento social, a intervenção ocorreu por meio de vídeo conferência transmitido das residências dos alunos organizadores e expectados por seus familiares também em seus domicílios

Para o embasamento teórico buscou-se materiais científicos relacionados ao tema identificados na Biblioteca Virtual de Saúde (BVS), contribuindo na confecção de slides, vídeos demonstrativos e simulação prática da utilização da máscara facial e do método de higienização das mãos. 
Nota-se que o ensino em saúde foi positivo referente a transmissão desse conhecimento para leigos, de forma que conseguiram após a explanação teórico-prática, demonstrar clareza sobre a forma correta de uso e manuseio da máscara facial e sobre a técnica correta de higinização das mãos, além de reconhecerem o momento adequado de esoclha do uso do álcool gel ou água e sabão, proporcionando consciência individual e coletiva da prevenção do contágio da COVID-19.

\section{CONSIDERAÇÕES FINAIS}

Percebe-se que a educação em saúde realizada propiciou à pessoas leigas que efetuassem corretamente o uso de máscara facial e a higienização das mãos, com o objetivo de prevenir o contágio pela COVID-19. Acredita-se que, por consequência, adotem uma consciência individual e coletiva, percebendo a influência do contexto atual de pandemia sobre a sua saúde e repassando os conhecimentos adquiridos para outras pessoas.

\section{REFERÊNCIAS}

GARCIA LP. Uso de máscara facial para limitar a transmissão da COVID-19. Epidemiologia e Serviços de saúde, 2020; 29(2): e1.

BRASIL. Ministério da Saúde. Sobre a Doença: Como se proteger. 2020.

ORGANIZAÇÃO PAN-AMERICANA DA SAÚDE. Folha informativa - COVID-19 (doença causada pelo novo coronavírus). 2020. 
048 | RESUMOS SIMPLES: Relato de Experiência

\section{Educação em saúde com estudantes de graduação: um relato de experiência}

Autor/coautores: Marcelino Maia Bessa, Maria Valéria Chaves de Lima, Laise Lara Firmo Bandeira, Maria Dianna de Souza, José Ednardo Soares Pereira da Silva.

Instituição: Universidade do Estado do Rio Grande do Norte (UERN), Pau dos Ferros-Rio Grande do Norte.

Palavras-chave: Educação em Saúde, Estudantes, Enfermagem.

\section{INTRODUÇÃO}

A educação em saúde pode ser dita como uma ação que visa a prática de conhecimento popular e de saúde simultaneamente, sendo que um dos resultados é a criação de vínculo e o conhecimento compartilhado entre população/estudantes e profissionais (PINHEIRO BC e BITTAR CML, 2017).

Adolescentes e jovens, muitas vezes, deixam de ser atendidos em suas necessidades de saúde relacionadas à sexualidade e à reprodução, tendo influência direta com o aumento da desinformação relacionada a doenças sexualmente transmissíveis. As políticas e os programas de saúde voltados para este público, frequentemente, desconsideram as diversas características da sua sexualidade (VIEIRO VSF, et al., 2015).

\section{OBJETIVO}

Relatar a experiência vivenciada por acadêmicos de enfermagem sobre a realização de educação em saúde com estudantes de graduação.

\section{RELATO DE EXPERIÊNCIA}

A atividade foi desenvolvida com 17 estudantes de graduação de uma universidade do interior do Nordeste. Para tal, foram utilizadas metodologias ativas, para quebrar o paradigma de uma construção de conhecimento verticalizado. De início, utilizou-se uma metodologia de "quebra gelo", a qual cada aluno recebeu uma cartela de bingo adaptada para o momento contendo um número e uma frase. Posteriormente, realizou-se a metodologia de "dinâmica de conteúdo", onde realizou-se o sorteio das cartelas e o participante com o número sorteado lia a frase e relatava sobre o que sabia/entendia em relação a informação contida na cartela, posteriormente, a discussão se abria para os demais colegas da turma e os estudantes que estavam mediando a atividade. Por fim, 
realizou-se a metodologia de "avaliação", que consistiu na construção de um painel em que após a discussão grupal finalizada, estes afixaram as frases em dois lados do painel, divididos em um espaço para verdades e outro para mitos. As atividades evidenciaram a necessidade da discussão das temáticas sobre as infecções sexualmente transmissíveis, sobre tabus, preconceito, sexualidade. Assim sendo, propõe o debate de temas que fazem parte da vivência desses indivíduos que merece ser explorado. Ressalta-se que a realização de educação em saúde em espaços adequados, é fundamental para o sucesso das ações.

\section{CONSIDERAÇÕES FINAIS}

As atividades desenvolvidas apontam como sendo positivas, pois, proporcionam discussões relevantes para o público em questão. Essas discussões permitiram ainda a troca de conhecimentos, bem como a construção de novos. Além disso, cabe ressaltar a importância da utilização de metodologias cada vez mais participativas, tendo a educação em saúde como um importante instrumento para a construção do conhecimento.

\section{REFERÊNCIAS}

PINHEIRO BC, BITTAR CML. Práticas de educação popular em saúde na atenção primária: uma revisão integrativa. Cinergis, v. 18, n. 1, p. 77-82, 2017.

VIERO VSF, et al. Educação em saúde com adolescentes: análise da aquisição de conhecimentos sobre temas de saúde. Esc. Anna Nery, Rio de Janeiro, v. 19, n. 3, p. 484-490, Sept. 2015. 
049 | RESUMOS SIMPLES: Relato de Experiência

\title{
Neurotoxoplasmose em pacientes com AIDS: Contribuições da equipe multiprofissional em um Hospital Universitário
}

\author{
Autor/coautores: Camila Sane Viena, Juliana Florentino de Lucena, Larissa Cristina Araújo \\ Sacramento, Lívia Soares Santos e Lorena Vieira Santos. \\ Instituição: Universidade Federal da Bahia (UFBA), Salvador-Bahia. \\ Palavras-chave: Neurotoxoplasmose, Infectologia, Assistência integral à saúde.
}

\section{INTRODUÇÃO}

A Neurotoxoplasmose (NTX), patologia decorrente da reativação da infecção latente por Toxoplasma gondii, é uma doença oportunista que acomete pacientes imunodeprimidos, especialmente portadores da AIDS, sigla em inglês para a Síndrome da Imunodeficiência Adquirida (ARAÚJO IR, et al., 2019). Trata-se da causa mais comum de lesões cerebrais expansivas, apresentando alta morbimortalidade, principalmente em países de renda baixa e média (VIDAL JE, 2019), podendo gerar diversas sequelas neurológicas, transitórias ou permanentes, que comprometem a realização de atividades da vida cotidiana (ARAÚJO IR, et al., 2019). O manejo desses pacientes requer a atuação da equipe multiprofissional, que tem como principal ferramenta a construção do Projeto Terapêutico Singular (PTS), visando um cuidado integral abrangendo a complexidade de suas repercussões (SANTOS KH, et al., 2016).

\section{OBJETIVO}

Relatar a experiência de uma equipe multiprofissional em saúde no manejo de pacientes diagnosticados com Neurotoxoplasmose secundária à AIDS em âmbito hospitalar, ressaltando as contribuições da atuação multiprofissional para um cuidado integral.

\section{RELATO DE EXPERIÊNCIA}

Trata-se de um estudo descritivo do tipo relato de experiência em que realizou-se análise dos aspectos relacionados ao cuidado com pacientes diagnosticados com neurotoxoplasmose secundária à AIDS por meio de atendimentos e discussão de casos realizados por residentes de uma equipe multiprofissional na enfermaria de infectologia em um hospital universitário no município de Salvador/BA em agosto de 2019. Dentre as repercussões neurológicas, o déficit motor e alteração do nível de consciência reduzem significativamente a autonomia do paciente, além de impactar em questões psicossociais, gerando demandas diversas durante o internamento. Para 
atender a essas demandas, fez-se necessário a elaboração do PTS, uma importante ferramenta construída de forma coletiva que promove um cuidado singular e de forma horizontal, considerando não apenas a diversidade dos saberes de cada profissional na construção do cuidado, mas também o saber do paciente e suas potencialidades, identificando suas reais necessidades e proporcionando práticas que vão além do aspecto biológico. Destacamos a importância dos espaços de diálogo que possibilitam a reflexão e a complementariedade das formas distintas de produzir saúde.

\section{CONSIDERAÇÕES FINAIS}

É notória a necessidade de abordar o paciente de forma biopsicossocioespiritual, colaborando para o restabelecimento da autonomia do sujeito e possibilitando a continuidade do cuidado, a garantia de assistência e orientações pós-alta hospitalar, articulando-se com a rede socioassistencial desses pacientes.

\section{REFERÊNCIAS}

ARAÚJO IR, et al. Déficits motores e preditores de perda de mobilidade ao final da internação em indivíduos com neurotoxoplasmose. Fisioter. Pesqui. São Paulo, Dec. 2019; 26(4): 360-365.

SANTOS KH, et al. O trabalho de profissionais na residência multiprofissional em saúde. Rev APS 2016; 19(3):495-499.

VIDAL JE. HIV-related cerebral toxoplasmosis revisited: current concepts andcontroversies of an old disease. J. Int. Assoc. Provid. AIDS Care. 2019. 


\section{Revisão Bibliográfica}

050 | RESUMOS SIMPLES: Revisão Bibliográfica

\section{Abordagem da Síndrome da Dor Miofascial na Atenção Primária}

Autor/coautores: Henrique Guimarães Vasconcelos, Sílvio Henrique da Silva Vaz, Alda Luíza Alves Silva, Matheus Costa Lima, Daiane Guimarães da Silveira.

Instituição: Universidade de Itaúna (UIT), Itaúna - Minas Gerais; Universidade Federal de Lavras (UFLA), Lavras - Minas Gerais.

Palavras-chave: Dor Miofascial, Atenção Primária, Dor Muscular.

\section{INTRODUÇÃO}

A síndrome da dor miofascial (SDM) é uma desordem regional neuromuscular bastante identificada na atenção primária (AP), com prevalência na faixa etária entre 31 e 50 anos de idade (BRAHIM CB, et al., 2017). Dessa forma, a abordagem integral do médico da família nesses casos é primordial para compreender o processo saúde-adoecimento e promover bem-estar ao paciente (DALL' AM, et al., 2013).

\section{OBJETIVO}

O presente trabalho objetivou discutir como a abordagem da dor miofascial pelo médico de família pode potencializar a resolutividade dos casos na AP.

\section{REVISÃO BIBLIOGRÁFICA}

A SDM é caracterizada pela existência de pontos-gatilho (PG) ativos que, ao serem estimulados, referem à dor usual do paciente. A dor referida manifesta-se, usualmente, em uma região de maior extensão que a do PG. Nos músculos com PG, a banda de tensão limita o alongamento muscular e, por isso, há restrição do movimento (CULPI M e MARTINELL ABMC, 2018).

Fraqueza e encurtamento muscular também podem ser observados na síndrome. Geralmente, ocorre pelo estresse excessivo sobre os músculos (movimentos repetitivos, postura inadequada, trauma, distensão muscular, estresse emocional e por roupas apertadas) (DALL' AM, et al., 2013). 
Pode também estar associada a doenças como diabetes, depressão, doenças reumatológicas e neurológicas, sendo o diagnóstico eminentemente clínico (BRAHIM CB, et al., 2017).

Algumas manobras são importantes ferramentas terapêuticas, como o agulhamento seco. A abordagem centrada na pessoa, incluindo avaliação do significado da dor na vida do indivíduo, é essencial para o cuidado integral. Orientações de exercícios específicos e tratamento medicamentoso fazem parte do arsenal terapêutico (CULPI M e MARTINELL ABMC, 2018).

\section{CONSIDERAÇÕES FINAIS}

A dor miofascial é um sintoma frequente na atenção primária, requerendo cuidado integral ao indivíduo. A abordagem desse quadro requisita do médico da família raciocínio clínico eficaz, com o intuito de evitar mal uso de recursos diagnósticos e terapêuticos, privilegiando a prevenção e a resolutividade.

\section{REFERÊNCIAS}

BRAHIM CB, et al. Eficácia da técnica de agulhamento seco no controle da síndrome da dor miofascial. Cadernos UniFOA. 2017; 12(34): 105-124.

CULPI M, MARTINELL ABMC. Desativação de pontos-gatilho no tratamento da dor miofascial. Revista Brasileira de Medicina de Família e Comunidade. 2018; 13(40): 1-9.

DALL' AM, et al. Dor miofascial dos músculos da mastigação e toxina botulínica. Rev. Dor. $2013 ; 14(1): 52-57$. 
051 | RESUMOS SIMPLES: Revisão Bibliográfica

\section{A importância clínica da aortite sifilítica: uma revisão de literatura}

Autor/coautores: Henrique Guimarães Vasconcelos, Sílvio Henrique da Silva Vaz, Alda Luíza Alves Silva, Matheus Costa Lima, Daiane Guimarães da Silveira.

Instituição: Universidade de Itaúna (UIT), Itaúna - Minas Gerais; Universidade Federal de Lavras (UFLA), Lavras - Minas Gerais.

Palavras-chave: Aortite, Sífilis, Patologia.

\section{INTRODUÇÃO}

Mesmo com os avanços da Medicina e da educação em saúde, as infecções sexualmente transmissíveis (ISTs) ainda acometem parte significativa da população (PIVATTO JÚNIOR F, et al, 2017). Entre elas, destaca-se a sífilis, cujo agente etiológico é o Treponema Pallidum e que apresenta diagnóstico, tratamento e cura estabelecidos e de baixo custo, mas que pode evoluir para cronicidade quando não tratada, provocando graves consequências, como a aortite sifilítica (PIVATTO JÚNIOR F, et al, 2017; TO F e KIAMANESH O, 2017).

\section{OBJETIVO}

Relatar as condições clínicas gerais, as modificações morfofuncionais e histológicas da aortite sifilítica vinculada à conscientização coletiva.

\section{REVISÃO BIBLIOGRÁFICA}

A sífilis terciária é responsável por provocar agravos cardiovasculares, sendo a aortite sifilítica a lesão mais comum, que pode tornar-se evidente depois 10 a 40 anos após o contágio e quando não é implementado o tratamento adequado (SPALTENSTEIN M, et al., 2017).

Nessa lesão, é possível observar a presença do Treponema pallidum na parede da aorta, a princípio na adventícia e posteriormente nos vasos linfáticos, podendo ocorrer endarterite obliterante, que é uma condição caracterizada pela inflamação na parede de grandes vasos sanguíneos, pela destruição do tecido elástico e consequente substituição por tecido de cicatrização (TO F e KIAMANESH O, 2017).

Entre os sinais mais comuns, destaca-se o alargamento da raiz da aorta, especialmente a aorta ascendente, que é acometida em $50 \%$ dos casos, seguindo-se da crossa da aorta, aorta 
descendente e aorta abdominal ${ }^{6,7}$. Ademais, os óstios coronarianos e a valva aórtica podem ser comprometidos, além do aumento do ventrículo esquerdo e a presença crônica de regurgitação aórtica (PIVATTO JÚNIOR F, et al., 2017; TO F e KIAMANESH O, 2017).

Em relação ao diagnóstico, são usados exames complementares como o ecocardiograma e a tomografia computadorizada. Já o tratamento para essa lesão é cirúrgico, pois trata-se de uma doença rara e cujo diagnóstico é difícil (SPALTENSTEIN M, et al., 2017).

\section{CONSIDERAÇÕES FINAIS}

É de fundamental importância que o Ministério da Saúde e a comunidade civil adotem medidas eficazes de prevenção, controle e diagnóstico precoce das ISTs, a fim de diminuir a progressão dessas enfermidades para estágios crônicos e severos, como é o caso da aortite sifilítica.

\section{REFERÊNCIAS}

PIVATTO JÚNIOR F, et al. Aneurysm and dissection in a patient with syphilitic aortitis. Braz J. Infect. Dis. $2017 ; 21(3): 349-352$.

SPALTENSTEIN M, et al. A case report of CT-diagnosed renal infarct secondary to syphilitic aortitis. BMC Infect Dis. 2017; 17(1): 520.

TO F, KIAMANESH O. Coronary ostial stenosis and aortic aneurysm caused by syphilis. CMAJ. 2017; 189(9): e369. 
052 | RESUMOS SIMPLES: Revisão Bibliográfica

\section{O despreparo durante a formação médica para a assistência ao paciente surdo}

Autor/coautores: Henrique Guimarães Vasconcelos, Sílvio Henrique da Silva Vaz, Alda Luíza Alves Silva, Matheus Costa Lima, Daiane Guimarães da Silveira.

Instituição: Universidade de Itaúna (UIT), Itaúna - Minas Gerais; Universidade Federal de Lavras (UFLA), Lavras - Minas Gerais.

Palavras-chave: Acessibilidade, Educação Médica, Surdez.

\section{INTRODUÇÃO}

Os indivíduos portadores de deficiência auditiva representam uma grande parcela que enfrenta dificuldades de entender o código oral auditivo e, por isso, tendem a adotar a LIBRAS (Língua Brasileira de Sinais) como estratégia de comunicação, que constitui a base para a anamnese na área da saúde (IACHINSKI LT, et al., 2019). No instante em que essa comunicação se torna falha, são grandes as chances de um equívoco na assistência ao paciente. Embora existam respaldos legais, a população surda ainda está susceptível a enfrentar dificuldades em relação à acessibilidade aos serviços de saúde (GALASSO BJB, et al., 2018).

\section{OBJETIVO}

Detectar os obstáculos na relação entre médicos e pacientes surdos e analisar a preparação para a comunicação com pacientes surdos na formação médica.

\section{REVISÃO BIBLIOGRÁFICA}

A ausência de capacitação dos profissionais de saúde pode gerar dano durante o atendimento médico, podendo resultar em constrangimento e sentimento de discriminação por parte do paciente, diagnóstico errôneo, dificuldade de elaborar corretamente o prontuário médico e, ainda, tratamento falho da possível patologia (COSTA BSL e RIBEIRO SS, 2018).

Ademais, nota-se que o paciente surdo enfrenta dificuldades no processo de atendimento médico, desde o acolhimento, até a consulta e o tratamento (GALASSO BJB, et al., 2018). Muitas vezes, ele pode encontrar obstáculos na marcação da consulta ao chegar à recepção com a finalidade de ser instruído sobre seu atendimento e na consulta direta com o profissional de saúde (IACHINSKI LT, et al., 2019). 
Nesse cenário, a acessibilidade no atendimento clínico dos surdos é um assunto relevante para melhor compreensão de uma possível reestruturação na formação dos profissionais de saúde (COSTA BSL e RIBEIRO SS, 2018). Embora o ensino de Libras seja oferecido facultativamente para a maioria dos cursos no ensino superior, vê-se pouca expressividade deste conhecimento entre os médicos (GALASSO BJB, et al., 2018). Com isso, ressalta-se a linguagem não-verbal como um recurso de comunicação que precisa ser valorizado na prática das ações em saúde (COSTA BSL e RIBEIRO SS, 2018).

\section{CONSIDERAÇÕES FINAIS}

A conscientização de profissionais de saúde sobre o atendimento integral do paciente surdo é essencial para a implementação efetiva do ensino de Libras no ensino médico, resultando em maior confiança e qualidade na relação médico-paciente. Além disso, é necessário que essa capacitação com vista à acessibilidade englobe não somente o médico, mas todo o processo da consulta clínica, desde a sua marcação, até a sua finalização. Dessa forma, a inclusão social torna-se integral.

\section{REFERÊNCIAS}

COSTA BSL, RIBEIRO SS. A representação da surdez na literatura: vivências e experiências de surdos e familiares de surdos. Estud. Lit. Bras. Contemp. 2018; 54: 101-121.

GALASSO BJB, et al. Processo de produção de materiais didáticos bilíngues do Instituto Nacional de Educação de Surdos. Rev. Bras. Educ. Espec. 2018; 24(1): 59-72.

IACHINSKI LT, et al. A inclusão da disciplina de Libras nos cursos de licenciatura: Visão do futuro docente. Audiol., Commun. Res. 2019; 24: e2070. 
053 | RESUMOS SIMPLES: Revisão Bibliográfica

\section{Abordagem multiprofissional no tratamento da anquiloglossia em recém-nascidos}

Autor/coautores: Leticia Monteiro Rocha; Maria Antônia Duarte Silva; Larissa Maria Alves dos Santos; Alessa Laila Rodrigues Lucas; Sandra Hipólito Cavalcanti.

Instituição: Faculdade Pernambucana de Saúde (FPS), Recife-Pernambuco; UNISÃOMIGUEL, Recife-Pernambuco; Faculdade de Ciências Humanas de Olinda (FACHO), Recife-Pernambuco. Palavras-chave: Anquiloglosia, Recém-nascido, Freio lingual.

\section{INTRODUÇÃO}

A equipe multidisciplinar acompanha o indivíduo desde a vida intra-uterina. $\mathrm{O}$ diagnóstico e a intervenção precoce são importantes para o desenvolvimento das crianças com anquiloglossia, tornando-se imprescindível compreender melhor como ocorre o desenvolvimento da criança como um todo. (POMINI MC, et al., 2018).

Em 20 de junho de 2014, foi sancionada a lei federal que institui a obrigatoriedade da aplicação do protocolo de avaliação do freio da língua em recém-nascidos, nos hospitais de todo país (MARTINELLI VLC, et al., 2017). A anquiloglossia é uma anomalia no desenvolvimento da língua caracterizada pelo freio lingual curto, limitando seus movimentos, e que pode ser identificado desde a fase lactante, já que o freio ajuda a língua a se manter na posição correta ao mamar (PENHA ES, et al., 2019).

\section{OBJETIVO}

Revisar a importância da atuação da equipe multidisciplinar na avaliação, diagnóstico e tratamento dos recém-nascidos com anquiloglossia, através do teste da linguinha precoce.

\section{MÉTODO}

Estudo do tipo revisão integrativa. Os dados foram coletados em bases eletrônicas Acervo Saúde, PubMed, SciELO, utilizando-se os descritores "anquiloglosia", "recém-nascido" e "freio lingual", e como critérios de inclusão, artigos em português e inglês, publicados no período de 2015 a 2020. Aplicando os critérios de exclusão, 3 artigos foram eliminadose por não estarem relacionados ao assunto ou artigos cujo idioma de publicação não fosse o português ou o inglês. 
Após aplicados os critérios, 10 artigos foram lidos e analisados integralmente, a fim de elaborar uma análise crítica e objetiva acerca do tema.

\section{RESULTADOS E DISCUSSÃO}

A anquiloglossia em recém-nascidos é um fator de relevância nas maternidades brasileiras, tornando importante o diagnóstico multiprofissional, formado pelas equipes de odontologia, enfermagem, medicina, fonoaudiologia, equipe do banco de leite e outros, fornece resultados mais fidedignos quanto ao diagnóstico precoce, para uma intervenção imediata (POMINI MC, et al., 2018). Assim, amenizando os problemas que um freio lingual curto acarreta, como o atraso da linguagem oral, dificuldades no desenvolvimento correto do sistema estomatognático e a exclusão desse indivíduo no âmbito social (PENHA ES, et al., 2019).

\section{CONSIDERAÇÕES FINAIS}

A equipe multiprofissional atua na integração dos conhecimentos para melhor atender aos pacientes que apresentam anquiloglossia, através de uma abordagem ampla e resolutiva do cuidado, entrarão em consenso, e decidirão se o melhor tratamento será a intervenção cirúrgica ou apenas a fonoterapia (POMINI MC, et al., 2018). Também é preciso orientar a família quanto a importância da realização do exame e a necessidade do seu tratamento, sendo a abordagem cirúrgica do freio pela técnica convencional um procedimento seguro, simples e bastante econômico, com resultados satisfatórios em pouco tempo (PENHA ES, et al., 2019).

\section{REFERÊNCIAS}

MARTINELLI VLC, et al. Elaboração e desenvolvimento de um website sobre o teste da linguinha. Rev. CEFAC, 2017; 1: 260-264.

PENHA ESDA, et al. Teste da linguinha: as gestantes sabem do que se trata?. Revista Eletrônica Acervo Saúde, 2019; 2: e957.

POMINI MC, et al. Conhecimento de gestantes sobre o teste da linguinha em neonatos. Rev. odontol. UNESP, 2018; 2: 341-347. 
054 | RESUMOS SIMPLES: Revisão Bibliográfica

\section{Neuropatia Autonômica Cardiovascular na Diabetes Mellitus: compreendendo sua fisiopatologia e manifestações clínicas}

Autor/coautores: Luiza Lopes Magalhães, Adriana Oliveira Salles, Bárbara Januzzi Carvalho Silva e Júlio César Salles Santos.

Instituição: Centro Universitário Fundação de Ensino Octávio Bastos (UNIFEOB), São João da Boa Vista, São Paulo. Universidade José do Rosário Vellano (UNIFENAS), Alfenas, Minas Gerais. Centro Universitário das Faculdades Associadas de Ensino (UNIFAE), São João da Boa Vista, São Paulo.

Palavras-chave: Diabetes Mellitus, Neuropatia Diabética, Neuropatia Autonômica Cardiovascular.

\section{INTRODUÇÃO}

O Diabetes Mellitus (DM) é uma doença metabólica conhecida por ter várias complicações, entre elas, as Neuropatias Autonômicas (NA). Elas são um conjunto de desordens que afetam as fibras nervosas amielínicas do Sistema Nervoso Periférico (SNP) e podem acometer os sistemas gastrointestinal, cardiovascular, urogenital, a motilidade da pupila e a função sudomotora (NASCIMENTO OJM, et al. 2016). Em especial, a Neuropatia Autonômica Cardiovascular (NAC) causa modificações no funcionamento cardíaco e possui uma prevalência variável entre os tipos de DM: até $91 \%$ dos pacientes com DM tipo 1 podem apresentar a complicação, enquanto que no DM tipo 2, esse número alterna entre 25\% a 75\% (AGASHE S e PETAK S, 2018).

\section{OBJETIVO}

Revisar a literatura acerca dos estudos recentes sobre a neuropatia autonômica cardiovascular em pacientes com Diabetes Mellitus, a fim de compreender a fisiopatologia dessa complicação e as principais manifestações clínicas encontradas nesses indivíduos.

\section{REVISÃO BIBLIOGRÁFICA}

Os resultados encontrados até o momento informam que a fisiopatologia da NAC em pacientes com DM é multifatorial. Em geral, considera-se que a hiperglicemia seja a razão primária por estimular o estresse oxidativo, causando, assim, uma disfunção que leva a morte neural. Por ora, sabe-se que a NAC acomete o sistema nervoso autônomo parassimpático e simpático. A princípio, ocorre o aumento da frequência cardíaca em repouso, enfraquecimento do tônus parassimpático e posteriormente a desnervação simpática do coração (AGASHE S e PETAK S, 2018). 
Além disso, os resultados preliminares evidenciam que as manifestações clínicas da NAC no DM variam de acordo com o tempo de instalação da doença. Podem acontecer em uma ou demais formas, como: diminuição da variabilidade da Frequência Cardíaca (FC) em fase subclínica; taquicardia em repouso ou FC fixa; intolerância aos esforços; instabilidade cardiovascular intraoperatória; hipotensão pós-prandial; hipotensão ortostática relacionada a danos autonômicos irreversíveis; taquicardia em ortostatismo; isquemia miocárdica silenciosa; aumento do intervalo QT em episódios de hipoglicemia noturna; arritmias graves e morte súbita (LOZANO T e ENA J, 2017).

\section{CONSIDERAÇÕES FINAIS}

Portanto, é possível concluir até o momento que a NAC é uma das causas principais da morbimortalidade no DM. Sua fisiopatologia necessita de mais estudos, sobretudo para aperfeiçoar as formas de tratamento de suas manifestações, que variam desde intolerância aos esforços, até a hipotensão ortostática. Assim, compreender a fisiopatologia e as manifestações clínicas da NAC é essencial para aumentar a sobrevida e, principalmente, a qualidade de vida dos pacientes diabéticos.

\section{REFERÊNCIAS}

AGASHE S, PETAK S. Cardiac Autonomic Neuropathy in Diabetes Mellitus. Metodista Debakey Cardiovasc J, 2018; 14(4): 251-256.

LOZANO T, ENA J. Neuropatía autonómica cardiovascular en pacientes con diabetes mellitus. Revista Clínica Española, 2017; 217(1): 46-54.

NASCIMENTO OJM, et al. Diabetic neuropathy. Revista Dor, 2016; 17(suppl. 1): 46-51. 
055 | RESUMOS SIMPLES: Revisão Bibliográfica

\section{Recomendações sobre o aleitamento materno no enfrentamento ao COVID-19}

Autor/coautores: Maria Beatriz Falcão Pinto, Lorena Ribeiro de Carvalho, Sandra Hipólito Cavalcanti.

Instituição: Faculdade Pernambucana de Saúde (FPS), Recife - Pernambuco.

Palavras-chave: Amamentação, Coronavírus, Breastfeeding.

\section{INTRODUÇÃO}

O aleitamento materno é uma estratégia de vínculo, afeto, proteção e nutrição para o bebê que influencia na redução da morbimortalidade infantil (CARRASCO FJF, et al.,2020). A Organização Mundial de Saúde, preconiza o aleitamento materno exclusivo nos primeiros seis meses de vida, podendo ser complementado até dois anos ou mais. O leite materno possui todos os nutrientes necessários para o crescimento e desenvolvimento adequado do recém-nascido (WORLD HEALTH ORGANIZATION, 2017). Contudo, com a pandemia do novo coronavírus/covid-19, surgiram questionamentos sobre sua transmissibilidade através do leite materno.

\section{OBJETIVO}

Estabelecer as recomendações do aleitamento materno no enfretamento ao COVID-19, revisando as orientações e cuidados de biossegurança das formas de transmissão do vírus através de evidências científicas em artigos atualizados.

\section{MÉTODO}

Trata-se de um estudo de Revisão de Literatura com bases de dados PubMed, Biblioteca Virtual em Saúde, Scientific Electronic Library e Protocolos do Ministério da Saúde. Inclui artigos completos relacionados ao tema, publicados em 2017 e 2020, com Descritores em Ciência da Saúde: "amamentação, coronavírus e breastfeeding", onde excluiu-se artigos incompletos e sem relação com o tema.

\section{RESULTADOS E DISCUSSÃO}

Os resultados encontrados nos artigos pesquisados não evidenciam a transmissibilidade do coronavírus da mãe para o filho através do leite materno. Portanto, a transmissão por gotículas pode ocorrer no ato de amamentar, sendo necessário e recomendado a utilização de precauções 
pela mãe com suspeita ou confirmação do covid-19, que inclui a higienização das mãos, com posterior uso do álcool à $70 \%$ e uso de máscara facial, garantindo assim, os cuidados de biossegurança (CARRASCO FJF, et al., 2020).

Segundo a Sociedade Brasileira de Pediatria, as mães que desejarem amamentar, devem seguir as orientações de proteção, quanto àquelas que não se sentirem a vontade em colocar seu filho no peito, é recomendado a extração manual ou com ordenhadeira elétrica (seguindo os cuidados higiênicos-sanitário) e oferecer ao recém-nascido por técnica adequada através de copinho, colher ou xícara, pela própria mãe ou acompanhante saudável (com uso de adequado da parametação e após alta hospitalar) (SBP, 2020).

\section{CONSIDERAÇÕES FINAIS}

A pesquisa revelou que a amamentação é uma importante estratégia para a saúde do recémnascido mesmo na situação atual, por proporcionar o desenvolvimento saudável ao longo da vida e ainda atuar na redução da taxa de morbimortalidade infantil. Foi visto que, os benefícios da amamentação superam quaisquer riscos quanto a transmissão do covid-19, podendo ser ofertado com total segurança, sendo necessário ressaltar sempre as normas de biossegurança.

\section{REFERÊNCIAS}

CARRASCO FJF, et al. Infección por coronavirus Covid-19 lactancia maternal: una revision exploratoria. Rev Esp Salud Publica, 2020; 94:e202005055.

SOCIEDADE BRASILEIRA DE PEDIATRIA (SBP). Nota de alerta: o aleitamento materno nos tempos de COVID-19! [Internet]. Rio de Janeiro: SBP; 2020.

WORLD HEALTH ORGANIZATION. Guideline: protecting, promoting and supporting breastfeeding in facilities providing maternity and newborn services, Geneva, 2017. 
056 | RESUMOS SIMPLES: Revisão Bibliográfica

\section{Fakes news em saúde na pandemia de COVID-19: Uma revisão da literatura}

Autor/coautores: Robson Muniz Barreto da Cruz Souza, Rebeca Fernandes de Deus, Rosa

Stephanny Melquides Lima, Suzane Ferreira da Costa e Thaís Ranielle Souza de Oliveira.

Instituição: Centro Universitário Unieuro (UNIEURO), Brasília-Distrito Federal.

Palavras-chave: Fake news, Coronavírus, Pandemia.

\section{INTRODUÇÃO}

Com a pandemia de COVID-19, medos e incertezas se instauraram na população. Nesse contexto, as fakes news, outra adversária da saúde pública, se intensificou dificultando o enfrentamento da doença (GELDENHUYS, 2020). Elas são disseminadas de diversas formas, em geral apresentam um texto afirmativo, fazendo com que as pessoas deixem de verificar as informações, acreditem e compartilhem a notícia falsa. Essas notícias espalham a desinformação entre a população, atrapalhando o trabalho dos órgãos envolvidos no controle do novo vírus (SOUZA J, et al., 2020). Diante esse cenário, é natural que haja preocupação científica, a fim de alertar a população sobre os perigos das fake news.

\section{OBJETIVO}

Analisar o aumento de publicações relacionados às fake news em saúde na pandemia da COVID-19 durante a primeira metade de 2020, identificando os principais temas abordados entre os artigos selecionados.

\section{MÉTODO}

Foi realizado um estudo de revisão bibliográfica para quantificar artigos sobre fake news em saúde na pandemia de COVID 19. Pesquisou-se artigos publicados entre janeiro e junho de 2020, no Google Acadêmico, com descritores Fake News e corona vírus, totalizando 15 publicações. Critérios de inclusão: idioma português e data.

\section{RESULTADOS E DISCUSSÃO}

Foram contabilizadas 15 publicações, classificadas por data, 2 artigos foram publicados no mês de março, 5 no mês de abril e 8 no mês de maio, isto é, observa-se um aumento na quantidade de publicações durante os meses. A concentração das publicações no período segue a data oficial de 
chegada do vírus no país, em março de 2020. Assim, ficou demonstrado a importância do tema nesta de pandemia. Os artigos foram divididos nas seguintes categorias: Disseminação de fake news em saúde (5 artigos); Busca e importância da ciência na pandemia (7 artigos); fake news associada à política e saúde na pandemia (3 artigos).

\section{CONSIDERAÇÕES FINAIS}

O crescente aumento de publicações em saúde com a associação as fakes news demonstra a preocupação sobre tema, bem como seus impactos, mesmo que indireto na saúde. A classe científica tem se empenhado para produzir informações, objetivando a conscientização e sensibilização dessa população. A propagação de notícias falsas dificulta a correta prevenção da pandemia.

\section{REFERÊNCIAS}

GELDENHUYS, K. Disinformation spreads faster than the real threat. Servamus Community-based Safety and Security Magazine, v. 113, n. 6, p. 34-36, 2020.

SOUSA JJH, et al. Da Desinformação ao Caos: uma análise das Fake News frente à pandemia do Coronavírus (COVID-19) no Brasil. Cadernos de Prospecção, Salvador, v. 13, n. 2, p. 331-346, abr. 2020. 
057 | RESUMO SIMPLES: Revisão Bibliográfica

\section{As implicações do uso de cigarros eletrônicos no tratamento contra o tabagismo}

Autor/coautores: Vitória Leite Silva, Tayná Beato Ferreira, Francielle Bianca Moreira de Mesquita, Ruan Teixeira Lessa, Artur Laizo.

Instituição: Centro Universitário Presidente Antônio Carlos (UNIPAC), Juiz de Fora - Minas Gerais. Palavras-chave: Sistemas Eletrônicos de Liberação de Nicotina, Vaping, Tabagismo.

\section{INTRODUÇÃO}

A Organização Mundial da Saúde (OMS) afirma: o tabagismo é a principal causa de morte evitável no mundo. O cigarro eletrônico (CE) ou vaporizador pessoal é um dispositivo movido à bateria que produz uma sensação semelhante ao fumo do tabaco. Os CEs produzem um aerossol, chamado vapor, ao contrário da fumaça de cigarro, que o usuário inala. Comumente, os vaporizadores são utilizados por muitos tabagistas para fins terapêuticos ou não, e possuem um elemento de aquecimento que atomiza uma solução conhecida como líquido eletrônico. Geralmente esse líquido contêm uma mistura de propileno glicol, glicerina, nicotina e aromas, caracterizando os elementos constitutivos do cigarro eletrônico (YU V, et al., 2015).

\section{OBJETIVO}

Averiguar e apontar os efeitos e consequências acerca da aplicabilidade do uso de cigarros eletrônicos no tratamento de tabagistas de curto e longo prazo; e a sua complexa relação com os usuários.

\section{REVISÃO BIBLIOGRÁFICA}

O cigarro eletrônico contendo ou não nicotina permanece citotóxico para células epiteliais, demonstrando viabilidade celular reduzida, concomitantemente às altas taxas de apoptose e necrose independente do conteúdo de nicotina do vapor do CE (YU V, et al., 2015). Em uma pesquisa avaliativa acerca do conhecimento errôneo sobre o uso de CEs, foi verificado que $50 \%$ dos entrevistados consideravam os vaporizadores inofensivos quanto ao possível aparecimento de cânceres de pulmão e bexiga, assim como, prejuízos nos sistemas respiratório e cardiovascular. $65 \%$ desse mesmo grupo os julgavam não viciantes (AGHAR H, et al., 2020). Um outro estudo denotou que usuários de cigarro eletrônico, o apontaram como uma boa substituição do cigarro 
convencional, porém temiam que ele viesse a ser um novo vício. Além disso, o CE pode estar relacionado a um afastamento do tratamento adequado (QUELOZ S e ETTER JF, 2019).

\section{CONSIDERAÇÕES FINAIS}

Os fumantes relatam o uso de CEs para reduzir os riscos de fumar. Ademais, ainda existe desconhecimento referente aos malefícios do uso de vaporizadores por parte de fumantes e não fumantes; e divergência, no que diz respeito a sua funcionalidade para o tratamento.

\section{REFERÊNCIAS}

YU V, et al. Electronic cigarettes induce DNA strand breaks and cell death independently of nicotine in cell lines. Oral oncology, 2015: (52) 58-65.

AGHAR $\mathrm{H}$, et al. Knowledge and attitudes towards E-cigarette use in Lebanon and their associated factors. BioMed Central Public Health, 2020; 20(1): 1-18.

QUELOZ S, ETTER JF. An online survey of users of tobacco vaporizers, reasons and modes of utilization, perceived advantages and perceived risks. BioMed Central Public Health, 2019; 19(1): 642. 
058 | RESUMOS SIMPLES: Revisão Bibliográfica

\section{Atuação da enfermagem na assistência em urgência e emergência à motociclistas vítimas de traumatismo cranioencefálico}

Autor/coautores: Nayanne Victória Sousa Batista; Thaysa Clébia de Souza Oliveira; Jamille Almeida Alves Bezerra; Kalyane Kelly Duarte de Oliveira; Cândido Nogueira Bessa.

Instituição: Universidade do Estado do Rio Grande do Norte - UERN, Pau dos Ferros-Rio Grande do Norte.

Palavras-chave: Enfermagem, Assistência, Motociclistas.

\section{INTRODUÇÃO}

Os acidentes de trânsito configuram-se como um importante problema de saúde pública, sendo uma das principais causas de mortes no mundo. Os acidentes motociclísticos possuem grande magnitude e transcendência (LESSA RPR, 2018). Estes podem ser decorrentes do aumento e grande aceitação deste veículo, custo acessível e rapidez, porém possuem baixas condições de proteção em caso de colisão ou queda, podendo causar traumas como o Traumatismo Craniocerebral ou cranioencefálico (TCE) (SILVA RF e PAIVA ARO, 2017). Salienta-se que os serviços de Urgência e Emergência exigem que a equipe de enfermagem promova atendimento dinâmico em curto tempo, a fim de salvar a vida do cliente ou restaurar seu equilíbrio orgânico mais prontamente possível.

\section{OBJETIVO}

Descrever o panorama da produção científica brasileira acerca da assistência de enfermagem nas urgências e emergências de motociclistas com traumatismos craniocerebrais.

\section{REVISÃO BIBLIOGRÁFICA}

$\mathrm{Na}$ Biblioteca Virtual em Saúde (BVS), foram utilizados os descritores "Urgência" OR "Emergência" AND "Traumatismo Craniocerebral" AND "Acidentes de Trânsito" associados com os operadores booleanos. Quando associados, os resultados revelaram 133 documentos disponíveis. Ao aplicar o critério de inclusão "texto completo", foram reduzidos para 47 e após aplicar "idioma na língua portuguesa", decaiu para 13, sendo extraídos para leitura flutuante. Após leitura, foram selecionados 09 documentos. 
Os resultados apontaram que $90 \%$ dos documentos fazem parte da grande área Enfermagem, $90 \%$ desenvolvidos na ótica quantitativa e 10\% qualitativa. Com relação a assistência de enfermagem nas urgências e emergências de motociclistas com TCE, foi possível observar que $60 \%$ realizam assistência com ênfase na monitorização, controle, administração de medicamentos conforme prescrição médica, realizam curativos, aspirações e contenções hemorrágicas. $20 \%$ atuam na educação em saúde e $20 \%$ realizam orientação e suporte as famílias das vítimas.

Ainda foi possível observar que os fatores causais que desencadeiam o TCE estão intimamente relacionados com imprudência no trânsito provenientes de drogas lícitas e ilícitas, bem como ao não uso de equipamentos protetivos e grande número de motocicletas.

\section{CONSIDERAÇÕES FINAIS}

Diante deste estudo, percebe-se que é necessário investir mais em educação no trânsito, reforçando as medidas educativas em toda rede assistencial. A assistência em enfermagem diante do TCE é a mesma direcionada para toda assistência ao trauma, diferenciando-se apenas pela complexidade. Considera-se ainda que o aumento de motocicletas, uso de substâncias psicoativas e a falta de proteção, como o capacete, estão entre as causas principais de acometimento de TCE.

\section{REFERÊNCIAS}

LESSA RPS. Perfil dos acidentes com motocicletas no município de São Felipe-Bahia, 2017. Trabalho de conclusão de Curso (monografia), Faculdade Maria Milza (FAMAM), 2018.

SILVA RF, PAIVA ARO. Incidência de acidentes com motocicletas no Brasil: Revisão integrativa da literatura. Revista Uningá, v. 51, n. 3, 2017. 
059 | RESUMOS SIMPLES: Estudo Original

\section{Proposta de modelagem molecular da Isotretinoína através de programas de química computacional}

Autor/coautores: Camila Cristina da Silva Miranda1, Victor Alexandre Cardoso Salazar2, Helena Rayssa Sousa Lima ${ }^{3}$, Kayo Duarte Oliveira ${ }^{4}$, Cristiano Ribeiro Goçalves Affonso ${ }^{5}$.

Instituição: $122{ }^{4}{ }^{4}$ Centro Universitário Facid (UNIFACID) Teresina-Piauí; ${ }^{5}$ Universidade Federal do Piauí (UFPI) Teresina-Piauí

Palavras-chave: Isotretinoína; Química computacional; Química medicinal.

\section{INTRODUÇÃO}

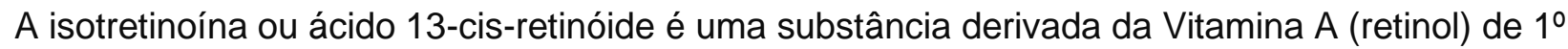
geração, sendo utilizado de forma sistêmica ou tópica. Sua aplicação clínica abrange o tratamento da acne inflamatória grave, dos tipos cística e conglobata (MENDES VS, et al., 2016). A Isotretinoína, por sua vez, tem função sebostática e possui efeito na queratinização folicular. $O$ principal mecanismo de ação da isotretinoína ocorre na glândula sebácea, reduzindo seu tamanho, atividade e quantidade de sebo (FERNANDES VQ, et al., 2020). A isotretinoína e seus metabólitos possuem características altamente lipofílicas, conseguindo atravessar a placenta com facilidade, tornando-se um agente embriotóxico e com potencial teratogênico (ALSHAMMARI SA, et al., 2020).

\section{OBJETIVO}

Propor modificações moleculares, a fim de otimizar propriedades físico-químicas, farmacocinéticas e toxicológicas da Isotretinoína - principalmente sua lipoficidade - demostrando procedimentos e técnicas computacionais empregados no planejamento e desenvolvimento de fármacos em programas gratuitos.

\section{MÉTODO}

As propostas foram renomeadas para ISOP1 e ISOP2, baseando-se em substituição de átomos e/ou ligações duplas. Utilizou-se os programas gratuitos: ACD/ChemSketch Freeware 14.01, para design do fármaco original e congênere; Marvin Sketch 6.2.2, a fim de se análisar as propriedades fisico-químicas; PreADMET 2.0 para propriedades farmacocinéticas (capacidade em atravessar a barreira hematoencefálica, taxa de absorção do fármaco, excreção) e o Osíris Property Explorer apresentando características toxicológicas in silico. 


\section{RESULTADOS E DISCUSSÃO}

A Isotretinoína apresenta massa 300,2 Dalton, LogP 5,75 e doadores/aceptores de hidrogênio igual a $1 / 2$. A ISOP1 apresentou significativa mudança no LogP, indo para o valor 4,98. Os demais parâmetros não mostraram grande variação. Quanto a farmacocinética do protótipo, a capacidade de atravessar a barreira hematoencéfalica (BHE) equivale 3.88; Caco2 (taxa de absorção) 22.89 e MDCK (taxa de excreção) 39.99. A ISOP1 e ISOP2 mostraram relevante mudança no valor de BHE 1.59 e 12.24, respectivamente. Um dos dados referentes ao programa Osíris apresenta valor de LogP alto, o que pode caracterizar certo potencial tóxico ao fármaco, quesito esse modificado e melhorado posteriormente nos congêneres.

\section{CONSIDERAÇÕES FINAIS}

Diante do exposto, as propostas apresentaram certa variação nas características farmacocinéticas e toxicológicas da Isotretinoína. Houve maiores alterações na lipofilicidade e entrada na barreira hematoencefálica, fatos que influem diretamente na ação terapêutica. Com isso, ambos análogos alcançaram o objetivo proposto para sua otimização. No entanto, ainda é necessário maiores estudos, uma vez que se trata de um estudo in silico preliminar.

\section{REFERÊNCIAS}

ALSHAMMARI SA, et al. Prevalence and associated risk factors of acne relapse among Saudi acnevulgaris patients using isotretinoin Saudi Pharmaceutical Journal (2020); 28: e374.

FERNANDES VQ, et al. Determination of isotretinoin (13-cis-retinoic acid) using a sensor basedon reduced graphene oxide modified with copper nanoparticles. Journal of Electroanalytical Chemistry, 2020; 856; e113692.

MENDES VS, et al. Efeitos do uso da Isotretinoína e Acitretina nos tecidos bucais - Revisão de Literatura. Arquivo Brasileiro de Odontologia, 2016; 12 (1). 
060 | RESUMOS SIMPLES: Estudo Original

\section{HIV/AIDS e o público feminino: prevalência em município de referência no Oeste da Bahia}

Autor/coautores: Alialdo Dantas Damascena'; Lisiane Cristine Welzel².

Instituição: 'Universidade Federal do Oeste da Bahia; 'Universidade Regional do Noroeste do Estado do Rio Grande do Sul.

Palavras-chave: Doenças Sexualmente Transmissíveis, Infecções por HIV, Saúde da Mulher.

\section{INTRODUÇÃO}

Desde a pandemia do HIV no Brasil na década de 80, o vírus passou por um processo de transformação biológica e social. Prova disso é o aumento do número de heterossexuais contaminados atualmente em relação ao início da pandemia, principalmente mulheres (BARBOSA GP, et al., 2019). Conviver com o vírus torna a mulher passível de violência em diferentes formas, seja ela culpabilização, estigma social e preconceito nos estabelecimentos de saúde (STEFANINI JR, et al., 2020) e desgastes quanto a uma possível maternidade (SANTANA AF, 2020). Diante disso, torna-se necessário quantificar o número de mulheres vivendo com HIV em um município de referência no Oeste da Bahia.

\section{OBJETIVO}

Analisar a prevalência de casos registrados de HIV e AIDS em mulheres ao longo da última década em um município de referência regional em saúde no oeste do estado da Bahia.

\section{MÉTODO}

Os dados apresentados foram retirados dos "Indicadores e Dados Básicos da Sífilis nos Municípios Brasileiros", base de dados pública do Departamento de Doenças de Condições Crônicas e Infecções Sexualmente Transmissíveis do Ministério da Saúde. Foram colhidas informações referentes a um município de referência em saúde para a região Oeste da Bahia -, a fim de analisar a quantidade de casos de HIV em mulheres nos últimos 10 anos.

\section{RESULTADOS E DISCUSSÃO}

O município contabilizou - entre 2010 e 2019 - um total de 249 casos de AIDS registrados no SINAN, destes, as mulheres correspondiam a 84 casos, cerca de $34 \%$ dos casos. Essa taxa dobrou de 5 casos em 2010 para 12 casos em 2018, evidenciando a tendência de feminização e 
interiorização dos casos de HIV e AIDS no país. No mesmo período, 20 destas mulheres estavam gestantes e, boa parte dessas mulheres só toma conhecimento do seu status soropositivo no momento do parto, aumentando as taxas de transmissão vertical no país e gerando a impossibilidade de amamentação para o recém-nascido.

\section{CONSIDERAÇÕES FINAIS}

Apesar da infecção por HIV ou quadro de AIDS serem de notificação compulsória no país, ambas tem figurado em número significativos, especialmente entre as mulheres, tornando-as estigmatizadas e socialmente ostracizadas. Diante disso, se torna necessário o estímulo a um debate sobre saúde da mulher nos diferentes serviços de saúde, incluindo a educação sexual e planejamento familiar, a fim de que as taxas de mulheres infectadas possam ser reduzidas futuramente.

\section{REFERÊNCIAS}

BARBOSA GP, et al. A sexualidade de mulheres com HIV/ Aids: uma revisão integrativa. Revista Interdisciplinar, v. 12, n. 1, jan. - mar. 2019.

SANTANA AF. NÃO ALEITAMENTO MATERNO EM MULHERES SOROPOSITIVAS. Revista Eixos Tech, v. 6, n. 1, mar. 2020.

STEFANINI JR, et al. Violência por parceiro íntimo em mulheres que vivem com HIV. Perspectivas Em Psicologia, v. 23, n. 2, jan. 2020. 
061 | RESUMOS SIMPLES: Revisão Sistemática

\section{Os efeitos terapêuticos do Allium sativum (alho) no sistema imunológico: uma revisão da literatura}

Autor/coautores: Amanda Silva de Almeida Santos; Drieli Ferreira Batista; Maria Beatriz Batista de Araújo; Maria Eduarda Santiago Costa; Diego Roberto da Cunha Pascoal.

Instituição: Universidade Católica do Salvador (UCSAL); Salvador- Bahia.

Palavras-chave: Allium sativum, Alho, Imunoestimulador.

\section{INTRODUÇÃO}

As medidas antes consideradas tradicionais, como o uso de alimentos e seus benefícios, atualmente difundem os processos de prevenção/tratamento de afecções (CRUZ et. al, 2019).

Dentre os alimentos que fortalecem o sistema imunológico, se destaca o alho (Allium sativum), devido seu alto valor nutritivo e por possuir compostos inorgânicos, como $23 \%$ de Manganês, $17 \%$ de vitamina B6, 15\% de vitamina $C$ da ingestão diária recomendada, além de quantidades significativas de cálcio, potássio, ferro e vitamina B1 (ANVISA, 2015).

Ademais, o alho possui ação antiviral, antifúngica, antibiótica e antioxidante. Seus compostos possuem atividade hipotensora, hipoglicemiante, imunoestimuladora, anticancerígena, antidiabética e cardioprotetora (KUETE, 2017).

\section{OBJETIVO}

Revisar as vantagens do uso de Allium s. como alimento, bem como seu potencial no fortalecimento do sistema imune.

\section{MÉTODO}

A partir de uma revisão da literatura pelas plataformas de periódicos MEDLINE e SciELO, na língua portuguesa e inglesa. Como critério de inclusão considerou-se publicações no período máximo de 20 anos, usando como palavras chaves: "garlic", "alho", "Allium sativum", e "sistema imunológico". Foram encontrados 291 artigos, e excluídos os que se distanciavam do objetivo do estudo. 


\section{RESULTADOS E DISCUSSÃO}

O alho detém constituintes vantajosos para o tratamento/prevenção de doenças e sintomatologias associadas. É um dos alimentos que mais possui compostos organosulfurados, ou seja, compostos prevalentemente orgânicos, com pelo menos uma ligação covalente carbonoenxofre, destacando-se a alicina (ANVISA, 2015). Um fitoquímico com ação anti-inflamatória, hipotensora, além de antibiótica, antifúngica e antiviral, adjutora no combate a infecções por microrganismos (CRUZ, et al., 2019).

Como consequência do uso do alho, foi relatada a estimulação imunológica no que diz respeito a contagem de glóbulos brancos e melhora das células da medula óssea devido os compostos organosulfurados, seja na forma encapsulada ou em óleo. Complementarmente, verificou-se a capacidade de eliminar oxidantes e impedir a formação de mensageiros pró-inflamatórios. O extrato de alho demonstrou ampla atividade no auxílio a doenças inflamatórias, inibindo Th1 e suas citocinas $O$ alho também demonstrou atividade antimicrobiana contra espécies intestinais patogênicas como: Shigella dysenteriae, Staphylococcus aureus e Escherichia coli (KUETE, 2017).

Neste sentido, entende-se a importância do consumo do alho, visando a capacidade de atuação no organismo, melhor aproveitamento das substâncias e, potencialização dos efeitos terapêuticos.

\section{CONSIDERAÇÕES FINAIS}

Observa-se que o combate aos microrganismos, a ação terapêutica e, sobretudo, imunológica, compõem os principais efeitos curativos que o Allium sativum exerce ao organismo humano. Assim, o objetivo da revisão foi alcançado, visto que os indícios na literatura reforçam a ação do alho de fortalecimento do sistema imunológico.

\section{REFERÊNCIAS}

CRUZ, et al. Uma abordagem da importância do alho (Allium sativum) no sistema imunológico. Revista Científica Multidisciplinar Núcleo do Conhecimento, 2019; v. 5: (65-71).

KUETE, V. Allium sativum. Medicinal Spices and Vegetables from Africa, 2017; (363-377).

MINISTÉRIO DA SAÚDE, ANVISA. Monografia da espécie Allium sativum (alho), 2015. 
062 | RESUMOS EXPANDIDOS: Revisão Bibliográfica

\section{Violência interparental e o processo de desenvolvimento infantil}

Autor/coautores: Matheus de Oliveira Silva; Matheus Augusto da Silva Belidio Louzada; Priscila Cristina Pereira de Oliveira da Silva; Caroline Moraes Soares Motta de Carvalho; Antonio da Silva Ribeiro.

Instituição: Universidade Estácio de Sá (UNESA), Nova Iguaçu - Rio de Janeiro.

Palavras-chave: Criança, Violência doméstica, Desenvolvimento infantil.

\section{INTRODUÇÃO}

Os comprometimentos da violência para a saúde humana são intensos. Isto por existirem resultados negativos para os envolvidos e descrevem importante fonte de custo mundial para os sistemas de saúde. O conceito de violência envolve questões densas, mas, de modo geral, toda e qualquer prática que possua origem de força contra um indivíduo ou coletividade que resulte em danos, no presente ou futuro, é considerada violência. Quando inserida no ambiente familiar, a violência pode ser omissa, pois os familiares envolvidos não desejam que a comunidade vizinha a identifique. Como resultado, a exposição de filhos aos diferentes conflitos violentos entre seus pais é de difícil identificação (MARTINS PDN, et al., 2017).

\section{OBJETIVO}

Identificar mudanças no desenvolvimento infantil de crianças inseridas no contexto de violência interparental conjugal.

\section{REVISÃO BIBLIOGRÁFICA}

A violência interparental intensifica o estresse conjugal. Sob este viés, existe uma tendência em transmitir esse estresse para a relação com o filho, isto é, mães que enfrentam agressões podem vir a efetuar um controle extremamente rigoroso sobre seus filhos por enfrentar tamanho problema. O contexto de violência gera mudanças no sistema de apego interno dos pais. Portanto, nos períodos em que os filhos evidenciam uma profunda angústia pelo trauma de contemplar a violência, podem processar um mecanismo de evitação a seus sentimentos em favor do sofrimento próprio (JOURILES EN e MCDONALD R, 2015). 
Fatores como renda, escolaridade, etnia e raça influenciam em maior incidência de violência familiar. Embora não possuam perfeita discriminação, é possível considerar que os relacionamentos podem ser classificados em curtos, médios e longos quanto ao período de ocorrência de violência. Para os filhos, quanto maior é o tempo de exposição, mais difícil se torna o enfrentamento. Vivenciar as exposições revela significativo impedimento para o adequado desenvolvimento e para os relacionamentos interpessoais das crianças, pois origina grande vulnerabiliade à sua saúde mental (OVERBEEK MM, et al., 2017).

\section{CONSIDERAÇÕES FINAIS}

Em síntese, as crianças evolvidas em lares com violência interparental conjugal estão sujeitas à grandes vulnerabilidades biopsicossociais, pois enfrentam seus fortes impactos. É fundamental que profissionais de saúde e educadores, bem como os que de alguma maneira possam estar conectados à estas famílias, admitam o conhecimento dos prejuízos que partem das relações familiares conturbadas pela violência em direção ao desenvolvimento infantil.

\section{REFERÊNCIAS}

JOURILES EN, MCDONALD R. Intimate partner violence, coercive control, and child adjustment problems. J. Interpers. Violence, 2015; 30(3): pp.459-74.

MARTINS PDN, et al. Impacto da violência na saúde, família e trabalho no estado da Bahia, Brasil 2016. Revista ciencia, salud, educación y economia, 2017; 11: pp.20-31.

OVERBEEK MM, et al. Mediators and Treatment Factors in Intervention for Children Exposed to Interparental Violence. J. Clin. Child Adolesc. Psychol., 2017; 46(3): pp.411-427. 
063 | RESUMOS SIMPLES: Revisão Bibliográfica

\section{A Importância da biossegurança na odontologia em tempos do COVID-19}

Autor/coautores: Emily Míriam Araújo Taurino.

Instituição: Graduada pela UNINASSAU Recife-Pernambuco, CRO-PE 13443.

Palavras-chave: Biossegurança, Odontologia, Covid-19.

\section{INTRODUÇÃO}

Neste momento crítico do coronavírus (Covid-19), a informação é um aliado importante de como um cirurgião-dentista deve atuar na clínica odontológica. O alto risco de exposição a este, se faz necessário o reforço do uso adequado do equipamento de proteção individual (EPI). Visto que, a biossegurança vem processando-se de forma negligenciada há anos. A principal porta de entrada da infecção pelo vírus se dá por meio de transmissão direta através de vias respiratórias, mucosa oral e ocular, e indireta, exigindo assim, do cirurgião-dentista, postergar atendimentos eletivos e priorizar procedimentos de urgência e emergência odontológica (ADA, 2020).

\section{OBJETIVO}

Retratar a importância da biossegurança na odontologia em tempos do covid-19, bem como a modificação na rotina de atendimento no consultório odontológico, e como esta pode atenuar a contaminação cruzada.

\section{MÉTODO}

Consiste em uma revisão bibliográfica sistemática, com critérios de inclusão artigos publicados em português e inglês no período dos últimos quatro meses, utilizando-se os descritores "Biossegurança", Odontologia" e" Covid-19", com busca nas seguintes bases de dados: Google Acadêmico e SciELO, documentos legislativos e oficiais do Ministério da Saúde.

\section{RESULTADOS E DISCUSSÃO}

O SARS CoV-2 (COVID-19), possui um alto poder de transmissão, podendo ir desde casos leves a insuficiências respiratórias graves. Vale ressaltar que sua transmissibilidade ocorre por contato: pessoa-pessoa, tanto pelo ar e contato com secreções contaminadas (BRASIL, 2020). 
Em razão do elevado risco de exposição promovido pelo coronavírus aos dentistas, a fim de preservar a saúde do paciente e do profissional, demanda-se a necessidade do uso de cautelas e medidas no atendimento, realizando uma criteriosa triagem, para decidir o que é eletivo ou não.

Cabe ao Cirurgião dentista inserir protocolos de segurança, tais como: higienização das mãos seguindo as técnicas adequadas de assepsia e antissepsia, evitar o uso de caneta de alta rotação pois esta pode levar spray de aerossol por até um raio de 2 metros, seguir as orientações de segurança do uso do protocolo de epi, acrescentando-se o uso das máscaras N95, ou máscara cirúrgica e face shield e jaleco impermeável, protocolo do uso de bochechos de peróxido de hidrogênio a $1 \%$ ou iodopovina a $2 \%$ antes de cada atendimento (ZHANG W e JIANG X, 2020).

\section{CONSIDERAÇÕES FINAIS}

Conclui-se que diligências preventivas devem ser aplicadas com o propósito de reduzir a disseminação do vírus. Faz-se necessário refletir a importância da biossegurança praticada na graduação e levá-la para o consultório clínico quando profissional, que é negligenciada por muitos cirurgiões-dentistas.

\section{REFERÊNCIAS}

AMERICAN DENTAL ASSOCIATION. Covid-19 Resources for dentists, 2020.

BRASIL. Ministério da Saúde, Secretaria de Atenção Primária à Saúde. COVID-19: Atendimento odontológico no SUS. Brasília, DF: Ministério da Saúde; 2020.

ZHANG W, JIANG X. Measures and suggestions for the prevention and control of the novel coronavirus in dental institutions. Front Oral Maxillofac Med 2020. 
064 | RESUMOS SIMPLES: Revisão Bibliográfica

\section{O impacto da Síndrome de Burnout em enfermeiros do setor de urgência e emergência: uma revisão integrativa da literatura}

Autor/coautores: Dhayanna Cardoso Lima, lanny Caroline Mota de Melo, Zilma da Silva Campelo, Clerveson Lima da Costa, Ana Angelica Aparecida dos Santos Magalhães.Instituição: Singular Educacional

Palavras-chave: Burnout, Serviços médicos de emergência, Profissionais de enfermagem.

\section{INTRODUÇÃO}

A Síndrome de Burnout (SB) é definida pela dimensão exaustão emocional, constatada por sentimentos de fadiga, esgotamento físico e emocional; pela despersonalização, em que o indivíduo se distancia das relações interpessoais; e pela dimensão diminuída de realização profissional, em que o indivíduo supre sentimentos negativos de si mesmo (LIMA AS, et al., 2018). O trabalho no âmbito de urgência e emergência apresenta características próprias que podem ser propícias à SB. Ao verificar as atividades desenvolvidas, questões como a falta de tempo, grande quantidade de pacientes e a necessidade de agilidade das ações de enfermagem, faz com que o enfermeiro nesse setor esteja mais suscetível às questões relacionadas ao estresse (KOLHS M, et al., 2017).

\section{OBJETIVO}

Discorrer sobre o impacto da Síndrome de Burnout em enfermeiros do setor de urgência e emergência.

\section{MÉTODO}

Trata-se de uma revisão integrativa da literatura, buscando discorrer sobre o impacto da Síndrome de Burnout em enfermeiros do setor de urgência e emergência. A pesquisa bibliográfica foi consumada por meio de consulta nas bases de dados SciELO, LILACS e BDENF. Utilizaram-se os seguintes descritores: Burnout, serviços médicos de emergência, profissionais de enfermagem. Tal busca ocorreu nos meses de maio e junho de 2020.

\section{RESULTADOS E DISCUSSÃO}

Entre os sintomas da SB, a fadiga e a força física reduzidas são as queixas mais comuns, além de serem relacionadas à dor física, estresse e dores de cabeça, ocasionadas pela carga de trabalho 
excessiva. Em um estudo realizado em uma unidade de emergência de um hospital geral, identificou entre 80 profissionais de enfermagem, uma prevalência geral para transtornos mentais comuns de $26,3 \%$. Entre os enfermeiros, a prevalência foi de $53,3 \%$ e técnicos e auxiliares atingiu e $20 \%$ (AMARAL J, et al.,2015). O fator espaço físico do atendimento móvel de urgência - SAMU, é referido como inadequado, atribuído às ambulâncias, locais desfavorecidos onde os pacientes são pouco ventilados e com temperatura inadequada, além das pressões profissionais enfrentadas por esses profissionais em determinadas situações, podendo levar a problemas de saúde ou acidentes de trabalho (WORM F, et al., 2016).

\section{CONSIDERAÇÕES FINAIS}

O presente estudo proporcionou uma visualização a respeito do impacto da Síndrome de Burnout em enfermeiros do setor de urgência e emergência. A partir da leitura se confirma que o enfermeiro emergencista é bastante propenso a ser afetado pela SB e os fatores relacionados ao seu trabalho impulsionam doenças psíquicas afetando na qualidade de vida do profissional da saúde.

\section{REFERÊNCIAS}

AMARAL J, et al. Qualidade de vida no trabalho dos profissionais de enfermagem em ambiente hospitalar: uma revisão integrativa. Revista Espaço Para A Saúde, Londrina, v. 16, n. 1, p. 66-74, mar. 2015.

LIMA AS, et al. Análise da prevalência da síndrome de burnout em profissionais da atenção primária em saúde. Trab. educ. saúde, Rio de Janeiro, v. 16, n. 1, p. 283-304, Abr. 2018.

KOLHS, $M$ et al. A enfermagem na urgência e emergência: entre o prazer e o sofrimento. Revista de pesquisa: Cuidado é fundamental online. v. 9 pag 422-431 abr/jun 2017.

WORM FA, et al. Risco de adoecimento dos profissionais de enfermagem no trabalho em atendimento móvel de urgência. Rev Cuid, Bucaramanga, v. 7, n. 2, p. 1279-1287, Dez. 2016. 
065 | RESUMOS SIMPLES: Revisão Bibliográfica

\section{A relevância do exame citopatológico em mulheres lésbicas e bissexuais o conhecimento sobre os riscos das infecções sexualmente transmissíveis}

Autor/coautores: Maria Beatriz Falcão Pinto, Raila Gonçalves dos Santos; Tuanny Caroline Pereira de Santana; Maria Eduarda da Silva Valentino Ferreira; Joanna Francyne Silva de Barros. Instituição: Faculdade Pernambucana de Saúde (FPS), Recife-Pernambuco.

Palavras-chave: Teste de Papanicolau, Doenças Sexualmente Transmissíveis, Minorias Sexuais e de Gênero.

\section{INTRODUÇÃO}

O exame Citopatológico também conhecido como exame Papanicolau, tem como objetivo a detecção precoce de lesões no colo do útero, pois quando encontradas precocemente, pode-se intervir e alcançar melhores resultados (BRASIL, 2016). Tem o intuito de alcançar maior número de mulheres minimizando a incidência do câncer de colo de útero (BRASIL, 2020). A prevenção também ocorre através da diminuição do contágio pelo papilomavírus humano (HPV), transmitido por via sexual, consequentemente o uso de preservativo protege o contágio pelo HPV, assim como a prevalência de Infecções Sexualmente Transmissíveis (IST's), nos grupo de vulnerabilidade, entre eles a população lésbica (ARAÚJO LM, et al., 2019).

\section{OBJETIVO}

Revisar a relevância do exame citopatológico em mulheres lésbicas e bissexuais, enfatizando o conhecimento dos riscos relacionados às infecções sexualmente transmissíveis.

\section{MÉTODO}

Trata-se de um estudo do tipo Revisão de literatura realizada na bases de dados PubMed, Biblioteca Virtual em Saúde e protocolos do Ministério da Saúde. Inclui 3 artigos completos relacionados ao tema, publicados de 2016 a 2020, através dos Descritores em Ciência da Saúde: "Teste de Papanicolau, Doenças Sexualmente Transmissíveis e Minorias Sexuais e de Gênero". Foram excluídos os artigos que não tem relação com o tema pesquisado. 


\section{RESULTADOS E DISCUSSÃO}

Os resultados encontrados revelam que, as lésbicas procuram menos o serviço de saúde devido aos altos índices de discriminação no atendimento, apresentando medo de sofrer qualquer tipo de violência e preconceito, além do despreparo dos profissionais para lidar com as especificidades do grupo, ainda citado a negação para risco de doenças sexuais e ginecológicas (ARAÚJO LM, et al., 2019 e BRASIL, 2016).

Além disso, as mulheres lésbicas e bissexuais, admitem serem imunes ao risco de contrair as IST's, pois acreditam que são decorrentes apenas da penetração vaginal, entre o pênis e vagina, tornando-se uma infecção exclusiva das relações heterossexuais. Por esse motivo, não utilizam métodos de prevenção para IST, por não acharem necessário, relacionando-o apenas ao risco de gravidez e não ao risco de contrair uma IST (ARAÚJO LM, et al., 2019).

\section{CONSIDERAÇÕES FINAIS}

Conclui-se então, a importância de compreender a necessidade do exame, assim como os benefícios advindos a ele, bem como a utilização de métodos contra as IST's, orientando a forma de transmissão e os devidos cuidados, livre de julgamentos e preconceitos, assegurando um atendimento acolhedor e humanizado, de forma a ajudar as necessidades específicas da saúde sexual, sendo o preparo dos profissionais de fundamental importância para propiciar as quebras da comunicação.

\section{REFERÊNCIAS}

ARAÚJO LM, PENNA LHG, CARINHANHA JI, COSTA CMA. O cuidado às mulheres lésbicas no campo de saúde sexual e reprodutiva. Rev enferm UERJ, Rio de Janeiro, 2019; $27:$ 34262.

BRASIL. Ministério da Saúde. Instituto Nacional de Câncer. Prevenção do Câncer do Colo do Útero. 2020.

BRASIL. Ministério da Saúde. Protocolos da Atenção Básica: Saúde das Mulheres / Ministério da Saúde, Instituto Sírio-Libanês de Ensino e Pesquisa - Brasília: Ministério da Saúde, 2016. 
066 | RESUMOS SIMPLES: Revisão Bibliográfica

\title{
Processo de imunização no controle de doenças epidêmicas
}

\author{
Autor/coautores: Cryshna Leticia Kirchesch \\ Instituição: Universidade Federal de Pelotas (UFPel), Pelotas - Rio Grande do Sul. \\ Palavras-chave: Imunização, Epidemia, Promoção à Saúde.
}

\section{INTRODUÇÃO}

Em meio a epidemias, observa-se a necessidade de reorganização das ações de saúde do território, devido ao elevado número de casos de infectados em um curto período de tempo. Desenvolvem-se ações de coletividade voltadas às práticas não-farmacológicas, orientando a população sobre medidas preventivas, e investe-se em pesquisas na busca de novos medicamentos e vacinas (ABREU LC, 2020). As ações de imunização possuem uma boa relação custo/efetividade no setor saúde e o declínio acelerado da mortalidade por doenças imunopreveníveis nas décadas recentes, em nosso país e em escala mundial, serve de prova incontestável do benefício que é oferecido às populações através das vacinações (REIS NM, et al., 2020).

\section{OBJETIVO}

Identificar as vantagens e a importância das ações de imunização no controle de doenças epidêmicas.

\section{REVISÃO BIBLIOGRÁFICA}

No decorrer da história, observam-se grandes avanços na saúde brasileira, como a erradicação das doenças epidêmicas de varíola e poliomelite, bem como o controle de outras doenças infectocontagiosas obtidas por meio das ações de imunização. Durante a pandemia em 2009, a vacinação contra o vírus influenza foi capaz de reduzir o agravamento da doença e segue como estratégia de prevenção na rede pública até a atualidade. Já na pandemia da COVID-19, as vacinas ainda se encontram em fase de testes. No entanto, as ações de imunização devem ser reforçadas e organizadas por fluxos de atendimentos (RODRIGUES RR, et al., 2019).

Atualmente, são disponibilizadas 19 vacinas para mais de 20 doenças. O Calendário Nacional de Vacinação, abrange todos os públicos, como crianças, adolescentes, adultos, idosos, gestantes, trabalhadores da saúde e povos indígenas. A vacinação tem como vantagem ser um processo de 
baixo custo e alta efetividade, e como importância, evita milhões de mortes por ano e eleva a perspectiva de vida da população (REIS NM, et al., 2020).

\section{CONSIDERAÇÕES FINAIS}

Por meio da imunização, complicações de saúde podem ser evitadas, principalmente no que concerne aos grupos de maior exposição e menor competência imunológica. Sendo assim, é preciso sensibilizar a população para aumentar a adesão as campanhas de vacinação, visto que essa já tem sua trajetória de sucesso na área da saúde consolidada.

\section{REFERÊNCIAS}

ABREU LC. Ações integradas e o fortalecimento do Sistema Público de Saúde Brasileiro em tempos de pandemias. J Hum Growth Dev, 2020; 30(1):05-08.

REIS NM, et al. Inovações tecnológicas na relevância da vacinação no combate as doenças imunopreveníveis: um relato de experiência. Revista Eletrônica Acervo Enfermagem, 2020; 40: e2241.

RODRIGUES RR, et al. A síndrome respiratória aguda e a importância da imunização contra h1n1. Brazilian Applied Science Review, 2019; 3(5): 2149-2161. 
067 | RESUMOS SIMPLES: Revisão Bibliográfica

\section{Epidemiologia da mortalidade por agressões em idosos no município de Juiz de Fora - MG}

Autor/coautores: Beatriz Pereira Barioni; Anna Flávia Silva do Nascimento; Andyara do Carmo Pinto Coelho Paiva; Thaís Vasconselos Amorim; Adélia Dayane Guimarães Fonseca Instituição: Universidade Federal de Juiz de Fora (UFJF), Minas Gerais, Brasil.

Financiamento: Recursos Próprios

Palavras-chave: Agressão, Idoso, Sistemas de Informação.

\section{INTRODUÇÃO}

O processo de inversão da pirâmide etária advindo da transição demográfica traz consigo problemas e agravos que desafiam os sistemas de saúde e de previdência social, dentre esses agravos há que se considerar a violência contra a pessoa idosa que constitui um agravo à saúde merecendo destaque em função do incremento no número de casos. A violência é considerada um fenômeno mundial e independe de religião, raça, recursos econômicos. O quantitativo relacionado a violência é preocupante e foi citado em Estudo de Minayo, realizado em 524 municípios brasileiros, revelando que $67,7 \%$ dos idosos já sofreram violência física e 29,1\% destes já foram violentados psicologicamente (MINAYO MCS, et al., 2010).

\section{OBJETIVO}

Analisar os dados secundários disponíveis em uma base de dados do Ministério da saúde acerca da violência contra a pessoa idosa, especificamente óbitos, no município de Juiz de Fora - MG, no período de 1996 a 2017.

\section{MÉTODO}

Trata-se de um estudo quantitativo, epidemiológico e descritivo, realizado com dados do Sistema de Informação sobre Mortalidade (SIM). Analisou-se os óbitos por agressões, ocorridos entre 1996 e 2017, segundo a causa básica do óbito, o sexo, a faixa etária, a região, o município, o local da ocorrência (domicílio).

\section{RESULTADOS E DISCUSSÃO}

Identificou-se um número maior de óbitos por agressão entre idosos nos estados de São Paulo, Rio de Janeiro e Minas Gerais, respectivamente. Quando se avaliou a distribuição desses óbitos 
por macrorregiões de saúde observou-se que a macrorregião com maior índice de mortalidade foi a macrorregião centro, seguida da macrorregião sul e leste. Identificou-se, ainda, uma sobremortalidade masculina por agressões entre as faixas etárias 60 anos ou mais.

\section{CONSIDERAÇÕES FINAIS}

Os dados obtidos permitem inferir que os óbitos por agressões em idosos evidenciam a importância da utilização das políticas públicas direcionadas a esse estrato etário, além da importância de fazer o registro corretamente no SIM.

\section{REFERÊNCIAS}

MORÉ CLOO. A entrevista em profundidade ou semiestruturada, no contexto da saúde: dilemas epistemológicos e desafios de sua construção e aplicação. Atas CIAIQ, 2015.

PARAÍBA PMF, SILVA MCM. Profile of violence against the elderly in the city of Recife-PE, Brazil. Rev bras geriatr gerontol, 2015. 
068 | RESUMOS SIMPLES: Revisão Bibliográfica

\section{Repercussões do transtorno de déficit de atenção e da hiperatividade sobre o desempenho escolar: uma revisão da literatura}

Autor/coautores: Henrique Guimarães Vasconcelos, Fernanda Odete Souza Rodrigues, Daiane Guimarães da Silveira.

Instituição: Universidade de Itaúna (UIT), Itaúna - Minas Gerais; Universidade Federal de Lavras (UFLA), Lavras - Minas Gerais.

Palavras-chave: Transtorno de déficit de atenção, Aprendizagem, Ensino.

\section{INTRODUÇÃO}

O mau desempenho escolar é definido como um rendimento escolar abaixo do esperado para determinadas idades, habilidades cognitivas e escolaridade, e é um sintoma relacionado a várias patologias, sendo o Transtorno do Déficit de Atenção e Hiperatividade (TDAH) uma delas. Este transtorno é um problema de saúde pública, sendo conceituado como um distúrbio biopsicossocial caracterizado por comportamentos relacionados à falta de atenção, hiperatividade e impulsividade, que se manifestam de maneira desproporcional tendo em vista a idade e o nível de desenvolvimento do indivíduo (TOLENTINO AC, et al., 2019; MOURA LT, et al., 2019).

\section{OBJETIVO}

Realizar um estudo crítico da literatura no intuito de analisar e demonstrar a relação entre TDAH e o mau desempenho escolar, além de evidenciar as consequências dessa patologia para os alunos portadores.

\section{REVISÃO BIBLIOGRÁFICA}

O TDAH tem causado preocupações aos professores em sala de aula e, por vezes, frustrações, uma vez que os estudantes com esse agravo podem apresentar dificuldades de aprendizagem, tendo em vista a tríade que compõe esse transtorno que é formada por impulsividade, distúrbios de atenção, da impulsividade e descompasse entre a velocidade da atividade física e mental (MOURA LT, et al., 2019).

Estudos indicam que crianças com TDAH possuem três vezes mais chance de repetirem uma série em relação às crianças normais e que $48 \%$ dos portadores de TDAH já foram suspensos de 
algum colégio frente a 17\% dos alunos não portadores. Além disso, outras pesquisas apontam que, das crianças com TDAH avaliadas, $50 \%$ necessitou de aulas particulares e cerca de $30 \%$ foi alocada em turmas especiais ou foi reprovada (CARVALHO JS, et al., 2019; MOURA LT, et al., 2019; TOLENTINO AC, et al., 2019).

\section{CONSIDERAÇÕES FINAIS}

O impacto do transtorno do déficit de atenção e hiperatividade no aprendizado do portador é considerável, podendo trazer prejuízos em diversas esferas da vida social. No que diz respeito ao impacto sobre o aprendizado, faz-se fundamental a estruturação do ambiente escolar para melhor atender e ensinar àqueles que depositam confiança na instituição de ensino para auxiliar no aprendizado dos portadores de TDAH.

\section{REFERÊNCIAS}

TOLENTINO AC, et al. Psicoterapia infantil para transtorno de déficit de atenção e hiperatividade (TDAH) com enfoque na terapia cognitivo comportamental (TCC): revisão integrativa da literatura. Revista Ensino de Ciências e Humanidades - Cidadania, Diversidade e Bem-Estar. 2019; 5(2): 251-270.

MOURA LT, et al. Alunos com TDAH (Transtorno de Déficit de Atenção e Hiperatividade): um desafio na sala de aula. Revista Eletrônica Acervo Saúde. 2019; 22:e611.

CARVALHO JS, et al. Transtorno do déficit de atenção com hiperatividade (TDAH) e seus desafios no ambiente escolar: pesquisa de campo na EMEF Manoel Vieira Lessa, em Serra - ES. Conhecimento em Destaque. 2019. 1(1): 197-202. 
069 | RESUMOS SIMPLES: Revisão Sistemática

\section{Acidentes de trabalho com profissionais do ambiente hospitalar}

Autor/coautores: Cryshna Leticia Kirchesch.

Instituição: Mestre em Enfermagem pela Universidade Federal de Pelotas - Rio Grande do Sul.

Palavras-chave: Acidentes de trabalho, Saúde do Trabalhador, Hospital.

\section{INTRODUÇÃO}

Os acidentes de trabalho são classificados em típicos, quando ocorrem durante o labor e de trajeto, quando ocorrem durante o deslocamento externo do profissional. $\mathrm{Na}$ área da saúde, a taxa de acidentes é $34 \%$ maior quando comparada a outros campos, devido as exaustivas jornadas laborais e o dimensionamento de pessoal inadequado, que gera sobrecarga de atividades e favorecem a ocorrência dos eventos (SILVA VF, et al., 2016). Os acidentes com fluídos biológicos podem acarretar a transmissão de mais 20 patógenos infectocontagiosos, transmitidos por meio dos ferimentos causados por perfurocortantes e exposição cutânea (MIRANDA FMDA, et al., 2017).

\section{OBJETIVO}

Conhecer as características dos acidentes de trabalho ocorridos com profissionais que atuam no ambiente hospitalar, com o intuito de oferecer aos gestores, dados que possam balizar futuras ações dos setores responsáveis pela saúde do trabalhador.

\section{MÉTODOS}

Revisão Sistemática. Estabeleceu-se como critérios de inclusão: estudos indexados nas bases de dados da Literatura Latino-americana e do Caribe (LILACS), Banco de Dados em Enfermagem (BDENF), Scientific Electronic Library (SciELO) e Medical Literature Analysis and Retrieval System Online (MEDLINE), inseridos em um limite temporal de 10 anos (2007 a 2017), em formato de artigos, nos idiomas português, inglês e espanhol. Foram utilizados os descritores "acidentes de trabalho" e "hospital". Na MEDLINE utilizou-se o Medical Subject Headings (MeSH) "accidents occupational" AND "hospitals". Excluiu-se os estudos que tratavam sobre acidentes de trabalho ocorridos com trabalhadores que não eram funcionários de hospitais. Ao realizar os cruzamentos e aplicar os critérios, obteve-se uma amostra de oito artigos. 


\section{RESULTADOS E DISCUSSÃO}

Os riscos ocupacionais são classificados em físicos, biológicos, químicos, ergonômicos e psicossociais. No ambiente hospitalar os acidentes de trabalho ocorrem no manuseio de objetos perfuro cortantes, contato com fluidos corporais que atingem os olhos, nariz e boca, exposição à radiação/medicamentos, em acidentes de trajeto, em quedas e queimaduras. Torna-se assim, indispensável a adoção de medidas que promovam qualidade de vida e de trabalho, por meio de educação permanente, apoio psicológico e valorização do profissional (SANTOS SVM, et al., 2017).

\section{CONSIDERAÇÕES FINAIS}

A área da saúde é marcada por processos de trabalho que favorecem a ocorrência de acidentes laborais. No Brasil constituem-se em importante problema de saúde pública, visto que atingem número significativo de trabalhadores, graças à intensificação do trabalho na rotina hospitalar.

\section{REFERÊNCIAS}

MIRANDA FMDA, et al. Perfil dos trabalhadores brasileiros vítimas de acidente de trabalho com fluidos biológicos. Revista Brasileira de Enfermagem, 2017; 70(5):1117-1124.

SANTOS SVM, et al. Acidente de trabalho e autoestima de profissionais de enfermagem em ambientes hospitalares. Revista Latino-Americana de Enfermagem, 2017; 25: e2872.

SILVA VF, et al. Riscos ocupacionais e acidentes de trabalho na enfermagem. Mostra Interdisciplinar do Curso de Enfermagem, 2016; 2(1):1-4. 
070 | RESUMOS SIMPLES: Revisão Bibliográfica

\section{Atuação do enfermeiro na promoção do cuidado humanizado a pacientes na Unidade de Terapia Intensiva}

Autor/coautores: Myllena Ferreira Rabelo1, Jonas de Jesus Carvalho', Alessandra Rabelo Gonçalves Fernandes ?

Instituição: ${ }^{1}$ Graduando em Enfermagem na Faculdade Pitágoras de Feira de Santana, Feira de Santana - Bahia; ${ }^{2}$ Mestra em Saúde Coletiva, Universidade Estadual de Feira de Santana, Feira de Santana - Bahia.

Palavras-chave: Humanização, Unidade de Terapia Intensiva, Cuidados de Enfermagem.

\section{INTRODUÇÃO}

A Unidade de Terapia Intensiva (UTI) é uma unidade de alta complexidade no cuidado ao paciente crítico com instabilidade hemodinâmica. A unidade é composta por aparato tecnológico, que auxilia no tratamento e, por uma equipe multidisciplinar capacitada, na qual atua o enfermeiro, este é responsável por acompanhar a evolução do paciente e assumir questões administrativas, como o gerenciamento da equipe de enfermagem (SILVEIRA RE e COTIM D, 2015). A rotina intensa da unidade e a complexidade do cuidado é necessário a adoção de condutas que proporcionem um ambiente mais humanizado para o paciente, durante o período de internação (MICHELAN VCA e SPIRI WC, 2018).

\section{OBJETIVO}

Revisar achados científicos que abordem sobre a UTI e que descrevam sobre a atuação do enfermeiro intensivista na promoção do cuidado humanizado aos pacientes internados no setor.

\section{MÉTODOS}

Trata-se de uma revisão integrativa com abordagem qualitativa, descritiva. Foram realizados levantamento bibliográfico nas bases de dados do BVS, LILACS e SCIELO, em junho de 2020. Os critérios de inclusão foram artigos disponíveis em português, publicados entre os anos de 2015 a 2020. Foram excluídos artigos duplicados e referenciais que não tratam do tema. Os descritores utilizados foram: Humanização, UTI, Assistência de enfermagem, e os operadores booleanos utilizados foram: and, our. 


\section{RESULTADOS E DISCUSSÃO}

Para que a humanização seja agregada na rotina de cuidados na UTI, o enfermeiro deve prestar o cuidado holístico com abordagem biopsicossocial. O acolhimento, a escuta qualificada, a comunicação, verbal ou não verbal são condutas importantes para a humanização do cuidado ao paciente crítico (OUCHI JD, et al., 2018). A diminuição dos ruídos, a utilização da luz ambiente proporciona um ambiente mais agradável. A literatura aponta que a utilização da sedação e analgesia são como uns fatores importantes no controle da dor e diminuição de ansiedade. Outro fator em destaque é a inserção da família no cuidado e a presença de líderes espirituais durante a internação, pois promove sensação de conforto para o paciente. Em contraponto, as dificuldades enfrentadas pelo enfermeiro que compromete a prestação do cuidado humanizado é a sobrecarga de trabalho, excesso de vínculos trabalhistas, esses fatores podem impactar na prestação do cuidado (MICHELAN VCA e SPIRI WC, 2018).

\section{CONSIDERAÇÕES FINAIS}

Apesar da rotina intensa na UTI, o toque e a ambiência podem contribuir para o cuidado mais humanizado do setor. Ademais, a empatia é importante na prestação do cuidado, assim como estabelecimento de vínculo profissional - paciente, buscando sempre adotar condutas que promovam conforto e bem-estar.

\section{REFERÊNCIAS}

SILVEIRA RE, CONTIM D. Educação em saúde e prática humanizada da enfermagem em unidades de terapia intensiva: estudo bibliométrico. J. res.: fundam. care. online 2015. jan./mar. 7(1):21132122.

OUCHI JD, et al. O papel do enfermeiro na Unidade de Terapia Intensiva diante de novas tecnologias em saúde. Revista Saúde em Foco - Edição no 10 - Ano: 2018.

MICHELAN VCA, SPIRI WC. Percepção da humanização dos trabalhadores de enfermagem em terapia intensiva. Rev. Bras. Enferm. vol.71 no.2 Brasília Mar/abr. 2018. 
071 | RESUMOS SIMPLES: Revisão Bibliográfica

\section{Cuidados paliativos: atuação e recursos fisioterapêuticos utilizados para melhora da qualidade de vida do paciente terminal}

Autor/coautores: Juliana Alves de Medeiros; Alaíde Alves dos Santos; João Henrique Nunes de Miranda; Jéssica Gonçalves de Sousa; Angela Maria Ferreira de Moura.

Instituição: Centro Universitário Leão Sampaio - UNILEÃO, Juazeiro do Norte, Ceará, Brasil.

Palavras-chave: Cuidados paliativos, Qualidade de vida, Fisioterapia.

\section{INTRODUÇÃO}

O Cuidado Paliativo tem a finalidade de buscar aliviar o sofrimento de pacientes com doença progressiva e irreversível, bem como melhorar a qualidade de vida do indivíduo e de seus familiares (LOPES LL, 2019). A abordagem multidisciplinar é importante, pois o individualismo profissional não abrange todos os aspectos e particularidades envolvidas no tratamento desses pacientes. A junção dessas habilidades profissionais promove uma assistência completa e capacitada para o cliente, que necessita de cuidados que busquem controlar ou amenizar os sintomas e sinais físicos, psicológicos e espirituais destes e de seus familiares (SUDIGURSKY D e SILVA EP, 2008). Neste caso, o fisioterapeuta pode atuar de forma complementar, buscando obter dentro do seu alcance profissional o cuidado que o paciente necessita.

\section{OBJETIVO}

Analisar a atuação do fisioterapeuta e investigar os recursos terapêuticos disponíveis para atuar no cuidado com o paciente terminal.

\section{MÉTODO}

Trata-se de uma revisão de literatura, realizada a partir das bases de dados Scielo, Lilacs, BVS, Acervo Saúde, foram selecionado artigos escritos em língua portuguesa, nos anos de 2004 a 2019, onde foram selecionados artigos referentes aos cuidados paliativos associados a atuação multidisciplinar, com ênfase nos cuidados realizados pelos profissionais de fisioterapia, agregando aos protocolos de tratamento o uso de técnicas e equipamentos para buscar melhorar a qualidade de vida desses indivíduos. 


\section{RESULTADOS E DISCUSSÃO}

A fisioterapia possui um grande arsenal de métodos e intervenções que podem ser utilizadas no tratamento paliativo. As principais intervenções fisioterapêuticas analisadas são os métodos analgésicos, para essa finalidade são utilizados recursos de eletroterapia, termoterapia, massoterapia e terapias holísticas, para as disfunções osteomioarticulares e melhora da fadiga, recursos eletroterapêuticos, exercícios cinesioterapêuticos, para melhora da função pulmonar, busca melhorar o desconforto respiratório com técnicas que favoreçam a manutenção de vias aéreas, cinesioterapia respiratória, alongamento dos músculos da caixa torácica, manobras desobstrutivas e reexpansivas, orientação postural para prevenir deformidade e lesão por pressão que podem se desenvolver em lugares com pouco tecido adiposo e nos locais de proeminências ósseas (MARCUCCI FCI, 2015; FLORENTINO DM, et al., 2012).

\section{CONSIDERAÇÕES FINAIS}

O fisioterapeuta contribui de forma positiva para atuar no cuidado com o paciente crítico, entretanto a produção de conhecimento e evidências no cuidado paliativo ainda é escassa, nesse sentido, reforça-se a necessidade de realizarem mais pesquisas e ensino na área de Fisioterapia em Cuidado Paliativo com base em evidências científicas.

\section{REFERÊNCIAS}

LOPESS LL. Cuidados paliativos no âmbito hospitalar: compreensão de enfermeiros. Rev Eletrônica Acervo Saúde, 11(12), e781, 2019.

MARCUCCI FCI. O papel da fisioterapia nós cuidados paliativos a paciente com câncer. Rev Brás Cancerol 51 (1), 67-77, 2005.

SUDIGURSKY D, SILVA EP. Concepções sobre cuidados paliativos: revisão bibliográfica. Acta Paulista de Enfermagem 21 (3), 504-508, 2008.

FLORENTINO DM, et al. A fisioterapia no alívio da dor: uma visão reabilitadora em cuidados paliativos. Rev HUPE, 11(2), 50-57, 2012. 
072 | RESUMOS SIMPLES: Revisão Bibliográfica

\section{O potencial aumento da demência associado ao consumo de benzodiazepínicos na população idosa: uma revisão sistemática}

Autor/coautores: Bárbara Reis Coutinho Almeida, Ana Luisa Ervilha Sabioni, Otávio Coutinho de Almeida.

Instituição: Centro Universitário Unifaminas (UNIFAMINAS), Muriaé - MG; Faculdade de Ciências Médicas e da Saúde de Juiz de Fora (FCMS/JF), Juiz de Fora - MG; Universidade Estadual de Montes Claros (UNIMONTES), Montes Claros - MG.

Palavras-chave: Benzodiazepínicos, Dêmencia, Declínio cognitivo.

\section{INTRODUÇÃO}

O envelhecimento é um processo natural do ser humano, que pode possuir efeitos desfavoráveis, como a demência, apesar de não ser um aspecto normal do ato de envelhecer. Estima-se que até 2050 a população mundial com demência seja de 152 milhões de indivíduos, tornando-se destaque e prioridade na saúde global (RICHARDSON K, et al., 2019). Os benzodiazepínicos (BDZ) são ansiolíticos usualmente prescritos para o tratamento de depressão, transtornos de humor e ansiedade em idosos (TAKADA M, et al., 2016). Observou-se, em estudos realizados, efeitos deletérios agudos com a sua indicação, na memória e cognição, considerando-se a tendência de aumento do risco de demência (GRAY S L, et al., 2016).

\section{OBJETIVO}

Analisar, através de uma revisão sistemática da literatura sobre os possíveis efeitos ocasionados pelo consumo prolongado de benzodiazepínicos como eventual causa ou elevação dos casos de demência na população idosa.

\section{MÉTODO}

Realizou-se pesquisa dos últimos cinco anos sobre o tema, tendo como referência básica dados disponibilizados pela National Library of Medicine (MedLine), Nature, Science Direct, com os descritores "Benzodiazepine", "Dementia" e variações segundo $\mathrm{MeSH}$, abrangendo-se os casos realizados com humanos em idade superior a 65 anos. 


\section{RESULTADOS E DISCUSSÃO}

A aplicação dos descritores conduziu ao encontro de 1265 artigos, desse modo, posteriormente à adoção dos critérios de inclusão e exclusão, levaram ao o estudo de 64 publicações, a exclusão de 54 após a análise dos títulos, a seleção de 10 para a leitura do trabalho e a redução para 5 artigos clínicos randomizados controlados que foram selecionados sobre o tema. Diante de todos esses dados e a análise detalhada de suas perspectivas e dos aspectos mais significativos, foi possível a condução do encontro dos seguintes RESULTADOS três trabalhos apresentaram a ausência de evidências de que o BZD direcione o paciente ao declínio cognitivo, dentre estes, um afirma que o uso leva a pequeno risco de demência sem, no entanto, causar o declínio cognitivo no uso acumulativo; bem como, dois artigos indicaram que seu uso prolongado elevam os riscos de demência.

\section{CONSIDERAÇÕES FINAIS}

Avalia-se, com base nos trabalhos selecionados, que existem divergências e questões não abordadas nos resultados obtidos com o uso de benzodiazepínicos associados à demência, sendo necessário a continuação das pesquisas e estudos para obter maiores determinantes com a finalidade assegurar este vínculo.

\section{REFERÊNCIAS}

GRAY SL, et al. Benzodiazepine use and risk of incident demencia or cognitive decline: prospective population base study. BMJ, 2016 Feb 2; 352: i90.

RICHARDSON K, et al. History of benzodiazepine prescriptions and risk of dementia: possible bias due to prevalent users and covariate measurement timing in a nested case-control study. American journaul of epidemiology, 2019; 188(7): 1228-1236.

TAKADA M, et al. Association between benzodiazepine use and dementia: data mining of different medical databases. International Journal of Medical Sciences, 2016 oct. 18; 13(11): 825-834. 
073 | RESUMOS SIMPLES: Revisão Bibliográfica

\section{O impacto do exercício físico no prognóstico dos portadores da doença de Alzheimer: uma revisão sistemática}

Autor/coautores: Bárbara Reis Coutinho Almeida, Ana Luisa Ervilha Sabioni, Otávio Coutinho de Almeida.

Instituição: Centro Universitário Unifaminas (UNIFAMINAS), Muriaé - MG; Faculdade de Ciências Médicas e da Saúde de Juiz de Fora (FCMS/JF), Juiz de Fora - MG; Universidade Estadual de Montes Claros (UNIMONTES), Montes Claros - MG.

Palavras-chave: Exercício físico, Doença de Alzheimer, Declínio cognitivo.

\section{INTRODUÇÃO}

A doença de Alzheimer (DA) é um transtorno neurodegenerativo progressivo, que possui como característica determinante o declínio cognitivo e as manifestações neuropsiquiátricas, como a depressão, agitação, agressividade, que ao longo do curso patológico ocasionam o comprometimento gradual das atividades diárias (MORRIS JK, et al., 2017). Estudos recentes expõem o exercício físico como um método promissor para reduzir o declínio cognitivo, sendo um fator que não só tende a aprimorar esse aspecto da doença, como também seria uma importante ferramenta para estabelecer uma vida saudável otimizando a qualidade do bem-estar geral (SOBOL NA, et al., 2018).

\section{OBJETIVO}

Investigar através de uma revisão sistemática da literatura o impacto que o exercício físico pode acarretar como método de reduzir os danos promovidos pela doença de Alzheimer na população idosa.

\section{MÉTODO}

Revisão sistemática dos casos realizados nos últimos cinco anos com humanos em idade superior a 65 anos, disponibilizados na plataforma do PubMed, tendo como parâmetro dados fornecidos pela National Library of Medicine (MedLine), Nature, Science Direct, compreendendo os descritores "Physical excercise" e "Alzheimer disease". 


\section{RESULTADOS E DISCUSSÃO}

A aplicação dos descritores conduziu ao encontro de 2328 artigos, e por consequência, posteriormente à adoção dos critérios que selecionaram os aspectos mais significativos e descartaram os que não se adequavam a este trabalho levaram a avaliação de 51 publicações, sendo assim, foram excluídos 36 trabalhos após a leitura do título, selecionados 15 artigos para o estudo e definidos 3 estudos clínicos randomizados controlados para a revisão de suas interpretações. Evidencia-se que a prática da atividade física fornece aos pacientes com a doença de Alzheimer melhorias na mobilidade, bem como auxilia na redução dos sintomas depressivos e na resistência física, aprimorando assim a qualidade de vida. Os trabalhos concluem que há evidências que o exercício físico possivelmente eleva indiretamente a função cardiorrespiratória, podendo ser importante método de aprimoramento da memória e redução da atrofia do hipocampo dos portadores de DA.

\section{CONSIDERAÇÕES FINAIS}

Considera-se benéfica a prática contínua de exercício físico nos indivíduos com a doença de Alzheimer, uma vez que, as evidências apresentadas nos estudos exibem melhorias nos sintomas cognitivos e neuropsiquiátricos que poderiam ajudá-los a obter em vários aspectos, uma maior qualidade de vida.

\section{REFERÊNCIAS}

MORRIS JK, et al. Aerobic exercise for Alzheimer's disease: A randomized controlled pilot trial. PLoS One, 2017 Feb 10; 12(2):e0170547.

SOBOL NA, et al. Change in Fitness and the Relation to Change in Cognition and Neuropsychiatric Symptoms After Aerobic Exercise in Patients with Mild Alzheimer's Disease, 2018 Jan 1; 137 - 145. 
074 | RESUMOS SIMPLES: Revisão Bibliográfica

\section{Flora intestinal e a modulação no transtorno do espectro autista: uma revisão sistemática}

Autor/coautores: Ana Luisa Ervilha Sabioni, Bárbara Reis Coutinho Almeida, Rafaela Aparecida Ervilha Sato.

Instituição: Faculdade de Ciências Médicas e da Saúde de Juiz de Fora (FCMS/JF), Juiz de ForaMG; Centro Universitário Unifaminas (UNI-FAMINAS), Muriaé-MG; Fundação Presidente Antônio Carlos (FUPAC), Ubá-MG.

Palavras-chave: Microbiota intestinal, Autismo, Flora intestinal.

\section{INTRODUÇÃO}

O transtorno do espectro autista (TEA) é definido como um comportamento estereotipado, além de déficits na comunicação e nas interações sociais, associado a disfunção gastrointestinal (FATTORUSSO A, et al., 2019). Esse último sintoma tem sido alvo de pesquisas científicas com o intuito de elucidar um potencial papel da microbiota intestinal na fisiopatologia do TEA. Sua causa ainda é incerta, mas parece envolver uma interação complicada de fatores genéticos e ambientais (NIU M, et al., 2019). A partir das manifestações gastrointestinais surgiram estudos sobre a relação eixo cérebro-intestino com relação à doença.

\section{OBJETIVO}

Realizar uma revisão sistemática da literatura sobre as alterações de microbiota intestinal e manifestações do TEA em crianças.

\section{MÉTODO}

Revisão sistemática na base de dados Medline, utilizando expressões como "Autism Spectrum Disorders" e "Intestinal Microbiota", com suas respectivas variações segundo o MeSH, foram excluindo artigos que fugissem da temática do foco de pesquisa. Os filtros utilizados foram "Humans", "5 years", "Full text", sendo escolhidos 3 artigos diretamente relacionados ao tema dentre os 11 encontrados na pesquisa.

\section{RESULTADOS E DISCUSSÃO}

A relação entre intestino e o cérebro é cientificamente descrita como o eixo cérebro-intestino. Especificamente, observou-se aumento de Ruminococcus, Clostridium e diminuição de 
Bacteroides, Bifidobacterium, E. coli, Clostridium, Enterococcos e Lactobacillus em crianças com TEA (SALVATORE S, et al., 2018). Observou-se também que alta abundância de Candida albicans pode gerar menor absorção de carboidratos e minerais, tendo como consequência um nível maior de toxinas no trato gastrointestinal, contribuindo para comportamentos de TEA (NIU M, et al., 2019). A microbiota intestinal mantém a integridade dos epitélios intestinais, protege a barreira intestinal e previne o lipopolissacarídeo bacteriano na corrente sanguínea, que induz comprometimento comportamental e danifica a barreira hematoencefálica. Além disso, a microbiota intestinal pode regular as atividades do sistema nervoso central por meio de vias neurais, imunes, endócrinas, dentre outras vias (FATTORUSSO A, et al., 2019).

\section{CONSIDERAÇÕES FINAIS}

Por muito tempo o TEA foi considerado apenas uma patologia neurológica, porém com os recentes estudos é possível apontar fatores ambientais como os principais contribuintes para o início do distúrbio comportamental. Esse conhecimento poderá ser utilizado no futuro para desenvolvimento de novas estratégias terapêuticas para modulação da microbiota intestinal de crianças com TEA, como uso de probióticos, administração de anti-microbianos e transplante de microbiota.

\section{REFERÊNCIAS}

FATTORUSSO A, et al. Autism Spectrum Disorders and the Gut Microbiota. Nutrients; 11(3)2019.

NIU M, et al. Characterization of Intestinal Microbiota and Probiotics Treatment in Children with Autism Spectrum Disorders in China. Front Neurol; 10: 1084, 2019.

SALVATORE S, et al. Mind the gut: probiotics in paediatric neurogastroenterology. Benef Microbes; 9(6): 883-898, 2018. 
075 | RESUMOS SIMPLES: Revisão Bibliográfica

\section{Os efeitos do exercício físico aeróbico na melhora cognitiva: uma revisão sistemática}

Autor/coautores: Ana Luisa Ervilha Sabioni, Bárbara Reis Coutinho Almeida, Rafaela Aparecida Ervilha Sato.

Instituição: Faculdade de Ciências Médicas e da Saúde de Juiz de Fora (FCMS/JF), Juiz de ForaMG; Centro Universitário Unifaminas, Muriaé-MG, Fundação Presidente Antônio Carlos (FUPAC), Ubá-MG.

Palavras-chave: Cognição, Terapia por exercício, Qualidade de vida.

\section{INTRODUÇÃO}

A população mundial está envelhecendo e promover um envelhecimento cognitivo saudável é uma prioridade e um desafio à saúde pública (APÓSTOLO J, et al., 2019). A atividade física não só é benéfica para a saúde de uma pessoa, mas também pode ter uma influência positiva no funcionamento cognitivo de idosos com e sem comprometimento cognitivo (BALLIN M, et al., 2019). Estudos recentes sugerem que o exercício físico aeróbico pode diminuir a carga neuropato- lógica e aumentar a neurogênese do hipocampo, sendo uma alternativa para potencializar o trata- mento da DA leve (ZHU Y, et al., 2020).

\section{OBJETIVO}

Realizar uma revisão sistemática da literatura sobre os efeitos do exercício físico aeróbico na melhora da função cognitiva em idosos.

\section{MÉTODO}

Revisão sistemática na base de dados Medline, utilizando expressões como "older adults", "aerobic exercises" e "cognitive", com suas respectivas variações segundo o MeSH. Os filtros utilizados foram "Humans", "5 years", "Full text", sendo escolhidos 3 artigos diretamente relacionados ao tema dentre os 45 encontrados na pesquisa. Foram incluídos apenas estudos de ensaio clínico.

\section{RESULTADOS E DISCUSSÃO}

Os resultados sugerem que qualquer atividade física na terceira idade parece ter um impacto positivo na melhoria no funcionamento neurocognitivo, velocidade de processamento, atenção e 
flexibilidade cognitiva, indicando que o exercício físico, quando realizado de forma regular, está associado a melhora da função cognitiva geral (BALLIN M, et al., 2019). Além disso, parece que a dança, devido a seus múltiplos mecanismos, pode ter o maior efeito no aprimoramento do desempenho cognitivo em idosos saudáveis. A atividade física regular, voltada para o desenvolvimento de habilidades de automatismo, afeta o desempenho cognitivo e retarda a progressão da perda de memória para a demência em idosos (ZHU Y, et al., 2020). O efeito do exercício na função cognitiva depende da frequência com que o exercício é realiza- do, portanto o exercício regular, em oposição ao exercício ocasional, é essencial para experimentar uma melhora na função cognitiva. Todavia, foi verificado efeitos adversos de gravidade moderada em alguns participantes como dor no membro inferior (APÓSTOLO J, et al., 2019).

\section{CONSIDERAÇÕES FINAIS}

O exercício aeróbico foi capaz de melhorar a função cognitiva e o bem-estar mental em idosos. No entanto, estudos clínicos randomizados com amostras maiores são necessários para reivindicar conclusivamente o impacto da atividade física como instrumento que auxilia na melhora cognitiva.

\section{REFERÊNCIAS}

APÓSTOLO J, et al. Effectiveness of a Combined Intervention on Psychological and Physical Capacities of Frail Older Adults: A Cluster Randomized Controlled Trial. Int J Environ Res Public Health ; 16(17)20190828.

ZHU Y, et al. Effects of Aerobic Dance on Cognition in Older Adults with Mild Cognitive Impairment: A Systematic Review and Meta-Analysis. J Alzheimers Dis ; 74(2): 679-690, 2020.

BALLIN M, et al. Effects of interval training on quality of life and cardiometabolic risk markers in older adults: a randomized controlled trial. Clin Interv Aging ; 14: 1589-1599, 2019. 
076 | RESUMOS SIMPLES: Revisão Bibliográfica

\section{As influência de intervenções dietéticas em portadores do transtorno do espectro autista: uma revisão sistemática}

Autor/coautores: Ana Luisa Ervilha Sabioni, Bárbara Reis Coutinho Almeida, Rafaela Aparecida Ervilha Sato.

Instituição: Faculdade de Ciências Médicas e da Saúde de Juiz de Fora (FCMS/JF), Juiz de ForaMG; Centro Universitário Unifaminas, Muriaé-MG, Fundação Presidente Antônio Carlos (FUPAC), Ubá-MG.

Palavras-chave: Autismo, Intervenções dietéticas, Qualidade de vida.

\section{INTRODUÇÃO}

O Transtorno do Espectro do Autismo (TEA) é um transtorno do neurodesenvolvimento caracterizado por prejuízo na interação social. Uma em cada 69 crianças apresenta traços de autismo, com prevalência cinco vezes maior em meninos. A Organização Mundial da Saúde estima que 2 milhões estão no Brasil (MONTEIRO MA, et al., 2020). Os sintomas gastrointestinais são de particular interesse nesta população, devido à prevalência e correlação com a gravidade dos traços comportamentais, levando a alterações intestinais, como no revestimento da mucosa e em enzimas digestivas, que levam a má absorção de proteínas grandes (GONZÁLEZ-DOMENECH PJ, et al., 2020).

\section{OBJETIVO}

Realizar uma revisão sistemática da literatura sobre os efeitos de dietas livres de glúten, nos aspectos cognitivos de indivíduos com TEA.

\section{MÉTODO}

Revisão sistemática na base de dados Medline, utilizando expressões como "Autism Spectrum Disorder"; "Diet" e "Glúten", com suas respectivas variações segundo o MeSH. Os filtros utilizados foram "Humans", "5 years" e "Full text", sendo escolhidos 3 artigos diretamente relacionados ao tema dentre os 15 encontrados na pesquisa.

\section{RESULTADOS E DISCUSSÃO}

Os estudos sugerem que as intervenções dietéticas influenciaram na melhora do aspecto antissocial e da fala e além da diminuição nos distúrbios comportamentais. Sendo que, os indivíduos 
com idade entre 7 a 9 anos possuíram melhor resposta a abordagem (MONTEIRO MA, et al., 2020). O glúten e a caseína, que podem atravessar a parede do intestino, e então a barreira hematoencefálica (BHE), onde, no Sistema Nervoso Central (SNC), atuam como neuropeptídeos. Por conseguinte, uma dieta com glúten pode aumentar a concentração desse neuropeptídio no SNC, levando a alterações funcionais no individuo com TEA (GONZÁLEZ-DOMENECH PJ, et al., 2020). Evidências indicam que os peptídeos liberados na absorção do glúten, se ligam a receptores opioides, modulando seus níveis cerebrais, alterando o funcionamento de sistemas serotoninérgicos, dopaminérgicos e GABAérgicos, que se utilizam de opioides como reguladores, alterando funções neurológicas, levando a efeitos adversos nos campos da atenção, maturação cerebral, interações sociais e aprendizado (PIWOWARCZYK A, et al., 2020).

\section{CONSIDERAÇÕES FINAIS}

Há fortes evidências suportando a relação entre microbiota intestinal e as alterações encontradas em indivíduos com transtorno depressivo. Embora alguns autores relatem progresso nos sintomas associados ao autismo em indivíduos com Transtorno do Espectro Autístico submetidos a intervenções nutricionais, existem poucas evidências científicas para apoiar o uso de suplementos nutricionais ou terapias dietéticas em crianças e adolescentes com autismo.

\section{REFERÊNCIAS}

MONTEIRO MA, et al. Autism Spectrum Disorder: A Systematic About Nutritional Interventions. Rev Paul Pediatr ; 38: e2018262, 2020.

PIWOWARCZYK A, et al. Gluten-Free Diet in Children with Autism Spectrum Disorders: A Randomized, Controlled, Single-Blinded Trial. J Autism Dev Disord ; 50(2): 482-490, 2020 Feb.

GONZÁLEZ-DOMENECH PJ, et al. Influence of a Combined Gluten-Free and Casein-Free Diet on Behavior Disorders in Children and Adolescents Diagnosed with Autism Spectrum Disorder: A $12-$ Month Follow-Up Clinical Trial. J Autism Dev Disord ; 50(3): 935-948, 2020 Mar. 
077 | RESUMOS SIMPLES: Revisão Bibliográfica

\section{Comorbidades relacionadas ao transtorno do déficit de atenção e hiperatividade: uma revisão sistemática}

Autor/coautores: Ana Luisa Ervilha Sabioni, Bárbara Reis Coutinho Almeida, Rafaela Aparecida Ervilha Sato.

Instituição: Faculdade de Ciências Médicas e da Saúde de Juiz de Fora (FCMS/JF), Juiz de ForaMG; Centro Universitário Unifaminas, Muriaé-MG, Fundação Presidente Antônio Carlos (FUPAC), Ubá-MG.

Palavras-chave: Comorbidades, Transtorno do déficit de atenção e hiperatividade, Crianças.

\section{INTRODUÇÃO}

O Transtorno do Déficit de Atenção e Hiperatividade (TDAH) é considerado uma importante doença neuropsiquiátrica de início na infância caracterizado por desatenção, hiperatividade e impulsividade (SCIBERRAS E, et al., 2016). O TDAH pode persistir até a idade adulta e pode afetar o funcionamento social e ocupacional de indivíduos. Distúrbio do neodesenvolvimento relacionado a distúrbios internalizantes e externalizantes, além de queixas e distúrbios somáticos. Ademais as comorbidades são muito estudadas e consideradas frequentes nos adultos, contudo, elas podem começar na infância e persistir na vida adulta (EFRON D, et al., 2016).

\section{OBJETIVO}

Realizar uma revisão sistemática da literatura sobre as comorbidades mais frequentemente associadas com o TDAH em crianças e adolescentes.

\section{MÉTODO}

Revisão sistemática na base de dados Medline, utilizando expressões como "Autism Spectrum Disorder"; "Diet" e "Glúten", com suas respectivas variações segundo o MeSH. Os filtros utilizados foram "Humans", "5 years" e "Full text", sendo escolhidos 3 artigos diretamente relacionados ao tema dentre os 15 encontrados na pesquisa.

\section{RESULTADOS E DISCUSSÃO}

A comorbidade mais frequente foi a rinite, presente em 18,62\%, seguida da asma em 10,78\% dos pacientes portadores de TDAH (EFRON D, et al., 2016). As crianças com TDAH apresentaram pior saúde global, as crianças com TDAH apresentaram maior chance de problemas de sono 
moderados a grandes, em comparação a criança saudáveis. Ademais a enxaqueca esta presente em grande parto dos portadores, assim com a dor de cabeça por tensão (SCIBERRAS E, et al., 2016). Contudo, não houve diferenças entre as crianças com e sem TDAH em termos de lesões físicas ou sobrepeso e obesidade. A média da idade dos participantes com comorbidade foi de 12,39 anos. A prevalência de todos os sintomas foi maior no sexo masculino em relação ao feminino na proporção de 6:1 e entre os adolescentes em relação as crianças (KUTUK MO, et al., 2018)

\section{CONSIDERAÇÕES FINAIS}

As crianças pequenas com TDAH apresentam uma série de deficiências relacionadas à saúde, que são exacerbadas pela presença de comorbidades internalizantes e externalizante. No futuro, estudos genéticos poderão esclarecer melhor essa associação. Intervenções que incorporam estratégias focadas no manejo de doenças alérgicas e cuidados colaborativos para crianças com TDAH devem ser exploradas.

\section{REFERÊNCIAS}

SCIBERRAS E, et al. Health-related impairments in young children with ADHD: a community-based study. Child Care Health Dev ; 42(5): 709-17, 201609.

KUTUK MO, et al. Migraine and associated comorbidities are three times more frequent in children with ADHD and their mothers. Brain Dev ; 40(10): 857-864, 2018 Nov.

EFRON D, et al. Service use in children aged 6-8 years with attention deficit hyperactivity disorder. Arch Dis Child ; 101(2): 161-5, 2016 Feb. 
078 | RESUMOS SIMPLES: Revisão Bibliográfica

\section{Avaliação entre microbiota intestinal e transtorno depressivo: uma revisão sistemática}

Autor/coautores: Ana Luisa Ervilha Sabioni, Bárbara Reis Coutinho Almeida, Rafaela Aparecida Ervilha Sato.

Instituição: Faculdade de Ciências Médicas e da Saúde de Juiz de Fora (FCMS/JF), Juiz de ForaMG; Centro Universitário Unifaminas (UNI-FAMINAS), Muriaé-MG; Fundação Presidente Antônio Carlos (FUPAC), Ubá-MG.

Palavras-chave: Microbiota intestinal, Depressão, Intestino.

\section{INTRODUÇÃO}

A depressão é um problema médico grave e altamente prevalente na população em geral. De acordo com estudo epidemiológico a prevalência de depressão ao longo da vida no Brasil está em torno de 15,5\% (PASCALE A, et al., 2020). Pessoas depressivas tem maior risco de morte por todas as doenças comparadas aos não depressivos. A época comum do aparecimento é o final da $3^{\text {a }}$ década da vida, mas pode começar em qualquer idade. Evidências acumuladas indicam que pacientes com transtornos mentais graves, incluindo depressão maior, transtorno bipolar e esquizofrenia, apresentam várias alterações da microbiota intestinal e aumento da permeabilidade intestinal (PATTERSON T e GRANDHI, 2020).

\section{OBJETIVO}

Realizar uma revisão sistemática da literatura sobre os impactos da microbiota intestinal e sua provável interação com transtorno depressivo.

\section{MÉTODO}

Revisão sistemática na base de dados Medline, utilizando expressões como "Depression" e "Intestinal Microbiota", com suas respectivas variações segundo o $\mathrm{MeSH}$, foram excluindo artigos que fugissem da temática do foco de pesquisa. Os filtros utilizados foram "Humans", " 5 years", "Full text", sendo escolhidos 3 artigos diretamente relacionados ao tema dentre os 21 encontrados na pesquisa. 


\section{RESULTADOS E DISCUSSÃO}

As evidências sugerem que a microbiota intestinal pode ativar o eixo hipotálamo-pituitáriaadrenal (HPA) através de vários mediadores que atravessam a barreira hematoencefálica e incluem antígenos microbianos, citocinas e prostaglandinas (ZHOU N, 2020). Há também evidências de que várias espécies microbianas podem afetar a produção de corticosterona ileal, o que pode afetar a atividade do eixo HPA. Foi postulado que a ativação do eixo HPA pode afetar a microbiota intestinal e a permeabilidade intestinal, indivíduos com depressão tem seu conjunto de microorganismos intestinais diferente de indivíduos saudáveis (PATTERSON T e GRANDHI, 2020). Espécies associadas a mecanismos estressores e pró-inflamatórios em maior número, outras com atividade anti-inflamatória e no metabolismo da serotonina, ácido gama-aminobutírico (GABA) e Fator Neurotrófico derivado do Cérebro em menor quantidade. A doença também exibe níveis elevados de marcadores inflamatórios como IL-6, TNF- $\alpha$, IL-1 $\beta$, além de $\lg A$ e IgM, possivelmente associado aos outros achados (PASCALE A, et al., 2020).

\section{CONSIDERAÇÕES FINAIS}

As evidências identificadas nesta revisão da literatura mostram que há fortes destaques suportando a relação entre microbiota intestinal e as alterações encontradas em indivíduos com transtorno depressivo. Esses dados abrem a possibilidade para novas formas de prevenção e tratamento, as quais poderiam ser mais eficazes, melhor adesão e com menos efeitos colaterais que as utilizadas atualmente.

\section{REFERÊNCIAS}

ZHOU N. Gut Microbiota: A Pivotal Hub for Polyphenols as Antidepressants. J Agric Food Chem ; 68(22): 6007-6020, 2020 Jun 03.

PATTERSON T, GRANDHI R. Gut Microbiota and Neurologic Diseases and Injuries. Adv Exp Med Biol ; 1238: 73-91, 2020.

PASCALE A, et al. Targeting the microbiota in pharmacology of psychiatric disorders. Pharmacol Res ; 157: 104856, 2020 Jul. 
079 | RESUMOS SIMPLES: Revisão Bibliográfica

\section{Os efeitos da musicoterapia nas funções cognitivas e bem-estar metal de pacientes com doença de alzheimer: uma revisão sistemática}

Autor/coautores: Ana Luisa Ervilha Sabioni, Bárbara Reis Coutinho Almeida, Rafaela Aparecida Ervilha Sato.

Instituição: Faculdade de Ciências Médicas e da Saúde de Juiz de Fora (FCMS/JF), Juiz de ForaMG; Centro Universitário Unifaminas, Muriaé-MG, Fundação Presidente Antônio Carlos (FUPAC), Ubá-MG.

Palavras-chave: Doença de Alzheimer, Musicoterapia, Cognição.

\section{INTRODUÇÃO}

A Doença de Alzheimer (DA) é o causa mais comum de demência, sendo responsável por $60 \%$ dos casos de comprometimento cognitivo progressivo no idoso. É uma doença neurodegenerativa que envolve, entre outras manifestações, uma deterioração progressiva da memória e da linguagem, além de distúrbios comportamentais (KLIMOVA B e DOSTALOVA R, 2020). As terapias não farmacológicas têm recebido maior atenção no tratamento da demência nos últimos anos, destacando-se o emprego da musicoterapia que tem sido desenvolvido como estratégia de tratamento para minimizar sintomas, instrumento já utilizado em diversas áreas médicas (SALMOIRAGO EB, et al., 2018).

\section{OBJETIVO}

Realizar uma revisão sistemática da literatura sobre os efeitos da musicoterapia na função cognitiva e no bem-estar mental de pacientes com DA.

\section{MÉTODO}

Revisão sistemática na base de dados Medline, utilizando expressões como "music therapy", "cognition" e "Alzheimer's disease", com suas respectivas variações segundo o MeSH. Os filtros utilizados foram "Humans", "5 years", "Full text", sendo escolhidos 3 artigos diretamente relacionados ao tema dentre os 13 encontrados na pesquisa. Foram incluídos apenas estudos de ensaio clínico. 


\section{RESULTADOS E DISCUSSÃO}

A intervenção musical vem demonstrando eficácia no tratamento de sintomas comportamentais e cognitivos gerais em idosos saudáveis e com vários tipos de demência (LIU-AMBROSE T, et al., 2019). Há evidências que demonstram que em pessoas com DA, a capacidade de responder à música é potencialmente preservada mesmo nos estágios finais ou graves de demência quando a comunicação verbal pode estar gravemente comprometida (SALMOIRAGO EB, et al., 2018). A musicoterapia é eficaz para melhorar a capacidade de memória e linguagem em pacientes com DA leve e reduzir os sintomas psiquiátricos e o sofrimento do cuidador em pacientes com DA moderada ou grave, tal instrumento de base ativa ou passiva, representa uma intervenção de baixo custo com ampla gama de benéficos, sendo tratamento não invasivo, não farmacológico e envolvente, sem efeitos colaterais identificados no momento (KLIMOVA B e DOSTALOVA R, 2020).

\section{CONSIDERAÇÕES FINAIS}

A musicoterapia constitui uma terapia não farmacológica eficaz para melhorar a função cognitiva e o bem-estar mental em pacientes com DA. No entanto, estudos clínico randomizados com amostras maiores são necessários para reivindicar conclusivamente o impacto da musicoterapia nessa doença.

\section{REFERÊNCIAS}

LIU-AMBROSE T, et al. Active body, healthy brain: Exercise for healthy cognitive aging. Int Rev Neurobiol ; 147: 95-120, 2019.

SALMOIRAGO EB, et al. Exploring synergistic effects of aerobic exercise and mindfulness training on cognitive function in older adults: Protocol for a pilot randomized controlled trial. Medicine (Baltimore) ; 97(21): e10626, 2018 May.

KLIMOVA B, DOSTALOVA R. The Impact of Physical Activities on Cognitive Performance among Healthy Older Individuals. Brain Sci ; 10(6)2020 Jun 16. 
080 | RESUMO SIMPLES: Revisão Bibliográfica

\section{Aspectos da candidíase genital em mulheres diabéticas: revisão de literatura}

Autor/coautores: Vanuzia Ferreira Silva, Erivan Santos Andrade.

Instituição: Universidade Federal da Bahia (UFBA), Salvador - Bahia.

Palavras-chave: Candidíase, Diabetes, SGLT2.

\section{INTRODUÇÃO}

Diabetes Mellitus (DM) é um distúrbio metabólico que cursa com níveis elevados da glicose sérica devido a falhas na produção de insulina ou aumento da resistência corporal a essa. Hoje, 9\% da população mundial possui essa doença, e, em 2045, estimam que 628 milhões de pessoas sejam diabéticas (International Diabetes Federation, IDF). A Candidíase Vulvovaginal Recorrente (CVVR) pode ser um agravo dessa disfunção ou do seu tratamento. Manifesta-se com prurido, corrimento branco em grumos, edema vulvar, dispaurenia, disúria e odor, os quais afetam tanto físico quanto psicologicamente as mulheres (KALRA B e KALRA S, 2017).

\section{OBJETIVO}

Revisar as particularidades das mulheres portadoras de diabetes, associá-las a Candidíase Vulvovaginal (CVV) e verificar se a espécie de Candida que prevalece na população total é a mais comum nessas mulheres.

\section{MÉTODO}

Foram selecionados artigos nas bases de dados PubMed, Scielo e Portal CAPES, onde foi pesquisado por "diabetes e dandidíase" e "diabetes e vulvolvaginites". Os critérios para escolha foram: publicação entre 2016 e 2020, gratuidade do texto completo, ser estudo realizado em humanos, sem restrição de idioma. De 62 textos encontrados, 5 foram escolhidos após leitura. Esse estudo não inclui metanálise.

\section{RESULTADOS E DISCUSSÃO}

Muitos fatores facilitam a colonização vaginal por um fungo do gênero Candida. Os estudos analisados verificaram a microbiologia vaginal e a repercussão de um antidiabético usado pelas mulheres na prevalência de CVV. Concluíram que, semelhante à população não diabética, a C. albicans prevalece entre as mulheres com DM, apesar da incidência de C. grabata se elevar nesse 
grupo. Ademais, a secreção de fosfolipases não difere, enquanto há maior produção de aspartil proteinase na amostra diabética (BASSYOUNI RH, et al., 2015).

O uso do inibidor do co-transportador sódio-glicose 2(SGLT2) eleva de três a cinco vezes o risco de infecções por Candida devido glicosúria oriunda do bloqueio da reabsorção de glicose no túbulo proximal. Ademais, pacientes pós-menopausa, com microangiopatia e angiopatia são mais propensas a terem CVV associada ao uso daquele medicamento. No decorrer do tratamento, o número de mulheres positivas para cândida na amostra reduz. Mas salienta a importância de adequar o tratamento às condições do paciente (YOKOYAMA H, et al., 2019).

\section{CONSIDERAÇÕES FINAIS}

A Candida produz mais enzimas hidrolíticas em pacientes diabéticas, colonizando facilmente o epitélio vaginal, ademais, a taxa de infecção por C. albicans e C. grabata quase se iguala. Quanto ao tratamento antidiabético, há elevação da incidência de CVV quando o inibidor de SGLT2 é ministrado.

\section{REFERÊNCIAS}

AKIMOTO-GUNTHER L, et al. Highlights Regarding Host Predisposing Factors to Recurrent Vulvovaginal Candidiasis: Chronic Stress and Reduced Antioxidant Capacity. PLoS One. 2016; 11(7): e0158870

BASSYOUNI RH, et al. Phospholipase and Aspartyl Proteinase Activities of Candida Species Causing Vulvovaginal Candidiasis in Patients with Type 2 Diabetes Mellitus. J Microbiol Biotechnol. 2015; 25(10): e17341741.

DAVE CV, et al. Comparative risk of genital infections associated with sodium-glucose cotransporter-2 inhibitors. Diabetes Obes Metab. 2019; 21(2): e434438.

KALRA B, KALRA S. Vulvovaginitis and diabetes. J Pak Med Assoc. 2017;67(1): e143145.

YOKOYAMA H, et al. Incidence and risk of vaginal candidiasis associated with sodium-glucose cotransporter 2 inhibitors in real-world practice for women with type 2 diabetes. J Diabetes Investig. 2019; 10(2): e439445. 
081 | RESUMO SIMPLES: Revisão Bibliográfica

\section{A conduta do Cirurgião-Dentista frente as manifestações orais do abuso infantil}

Autor/coautores: Ana Carolina Paes Machado Itkes; Gabriela Gaby de Moraes Máximo; Alexandre Cursino de Moura Santos.

Instituição: Universidade de Taubaté (UNITAU), Taubaté-São Paulo.

Palavras-chave: Abuso infantil, Cirurgião-dentista, Manifestações bucais.

\section{INTRODUÇÃO}

O abuso infantil é algo recorrente no Brasil e no mundo. Os maus-tratos infantis constituem um problema social e de saúde (MOREIRA G, et al., 2015) caracterizado por qualquer abuso ou dano físico, sexual, psicológico, negligente, à saúde, desenvolvimento ou integridade do menor.

Nesse contexto, o cirurgião-dentista tem um papel fundamental na identificação e notificação de situações de maus-tratos, uma vez que a maioria das lesões se encontram em região de cabeça, face, pescoço e boca (MOREIRA G, et al., 2015). Por isso, o profissional deve ter conhecimento de tais injúrias e da conduta a ser tomada perante essas violências.

\section{OBJETIVO}

Revisar por meio deste trabalho a importância do Cirurgião-Dentista frente a descoberta do abuso infantil perante as manifestações orais e físicas apresentadas, e a correta conduta que este profissional deve seguir.

\section{REVISÃO BIBLIOGRÁFICA}

Estudos apontam que a maioria dos cirurgiões-dentistas não identificam ou sabem notificar situações de maus-tratos na sua prática profissional (MOREIRA G, et al., 2015). O diagnóstico começa com a avaliação da aparência geral da criança. No exame clínico as lesões nos lábios são as mais corriqueiras, seguidas de lesões na mucosa, dentes, gengiva e língua. Os principais sinais de abuso são a presença de lesões como equimoses, contusões, eritemas, úlceras, vesícula com drenagem purulenta, doenças sexualmente transmissíveis (DSTs), petéquias na boca e no palato e marcas de mordida. Os sintomas emocionais geralmente são depressão, ansiedade, desconfiança e agressividade (VELOSO A, et al., 2018). 
Ademais, nos aspectos legais, o profissional é obrigado a notificar situações de maus-tratos. A notificação deve ser feita através de ofício, aos Conselhos Tutelares ou por comunicação ao Juizado da Infância e Juventude; notificação da ocorrência à autoridade policial e solicitação de guia de encaminhamento da criança ao exame de corpo de delito. $E$ caso o profissional não comunique às autoridades poderá pagar multa de 3 a 20 salários de referência (VELOSO A, et al., 2018).

\section{CONSIDERAÇÕES FINAIS}

Desse modo, é essencial que o Cirurgião-Dentista tenha conhecimento da conduta a ser tomada diante dessas situações, e principalmente saiba identificar as lesões orais, comportamentos da criança individual e coletivamente e analisar se a história relatada condiz com o caso exposto clinicamente.

\section{REFERÊNCIAS}

MOREIRA G, et al. Atuação do cirurgião-dentista na identificação de maus-tratos contra crianças e adolescentes na atenção primária. Revista Saúde debate, Rio de Janeiro, V. 39, n. especial, 2015; P. 257-267.

VELOSO A, et al. Conhecimento e notificação do cirurgião dentista sobre o abuso infantil. Revista de Iniciação Científica da Universidade Vale do Rio Verde, Três Corações, v. 8, n. 1, 2018, p. 114129. 
082 | RESUMOS SIMPLES: Revisão Bibliográfica

\section{A tripla intervenção para o controle do câncer de colo de útero: uma revisão bibliográfica}

Autor/coautores: Anna Flávia Silva do Nascimento, Andyara do Carmo Pinto Coelho Paiva, Thaís Vasconselos Amorim, Adélia Dayane Guimarães Fonseca.

Instituição: Universidade Federal de Juiz de Fora (UFJF), Juiz de Fora - Minas Gerais.

Palavras-chave: Prevenção de Câncer de Colo Uterino, Vacina Contra o Papilomavírus, Tratamento.

\section{INTRODUÇÃO}

O câncer do colo uterino (CCU) é considerado um problema de saúde pública, apresentando maior incidência em países menos desenvolvidos. No ano de 2018, registrou-se 569.847 casos mundiais da doença, sendo mais de 56 mil mulheres acometidas na América Latina. No Brasil, é o terceiro mais frequente entre as mulheres (INTERNATIONAL AGENCY FOR RESEARCH ON CANCER, 2018). Segundo publicação recente, o CCU pode passar de problema de saúde pública à doença do passado. Para tal mudança, há a necessidade de uma tripla intervenção que contempla a vacinação contra o Papilomavírus (HPV), o rastreamento e ampliação do tratamento (WORLD HEALTH ORGANIZATION, 2019).

\section{OBJETIVO}

Revisar os estudos presentes na literatura que promovem uma discussão sobre a tripla intervenção como medida efetiva de controle do câncer de colo de útero no Brasil e no mundo.

\section{REVISÃO BIBLIOGRÁFICA}

Estudo corrobora com o exposto pela World Health Organization ao apontar que o adoecimento de mulheres por CCU pode alcançar um determinado controle, de modo que não seja mais considerado um problema de saúde pública mundial. Para isso é necessário um esforço global no empreendimento de recursos em medidas eficazes no controle da doença, dentre elas, destaca-se: a vacina profilática contra o HPV como forma de prevenção primária; realização do exame Papanicolau, periodicamente, para identificação na fase inicial de lesões precursoras ou do próprio câncer; e o tratamento adequado e precoce das lesões invasivas. Nos próximos 50 anos mais de 44 milhões de mulheres podem ser diagnosticadas com CCU, no entanto, com a ampla cobertura 
de vacinação e triagem cervical podem reduzir de 12,5 a 13 milhões de casos até 2069, com uma incidência média de 4 por 100 mil mulheres por ano (SIMMS KT, et al.,2019).

\section{CONSIDERAÇÕES FINAIS}

Acredita-se que políticas de saúde eficazes são fundamentais para o combate à doença, usando como recurso viável a tripla intervenção. Políticas de conscientização da população e abrangência do acesso em todas as regiões do país são fundamentais para evitar o surgimento e óbitos por câncer de colo uterino.

\section{REFERÊNCIAS}

INTERNATIONAL AGENCY FOR RESEARCH ON CANCER. Cervix uteri. Globocan. 2018.

SIMMS K, et al. Impact of scaled up human papillomavirus vaccination and cervical screening and the potential for global elimination of cervical cancer in 181 countries, 2020-99: a modelling study. The Lancet Oncology, 2019; 20 (3): 394-407.

WORLD HEALTH ORGANIZATION. Draft: Global strategy towards eliminating cervical cancer as a public health problem. Geneva: WHO, 2019. 
083 | RESUMOS SIMPLES: Revisão Bibliográfica

\section{Presença de manifestações orais associadas ao Lúpus Eritematoso Sistêmico}

Autor/coautores: Larissa Barbosa Rodrigues da Silva, Luana dos Santos Fonseca Peixoto, lasmin Fares Menezes de Lima, Ricardo José De Holanda Vasconcellos, Carolina Chaves Gama Aires. Instituição: Universidade de Pernambuco (UPE), Recife - Pernambuco.

Palavras-chave: Doenças autoimune, Mucosa oral, Manifestações bucais.

\section{INTRODUÇÃO}

O Lúpus Eritematoso Sistêmico (LES) apresenta-se como uma doença autoimune heterogênea e multissistêmica sendo caracterizada pela sua cronicidade que alterna entre períodos de piora do quadro e de remissão dos sintomas (PATROCíNIO VH, et al., 2019). É descrita como a criação de autoanticorpos contra as partes integrantes do próprio organismo mostrando-se recorrente em mulheres entre 20-40 anos. Expressa-se como eritemas ou úlceras crônicas com lesões de dimensões diferentes. Cerca de 6,5\%-21\% dos pacientes com LES manifestam lesões bucais acometendo principalmente língua, mucosa jugal, lábios e palato, representando um dos critérios de diagnóstico (SALDANHA KFD, et al., 2015).

\section{OBJETIVO}

Fazer uma revisão bibliográfica a respeito das manifestações orais em pacientes portadores do LES, com ênfase nas características clínicas das lesões encontradas e a sua importância no diagnóstico precoce da doença.

\section{REVISÃO BIBLIOGRÁFICA}

O LES evolui com características clínicas polimórficas, afetando a mucosa oral. As lesões podem se manifestar como uma erosão na mucosa, placas eritematosas, ulcerações, placas de superfície descamativa, fissuras com tendência hemorrágica e máculas avermelhadas no palato. Apesar da mucosa ser bastante susceptível, as lesões de boca e lábios são as mais comuns. Há a presença de sintomas como xerostomia, hipossalivação, disgeusia e glossodinia (SALDANHA KFD, et al., 2015; PATROCÍNIO VH, et al., 2019).

Essas manifestações são consequências do dano tecidual causado pela vasculopatia mediada pelos imunocomplexos, sendo a prevalência de lesões orais variável dependendo do estado da 
doença e tratamento recebido, sendo mais comuns em indivíduos com menos de dois anos de diagnóstico. A elevada ocorrência de manifestações orais da LES mostra a importância da inclusão das estruturas bucais no exame físico para os pacientes que possuem doenças autoimunes e em exames para identificar a presença de doenças dessa natureza (SALDANHA KFD, et al., 2015).

\section{CONSIDERAÇÕES FINAIS}

Pelo caráter debilitante que o LES pode ter, o cirurgião dentista precisa ter conhecimento acerca das múltiplas formas de como a doença pode se manifestar na cavidade bucal com o intuito de auxiliar no diagnóstico das lesões, além de contribuir na diferenciação e no tratamento de todas as alterações que podem estar presentes na região oral.

\section{REFERÊNCIAS}

PATROcÍNIO VH, et al. Extensa úlcera bucal em paciente com lúpus eritematoso. Revista Brasileira de Terapia Intensiva, 2019; 31(2):266-268.

SALDANHA KFD, et al. Lúpus eritematoso sistêmico em Odontologia: relato de caso. Archives of health investigation, 2015; 4(6): 21-24. 
084 | RESUMOS SIMPLES: Revisão Bibliográfica

\section{Os efeitos do exercício físico aeróbico na melhora cognitiva: uma revisão sistemática}

Autor/coautores: Ana Luisa Ervilha Sabioni, Bárbara Reis Coutinho Almeida, Rafaela Aparecida Ervilha Sato.

Instituição: Faculdade de Ciências Médicas e da Saúde de Juiz de Fora (FCMS/JF), Juiz de ForaMG; Centro Universitário Unifaminas, Muriaé-MG, Fundação Presidente Antônio Carlos (FUPAC), Ubá-MG.

Palavras-chave: Cognição, Terapia por exercício, Qualidade de vida.

\section{INTRODUÇÃO}

A população mundial está envelhecendo e promover um envelhecimento cognitivo saudável é uma prioridade e um desafio à saúde pública (APÓSTOLO J, et al., 2019). A atividade física não só é benéfica para a saúde de uma pessoa, mas também pode ter uma influência positiva no funcionamento cognitivo de idosos com e sem comprometimento cognitivo (BALLIN M, et al., 2019). Estudos recentes sugerem que o exercício físico aeróbico pode diminuir a carga neuropatológica e aumentar a neurogênese do hipocampo, sendo uma alternativa para potencializar o tratamento da demência. (ZHU Y, et al., 2020).

\section{OBJETIVO}

Realizar uma revisão sistemática da literatura sobre os efeitos do exercício físico aeróbico na melhora da função cognitiva em idosos.

\section{MÉTODO}

Revisão sistemática na base de dados Medline, utilizando expressões como "older adults", "aerobic exercises" e "cognitive", com suas respectivas variações segundo o MeSH. Os filtros utilizados foram "Humans", "5 years", "Full text", sendo escolhidos 3 artigos diretamente relacionados ao tema dentre os 45 encontrados na pesquisa. Foram incluídos apenas estudos de ensaio clínico.

\section{RESULTADOS E DISCUSSÃO}

Os resultados sugerem que qualquer atividade física na terceira idade parece ter um impacto positivo na melhoria no funcionamento neurocognitivo, velocidade de processamento, atenção e 
flexibilidade cognitiva, indicando que o exercício físico, quando realizado de forma regular, está associado a melhora da função cognitiva geral (BALLIN M, et al., 2019). Além disso, parece que a dança, devido a seus múltiplos mecanismos, pode ter o maior efeito no aprimoramento do desempenho cognitivo em idosos saudáveis .A atividade física regular, voltada para 0 desenvolvimento de habilidades de automatismo, afeta o desempenho cognitivo e retarda a progressão da perda de memória para a demência em idosos (ZHU Y, et al., 2020). O efeito do exercício na função cognitiva depende da frequência com que o exercício é realiza- do, portanto o exercício regular, em oposição ao exercício ocasional, é essencial para experimentar uma melhora na função cognitiva. Todavia, foi verificado efeitos adversos de gravidade moderada em alguns participantes como dor no membro inferior (APÓSTOLO J, et al., 2019).

\section{CONSIDERAÇÕES FINAIS}

O exercício aeróbico foi capaz de melhorar a função cognitiva e o bem-estar mental em idosos. No entanto, estudos clínicos randomizados com amostras maiores são necessários para reivindicar conclusivamente o impacto da atividade física como instrumento que auxilia na melhora cognitiva.

\section{REFERÊNCIAS}

APÓSTOLO J, et al. Effectiveness of a Combined Intervention on Psychological and Physical Capacities of Frail Older Adults: A Cluster Randomized Controlled Trial. Int J Environ Res Public Health ; 16(17)2019 0828.

ZHU Y, et al. Effects of Aerobic Dance on Cognition in Older Adults with Mild Cognitive Impairment: A Systematic Review and Meta-Analysis. J Alzheimers Dis ; 74(2): 679-690, 2020.

BALLIN M, et al. Effects of interval training on quality of life and cardiometabolic risk markers in older adults: a randomized controlled trial. Clin Interv Aging ; 14: 1589-1599, 2019. 
085 | RESUMOS SIMPLES: Revisão Bibliográfica

\section{A influência de intervenções dietéticas em portadores do Transtorno do Espectro Autista: uma revisão sistemática}

Autor/coautores: Ana Luisa Ervilha Sabioni, Bárbara Reis Coutinho Almeida, Rafaela Aparecida Ervilha Sato.

Instituição: Faculdade de Ciências Médicas e da Saúde de Juiz de Fora (FCMS/JF), Juiz de ForaMG; Centro Universitário Unifaminas, Muriaé-MG, Fundação Presidente Antônio Carlos (FUPAC), Ubá-MG

Palavras-chave: Autismo, Intervenções dietéticas, Qualidade de vida.

\section{INTRODUÇÃO}

O Transtorno do Espectro do Autismo (TEA) é um transtorno do neurodesenvolvimento caracterizado por prejuízo na interação social. Uma em cada 69 crianças apresenta traços de autismo, com prevalência cinco vezes maior em meninos. A Organização Mundial da Saúde estima que 2 milhões estão no Brasil (MONTEIRO MA, et al., 2020). Os sintomas gastrointestinais são de particular interesse nesta população, devido à prevalência e correlação com a gravidade dos traços comportamentais, levando a alterações intestinais, como no revestimento da mucosa e em enzimas digestivas, que levam a má absorção de proteínas grandes (GONZÁLEZ-DOMENECH PJ, et al., 2020).

\section{OBJETIVO}

Realizar uma revisão sistemática da literatura sobre os efeitos de dietas livres de glúten, nos aspectos cognitivos de indivíduos com TEA.

\section{MÉTODO}

Revisão sistemática na base de dados Medline, utilizando expressões como "Autism Spectrum Disorder"; "Diet" e "Glúten", com suas respectivas variações segundo o $\mathrm{MeSH}$. Os filtros utilizados foram "Humans", "5 years" e "Full text", sendo escolhidos 3 artigos diretamente relacionados ao tema dentre os 15 encontrados na pesquisa.

\section{RESULTADOS E DISCUSSÃO}

Os estudos sugerem que as intervenções dietéticas influenciaram na melhora do aspecto antissocial e da fala e além da diminuição nos distúrbios comportamentais. Sendo que, os indivíduos 
com idade entre 7 a 9 anos possuíram melhor resposta a abordagem (MONTEIRO MA, et al., 2020). O glúten e a caseína, que podem atravessar a parede do intestino, e então a barreira hematoencefálica (BHE), onde, no SNC, atuam como neuropeptídeos. Por conseguinte, uma dieta com glúten pode aumentar a concentração desse neuropeptídio no SNC, levando a alterações funcionais no individuo com TEA (GONZÁLEZ-DOMENECH PJ, et al., 2020). Evidências indicam que os peptídeos liberados na absorção do glúten, se ligam a receptores opioides, modulando seus níveis cerebrais, alterando o funcionamento de sistemas serotoninérgicos, dopaminérgicos e GABAérgicos, que se utilizam de opioides como reguladores, alterando funções neurológicas, levando a efeitos adversos nos campos da atenção, maturação cerebral, interações sociais e aprendizado (PIWOWARCZYK A, et al., 2020).

\section{CONSIDERAÇÕES FINAIS}

Há fortes evidências suportando a relação entre microbiota intestinal e as alterações encontradas em indivíduos com transtorno depressivo. Embora alguns autores relatem progresso nos sintomas associados ao autismo em indivíduos com Transtorno do Espectro Autístico submetidos a intervenções nutricionais, existem poucas evidências científicas para apoiar o uso de suplementos nutricionais ou terapias dietéticas em crianças e adolescentes com autismo.

\section{REFERÊNCIAS}

MONTEIRO MA, et al. Autism Spectrum Disorder: A Systematic About Nutritional Interventions. Rev Paul Pediatr ; 38: e2018262, 2020.

PIWOWARCZYK A, et al. Gluten-Free Diet in Children with Autism Spectrum Disorders: A Randomized, Controlled, Single-Blinded Trial. J Autism Dev Disord ; 50(2): 482-490, 2020 Feb.

GONZÁLEZ-DOMENECH PJ, et al. Influence of a Combined Gluten-Free and Casein-Free Diet on Behavior Disorders in Children and Adolescents Diagnosed with Autism Spectrum Disorder: A $12-$ Month Follow-Up Clinical Trial. J Autism Dev Disord; 50(3): 935-948, 2020 Mar. 
086 | RESUMOS SIMPLES: Revisão Bibliográfica

\section{Comorbidades relacionadas ao Transtorno do Déficit de Atenção e Hiperatividade: uma revisão sistemática}

Autor/coautores: Ana Luisa Ervilha Sabioni, Bárbara Reis Coutinho Almeida, Rafaela Aparecida Ervilha Sato.

Instituição: Faculdade de Ciências Médicas e da Saúde de Juiz de Fora (FCMS/JF), Juiz de ForaMG; Centro Universitário Unifaminas, Muriaé-MG, Fundação Presidente Antônio Carlos (FUPAC), Ubá-MG.

Palavras-chave: Comorbidades, Transtorno do déficit de atenção e hiperatividade, Crianças.

\section{INTRODUÇÃO}

O Transtorno do Déficit de Atenção e Hiperatividade (TDAH) é considerado uma importante doença neuropsiquiátrica de início na infância caracterizado por desatenção, hiperatividade e impulsividade (SCIBERRAS E, et al., 2016). O TDAH pode persistir até a idade adulta e pode afetar o funcionamento social e ocupacional de indivíduos. Distúrbio do neodesenvolvimento relacionado a distúrbios internalizantes e externalizantes, além de queixas e distúrbios somáticos. Ademais, as comorbidades são muito estudadas e consideradas frequentes nos adultos, contudo, elas podem começar na infância e persistir na vida adulta (EFRON D, et al., 2016).

\section{OBJETIVO}

Realizar uma revisão sistemática da literatura sobre as comorbidades mais frequentemente associadas com o TDAH em crianças e adolescentes.

\section{MÉTODO}

Revisão sistemática na base de dados Medline, utilizando expressões como "Autism Spectrum Disorder"; "Diet" e "Glúten", com suas respectivas variações segundo o $\mathrm{MeSH}$. Os filtros utilizados foram "Humans", "5 years" e "Full text", sendo escolhidos 3 artigos diretamente relacionados ao tema dentre os 15 encontrados na pesquisa.

\section{RESULTADOS E DISCUSSÃO}

A comorbidade mais frequente foi a rinite, presente em 18,62\%, seguida da asma em $10,78 \%$ dos pacientes portadores de TDAH (EFRON D, et al., 2016). As crianças com TDAH apresentaram pior saúde global, as crianças com TDAH apresentaram maior chance de problemas de sono 
moderados a grandes, em comparação a criança saudáveis. Ademais, a enxaqueca está presente em grande parto dos portadores, assim com a dor de cabeça por tensão (SCIBERRAS E, et al., 2016). Contudo, não houve diferenças entre as crianças com e sem TDAH em termos de lesões físicas ou sobrepeso e obesidade. A média da idade dos participantes com comorbidade foi de 12,39 anos. A prevalência de todos os sintomas foi maior no sexo masculino em relação ao feminino na proporção de 6:1 e entre os adolescentes em relação as crianças (KUTUK MO, et al., 2018)

\section{CONSIDERAÇÕES FINAIS}

As crianças pequenas com TDAH apresentam uma série de deficiências relacionadas à saúde, que são exacerbadas pela presença de comorbidades internalizantes e externalizante. No futuro, estudos genéticos poderão esclarecer melhor essa associação. Intervenções que incorporam estratégias focadas no manejo de doenças alérgicas e cuidados colaborativos para crianças com TDAH devem ser exploradas.

\section{REFERÊNCIAS}

SCIBERRAS E, et al. Health-related impairments in young children with ADHD: a community-based study. Child Care Health Dev; 42(5): 709-17, 201609.

KUTUK MO, et al. Migraine and associated comorbidities are three times more frequent in children with ADHD and their mothers. Brain Dev; 40(10): 857-864, 2018 Nov.

EFRON D, et al. Service use in children aged 6-8 years with attention deficit hyperactivity disorder. Arch Dis Child ; 101(2): 161-5, 2016 Feb. 


\section{Avaliação entre microbiota intestinal e transtorno depressivo: uma revisão sistemática}

Autor/coautores: Ana Luisa Ervilha Sabioni, Bárbara Reis Coutinho Almeida, Rafaela Aparecida Ervilha Sato.

Instituição: Faculdade de Ciências Médicas e da Saúde de Juiz de Fora (FCMS/JF), Juiz de Fora MG; Centro Universitário Unifaminas (UNI-FAMINAS), Muriaé-MG; Fundação Presidente Antônio Carlos (FUPAC), Ubá-MG.

Palavras-chave: Microbiota intestinal, Depressão, Intestino.

\section{INTRODUÇÃO}

A depressão é um problema médico grave e altamente prevalente na população em geral. De acordo com estudo epidemiológico a prevalência de depressão ao longo da vida no Brasil está em torno de 15,5\% (PASCALE A, et al., 2020). Pessoas depressivas tem maior risco de morte por todas as doenças comparadas aos não depressivos. A época comum do aparecimento é o final da $3^{\mathbf{a}}$ década da vida, mas pode começar em qualquer idade. Evidências acumuladas indicam que pacientes com transtornos mentais graves, incluindo depressão maior, transtorno bipolar e esquizofrenia, apresentam várias alterações da microbiota intestinal e aumento da permeabilidade intestinal (PATTERSON T e GRANDHI R, 2020).

\section{OBJETIVO}

Realizar uma revisão sistemática da literatura sobre os impactos da microbiota intestinal e sua provável interação com transtorno depressivo.

\section{MÉTODO}

Revisão sistemática na base de dados Medline, utilizando expressões como "Depression" e "Intestinal Microbiota", com suas respectivas variações segundo o $\mathrm{MeSH}$, foram excluindo artigos que fugissem da temática do foco de pesquisa. Os filtros utilizados foram "Humans", "5 years", "Full text", sendo escolhidos 3 artigos diretamente relacionados ao tema dentre os 21 encontrados na pesquisa. 


\section{RESULTADOS E DISCUSSÃO}

As evidências sugerem que a microbiota intestinal pode ativar o eixo hipotálamo-pituitáriaadrenal HPA através de vários mediadores que atravessam a barreira hematoencefálica e incluem antígenos microbianos, citocinas e prostaglandinas (ZHOU N, 2020). Há também evidências de que várias espécies microbianas podem afetar a produção de corticosterona ileal, o que pode afetar a atividade do eixo HPA. Foi postulado que a ativação do eixo HPA pode afetar a microbiota intestinal e a permeabilidade intestinal, indivíduos com depressão tem seu conjunto de microrganismos intestinais diferente de indivíduos saudáveis (PATTERSON T e GRANDHI R, 2020). Espécies associadas a mecanismos estressores e pró-inflamatórios em maior número; outras com atividade anti-inflamatória e no metabolismo da serotonina, ácido gama-aminobutírico (GABA) e Fator Neurotrófico derivado do Cérebro em menor quantidade. A doença também exibe níveis elevados de marcadores inflamatórios como IL-6, TNF- $\alpha$, IL-1 $\beta$, além de $\lg A$ e IgM, possivelmente associado aos outros achados (PASCALE A, et al., 2020).

\section{CONSIDERAÇÕES FINAIS}

As evidências identificadas nesta revisão da literatura mostram que há fortes evidências suportando a relação entre microbiota intestinal e as alterações encontradas em indivíduos com transtorno depressivo. Esses dados abrem a possibilidade para novas formas de prevenção e tratamento, as quais poderiam ser mais eficazes, melhor adesão e com menos efeitos colaterais.

\section{REFERÊNCIAS}

ZHOU N. Gut Microbiota: A Pivotal Hub for Polyphenols as Antidepressants. J Agric Food Chem ; 68(22): 6007-6020, 2020 Jun 03.

PATTERSON T, Grandhi R. Gut Microbiota and Neurologic Diseases and Injuries. Adv Exp Med Biol ; 1238: 73-91, 2020.

PASCALE A, et al. Targeting the microbiota in pharmacology of psychiatric disorders. Pharmacol Res; 157: 104856, 2020 Jul. 
088 | RESUMOS SIMPLES: Revisão Bibliográfica

\section{O impacto do abuso de analgésicos em migranosos: uma revisão sistemática}

Autor/coautores: Ana Luisa Ervilha Sabioni, Bárbara Reis Coutinho Almeida, Miguel Eduardo Guimarães Macedo.

Instituição: Faculdade de Ciências Médicas e da Saúde de Juiz de Fora (FCMS/JF), Juiz de ForaMG; Centro Universitário Unifaminas (UNI-FAMINAS), Muriaé-MG

Palavras-chave: Migrânea, Abuso de analgésicos, Comorbidades.

\section{INTRODUÇÃO}

Migrânea é uma cefaleia primária episódica e crônica, que ocupa no ranking da Organização Mundial de Saúde, a 19a posição entre todas as doenças que causam incapacidade. Desordem idiopática com sintomas neurológicos, localizadas no córtex ou tronco cerebral, apresenta dois substratos clínicos bem definidos, com e sem aura, representada por sintomas neurológicos focais (CORBELLI I, et al., 2018). Tipicamente os sintomas se manifestam por 4 a 72 horas e podem ser graves. Sintomatologia clássica é dor unilateral, pulsátil, piora com o esforço. Já a aura faz referência a sintomas neurológicos reversíveis, predominantemente prodrômicos em relação à cefaleia, com distúrbios visuais e sensitivos, principalmente (DIENER HC, et al., 2018).

\section{OBJETIVO}

Realizar uma revisão sistemática da literatura sobre os impactos proporcionado pelo uso abusivo de analgésicos em pacientes com migrânea.

\section{MÉTODO}

Revisão sistemática na base de dados Medline, utilizando expressões como "headache", "comorbidities" e "medication", com suas respectivas variações segundo o $\mathrm{MeSH}$, foram excluindo artigos que fugissem da temática do foco de pesquisa. Os filtros utilizados foram "Humans", " 5 years", "Full text", sendo escolhidos 3 artigos diretamente relacionados ao tema dentre os 21 encontrados na pesquisa.

\section{RESULTADOS E DISCUSSÃO}

Configura-se abuso por AINES ou analgésicos comuns seu uso $\geq 15$ dias ao mês, por $>3$ meses, enquanto no caso de opiáceos e triptanos, uso $\geq 10$ dias ao mês, por $>3$ meses. Dentre pacientes 
com tal comportamento, destacam-se os portadores de migrânea associada a distúrbios psiquiátricos (CORBELLI I, et al., 2018). Muitos doentes consomem analgésico em antecipação à cefaleia com receio de dor, cerca de $90 \%$ de migranosos se automedicam. De acordo com os dados analisados, 37\% utilizam os analgésicos compostos com Dipirona, 23\% Dipirona, 6\% compostos com Paracetamol, 16\% Paracetamol, 6\% triptanos e 12\% AINES (FERRARI A, et al., 2018). O uso excessivo de medicamentos é um importante fator de risco para aumento da frequência da cefaleia; pode levar à cefaleia secundária por abuso de analgésicos em $70 \%$ dos usuários, além de quadros psiquiátricos, como ansiedade, distúrbio de humor e depressão moderada ou grave em $60 \%$ (DIENER HC, et al., 2018).

\section{CONSIDERAÇÕES FINAIS}

A automedicação, se explica pela ausência de correto tratamento profilático ou até mesmo abortivo de crise; estudos indicam que pacientes não vão a consulta por relarem saber o que os médicos iram prescrever. Contudo, estudos clínicos randomizados com amostras maiores são necessários para reivindicar conclusivamente o impacto do abuso de analgésicos em migranosos.

\section{REFERÊNCIAS}

DIENER HC, et al. Chronic Headache Due to Overuse of Analgesics and Anti-Migraine Agents. Dtsch Arztebl Int; 115 (22): 365-370, 2018.

CORBELLI I, et al. Early management of patients with medication-overuse headache: results from a multicentre clinical study. Eur J Neurol; 25 (8): 1027-1033, 2018.

FERRARI A, et al. Polypharmacy Among Headache Patients: A Cross-Sectional Study. CNS Drugs; 32 (6): 567-578, 2018. 
089 | RESUMOS SIMPLES: Revisão Bibliográfica

\section{Uso do soft laser no controle da dor nas disfunções temporomandibulares}

Autor/coautores: Luana dos Santos Fonseca Peixoto, lasmin Fares Menezes de Lima, Larissa Barbosa Rodrigues da Silva, Ricardo José De Holanda Vasconcellos, Carolina Chaves Gama Aires. Instituição: Universidade de Pernambuco (UPE), Recife - Pernambuco.

Palavras-chave: Disfunção Temporomandibular, Dor orofacial, Laserterapia.

\section{INTRODUÇÃO}

A disfunção temporomandibular (DTM) é uma desordem multifatorial, definida como um conjunto de dor e/ou disfunções relacionadas com os músculos mastigatórios, a articulação temporomandibular (ATM) e estruturas próximas. Pelo menos $40 \%$ dos indivíduos já apresentaram sinal dessa disfunção e tem como queixa principal a dor na ATM, prejudicando nas atividades do trabalho (73\%), sono (85\%) e apetite/alimentação (82\%) (ARAÚJO IRS, et al., 2019; TORTELLI SAC, et al., 2019). O soft laser vem sendo utilizado para fins terapêuticos na odontologia, possibilitando seguimentos benéficos nas perspectivas de observação clínica e funcional, minimizando o quadro doloroso, através do seu efeito analgésico (SILVA NETO JMA, et al., 2019).

\section{OBJETIVO}

Revisar sobre a ação e utilização do soft laser pelos cirurgiões dentistas em indivíduos diagnosticados com DTM diante de sua eficácia na diminuição da dor e desconforto, observando vantagens de seu uso.

\section{REVISÃo BIBLIOGRÁFICA}

Por tratar-se de uma técnica minimamente agressiva, acessível, simples e não traumática, sem relatos de toxicidade, a utilização do laser é alegórica nos procedimentos terapêuticos de tecidos, não possuindo risco de prejudicar as células saudáveis (SILVA NETO JMA, et al., 2019).

Indivíduos diagnosticados com DTM tratados com soft laser têm mostrado resultados efetivos no tratamento da dor e função muscular. Isso porque, o soft laser é uma luz monocromática altamente concentrada que em contato com o tecido pode resultar em diversos efeitos e influências na síntese, liberação e metabolismo de substâncias sinalizadoras que estão envolvidas na analgesia pela irradiação direta sem causar resposta térmica (TORTELLI SAC, et al., 2019). 
Proporciona o estabelecimento terapêutico, analgesia, cicatrização, estímulo de biomodulação dos tecidos e efeitos anti-inflamatório, produzindo resultados positivos em relação a diminuição e controle da dor muscular da DTM, o que fez com que nos últimos anos os pacientes que sofrem com alguma dor crônica ou aguda busquem os Cirurgiões Dentistas (SILVA NETO JMA, et al., 2019).

\section{CONSIDERAÇÕES FINAIS}

A dor causada pela DTM é bastante comum e apresenta um impacto negativo na qualidade de vida do indivíduo. Diante disso, a aplicação do soft laser tem sido uma alternativa confiável de uso pelos cirurgiões dentistas, pelo seu fácil acesso, minimamente agressivo, não possuir efeitos colaterais e apresentar potencial analgésico, proporcionando assim um estabelecimento terapêutico.

\section{REFERÊNCIAS}

ARAÚJO IRS, et al. Conhecimento de cirurgiões-dentistas sobre a relação entre disfunção temporomandibular e fatores oclusais. Rev Odontol UNESP. 2019, 48:e20190065.

SILVA NETO JMA, et al. "Aplicação da laserterapia de baixa intensidade na odontologia: revisão integrativa." Revista Eletrônica Acervo Saúde 39, 2020, 39:e2142-e2142.

TORTELLI SAC, et al. Effectiveness of acupuncture, ozonio therapy and low-intensity laser in the treatment of temporomandibular dysfunction of muscle origin: a randomized controlled trial. Rev Odontol UNESP. 2019; 48:e20190107 
090 | RESUMOS SIMPLES: Revisão Bibliográfica

\section{Os benefícios da fenestração em pacientes submetidos ao procedimento Fontan: uma revisão sistemática}

Autor/coautores: Ana Luisa Ervilha Sabioni, Bárbara Reis Coutinho Almeida, Miguel Eduardo Guimarães Macedo.

Instituição: Faculdade de Ciências Médicas e da Saúde de Juiz de Fora (FCMS/JF), Juiz de ForaMG; Centro Universitário Unifaminas (UNI-FAMINAS), Muriaé-MG

Palavras-chave: Fontan, Univentricular, Cavo-pulmonar total.

\section{INTRODUÇÃO}

A anastomose cavo-pulmonar total (cirurgia de Fontan) é o último procedimento de uma estratégia estadiada, se tornar a cirurgia paliativa definitiva para os pacientes portadores de cardiopatias congênitas complexas com ventrículo único anatômico ou funcional; também chamada de cardiopatia congênita com coração univentricular (RAVISHANKAR C, et al., 2016). Em sua evolução histórica sofreu algumas modificações, que diminuíram sua morbidade e mortalidade de maneira significativa, possuindo diversas modalidades cirúrgicas, podendo correr da forma fenestrado e não fenestrado; estima-se que 1 a cada 100 nascidos vivos apresentem uma cardiopatia (LI D, et al., 2019).

\section{OBJETIVO}

Realizar uma revisão sistemática da literatura sobre os efeitos iniciais de um procedimento de Fontan fenestrado (F) em detrimento do não fenestrado (NF)

\section{MÉTODO}

Revisão sistemática na base de dados Medline, utilizando expressões como "Fontan" e "fenestrated" com suas respectivas variações segundo o $\mathrm{MeSH}$, foram excluindo artigos que fugissem da temática do foco de pesquisa. Os filtros utilizados foram "Humans", " 5 years", "Full text", sendo escolhidos 2 artigos diretamente relacionados ao tema dentre os 51 encontrados na pesquisa.

\section{RESULTADOS E DISCUSSÃO}

Foram analisados estudos tipo ensaio clínico, durante a análise estatística incluíram no grupo intervencionista paciente submetidos a cirurgia de Fontan fenestrado $(F)$, enquanto o grupo controle 
era representando pela cirurgia de Fontan não federado (NF) (RAVISHANKAR C, et al., 2016). De acordo com os dados analisados não houve diferença significativa quanto ao risco de falha em ambos os grupos, contudo o grupo controle (NF) apresentou maior pressão arterial pulmonar, maior necessidade de drenagem pleural, porém uma maior taxa de saturação de oxigênio quando comprado ao grupo que sofreu a intervenção (F) (RAVISHANKAR C, et al., 2016). A fenestração melhora o resultado imediato no pós-operatório, por descompressão do circuito venoso-pulmonar e aumento do débito cardíaco, a despeito da desnaturação arterial de oxigênio e do risco de embolia paradoxal, as técnicas de anastomose cavopulmonar têm dominado o cenário de tratamento das cardiopatias univentriculares. (LI D, et al., 2019).

\section{CONSIDERAÇÕES FINAIS}

A fenestração de Fontan reduziu efetivamente a pressão pulmonar e a necessidade de drenagem pleural prolongada. A técnica de conduto intracardíaco foi associada a menor morbidade pósoperatória, sendo a opção atual do nosso serviço na anastomose cavopulmonar total.

\section{REFERÊNCIAS}

LI D, et al. Comparison of the fenestrated and non-fenestrated Fontan procedures: A meta-analysis. Medicine (Baltimore). 2019 Jul;98(29):e16554.

RAVISHANKAR C, et al. Factors affecting Fontan length of stay: Results from the Single Ventricle Reconstruction trial. J Thorac Cardiovasc Surg. 2016 Mar;151(3):669-675.e1. 
091 | RESUMOS SIMPLES: Revisão Bibliográfica

\section{Benefícios das rodas de gestantes no ciclo gravídico puerperal: uma revisão integrativa da literatura}

Autor/coautores: Maria Eduarda da Silva Valentino Ferreira, Raila Gonçalves dos Santos, Tuanny Caroline Pereira de Santana, Maria Beatriz Falcão Pinto, Geyslane Pereira Melo de Albuquerque. Instituição: Faculdade Pernambucana de Saúde (FPS), Recife- Pernambuco

Palavras-chave: Educação em Saúde, Promoção da Saúde, Enfermagem.

\section{INTRODUÇÃO}

A gestação é caracterizada pelo surgimento de dúvidas, incertezas, inquietação, anseios e medos pelas diversas mudanças biopsicossociais. Neste contexto, roda de gestantes são espaços para ajudar as mulheres a compreender todo este processo da melhor forma possível de maneira com que ela se sinta protagonista da sua gravidez escolhendo a via de parto, acompanhando 0 crescimento do bebê e o bem-estar de todos em sua volta (ARAÚJO LAM, et al., 2018).

\section{OBJETIVO}

Revisar os benefícios das rodas de gestantes no ciclo gravídico puerperal, apresentando as principais evidências encontradas na literatura.

\section{MÉTODO}

Trata-se de um estudo do tipo Revisão de literatura realizada nas bases de dados PubMeb e Biblioteca Virtual em Saúde. Incluindo: 5 artigos completos relacionados ao tema, publicados de 2016 a 2020, utilizando como descritores: Educação em Saúde, Promoção da Saúde, Enfermagem. Foram excluídos os artigos que não se enquadravam nos objetivos propostos.

\section{RESULTADOS E DISCUSSÃO}

Após análise dos artigos observou-se diversos benefícios das rodas de gestantes, como compartilhamento de experiência e saberes, maior aproximação das gestantes com a equipe e o serviço de saúde, despertar da mulher e acompanhante para o protagonismo do cuidar, incentivo sobre a capacidade de realizar suas próprias escolhas de forma consciente, além de orientações sobre os cuidados tomados durante a fase gravídico-puerperal (MORAIS LO, et al., 2019).

O momento da roda de gestantes vem com a finalidade de proporcionar uma ausculta mediante as suas preferências e necessidades pessoais, orientando as mulheres sobre todos os eventos que 
acontecerão no processo do parto humanizado, nascimento e pós-parto. Desta forma, o atendimento a gestante permite que as mulheres se sintam no controle do seu plano de parto, mostrando a efetividade e importância das rodas no processo de promoção da saúde (ARAÚJO LAM, et al., 2018).

\section{CONSIDERAÇÕES FINAIS}

A presente pesquisa revelou que, os benefícios das rodas de gestantes no ciclo gravídico puerperal serão necessários para o melhor engajamento dos profissionais de saúde e empoderamento das mulheres num momento tão marcante de suas vidas. Desta forma, é de suma importância a roda de gestantes para que as mesmas que se encontram com dúvidas consigam esclarecer os seus questionamentos.

\section{REFERÊNCIAS}

ARAÚJO LAM, et al. Escolha de via de parto em uma maternidade de referência em TeresinaPI. Revista Eletrônica Acervo Saúde, 2018; 11(3), e196.

CARDOSO RF, et al. Educação em saúde na assistência pré-natal: revisão de literatura. Revista Eletrônica Acervo Saúde, 2019; (23), e397.

MORAIS LO, et al. O Parto Humanizado no contexto atual: Uma revisão integrativa. Revista Eletrônica Acervo Saúde, 2019; (37), e1375. 
092 | RESUMOS SIMPLES: Revisão Bibliográfica

\section{Uso da acupuntura no tratamento da parestesia do nervo alveolar inferior após cirurgia ortognática}

Autor/coautores: Luana dos Santos Fonseca Peixoto, Carolina Pereira da Silva, Heitor Tavares de Araújo, lasmin Fares Menezes de Lima, Rosa Rayanne Lins de Souza.

Instituição: Faculdade de Odontologia da Universidade de Pernambuco (FOP/UPE), Camaragibe PE. Hospital da Restauração Governador Paulo Guerra, Recife - PE.

Palavras-chave: Parestesia, Nervo alveolar Inferior, Cirurgia Ortognática.

\section{INTRODUÇÃO}

A cirurgia ortognática de caráter funcional e estético visa corrigir deformidades faciais e maxilomandibulares. A região mandibular, contém estruturas nervosas sensíveis como o nervo alveolar inferior, o nervo lingual e o nervo bucal que fazem dela uma zona frequentemente afetada por parestesias. Parestesia do nervo alveolar inferior (PNAI) é um distúrbio neurosensorial com alterações da sensibilidade, sensação de parestesias e dormência na região mandibular, lábio inferior e mento e configura-se como uma preocupação de pacientes e cirurgiões pós cirurgia ortognática. Geralmente é revertida de forma natural na maioria dos casos, contudo, há a possibilidade da prevalência desta parestesia após dois anos da cirurgia (VAZ PNC, et al., 2016).

\section{OBJETIVO}

Apresentar uma revisão bibliográfica sobre a técnica terapêutica oriental da acupuntura ser eficaz como terapia complementar no tratamento da parestesias no nervo alveolar inferior em pacientes submetidos à cirurgia ortognática.

\section{REVISÃO BIBLIOGRÁFICA}

O tratamento da parestesia pode variar de acordo com sua etiologia, sendo inclusos como terapias de destaque: acupuntura, laserterapia, tratamento medicamentoso, microneurocirurgia eletroestimulação, fisioterapia e calor úmido. Estudos mostram que a acupuntura tem se tornado muito eficiente para o tratamento de danos ao nervo alveolar inferior (MATOS FX, et al., 2019).

A palavra acupuntura é de origem latina e significa acus $=$ agulha, e puctura $=$ picada, é a introdução de agulhas em pontos específicos da pele, chamados acupontos com a finalidade de cura e prevenção de doenças. A acupuntura é um método da medicina tradicional chinesa que se 
baseia na busca da harmonia entre o corpo e a mente, por meio de canais, chamados "meridianos de energia", que representam as linhas imaginárias que percorrem todo o corpo. Ela atua liberando mediadores químicos endógenos como as acefalinas e endorfinas, com ação analgésica, relaxante e anti-inflamatória através de agulhas, sementes e massagens. (GONÇALVES A, et al., 2019).

\section{CONSIDERAÇÕES FINAIS}

A utilização da acupuntura no tratamento da parestesia do nervo alveolar inferior após a cirurgia ortognática tem demonstrado excelentes resultados na redução dos sintomas, auxiliando na velocidade de recuperação do paciente, que é submetido a menos desconforto e tem sua qualidade de vida devolvida.

\section{REFERÊNCIAS}

GONÇALVES A, et al. A Acupuntura Como Complementação Nos Tratamentos Odontológicos. Revista De Odontologia Contemporânea, 2019; 3(1):4-11.

MATOS FX, et al. Laserterapia para tratamento de parestesia do Nervo Alveolar Inferior após extrações de terceiros molares inferiores: Revisão de Literatura. Revista Multidisciplinar e de Psicologia, 2019; 13(48):1-13.

VAZ PNC, et al. ABORDAGEM DA MEDICINA CHINESA NA PARESTESIA DO NERVO ALVEOLAR INFERIOR PÓS CIRURGIA ORTOGNÁTICA. Revista UIIPS, 2016; 4(3):Vol 4 n. 3 (2016): Número Especial - Terapêuticas Não Convencionais. 
093 | RESUMO SIMPLES: Revisão Bibliográfica

\section{A acupuntura como terapia complementar na clínica odontológica}

Autor/coautores: Luana dos Santos Fonseca Peixoto, Carolina Pereira da Silva, Heitor Tavares de Araújo, lasmin Fares Menezes de Lima, Rosa Rayanne Lins de Souza.

Instituição: Faculdade de Odontologia da Universidade de Pernambuco (FOP/UPE), Camaragibe PE. Hospital da Restauração Governador Paulo Guerra, Recife - PE.

Palavras-chave: Acupuntura, Medicina Tradicional Chinesa, Odontologia.

\section{INTRODUÇÃO}

Terapias complementares vêm sendo utilizadas em paralelo ao tratamento indicado para cada caso, nas diferentes áreas da prática odontológica, assim como a utilização da Acupuntura. Essa terapêutica é uma intervenção não farmacológica e complementar que na maioria das vezes se destaca pelos seus resultados satisfatórios no tratamento de diversas doenças, além de possuir um custo-benefício significativo, pois se trata de uma terapia atóxica e de baixo custo. Tal feito, propicia melhor qualidade de vida, bem-estar e saúde ao paciente (MELO GAA, et al., 2020; FERNANDES NETO JA, et al., 2017).

\section{OBJETIVO}

Realizar uma revisão bibliográfica acerca da prática da acupuntura como forma de uma terapia complementar na clínica odontológica bem como a sua definição, indicação, suas técnicas utilizadas e os seus resultados.

\section{REVISÃO BIBLIOGRÁFICA}

Em 2015, o Conselho Federal de Odontologia (CFO), através da Resolução CFO-160/20151, reconheceu a acupuntura como uma especialidade odontológica, na qual há terapias que consistem na aplicação dos conceitos básicos da Medicina Tradicional Chinesa como sistema de conhecimento. Devido às suas propriedades anti-inflamatórias, ansiolíticas, miorrelaxantes e ativadoras da função imunológica, a acupuntura é aplicada como tratamento, prevenção e/ou manutenção do estado geral de saúde do paciente odontológico, sempre que houver circunstâncias clínicas em que exista a participação de estruturas do sistema estomatognático, respeitando os limites do cirurgião-dentista. Há indicações para o tratamento de desordens temporomandibulares 
(DTM), xerostomia e hipofluxo salivar, controle da parestesia, dor, síndrome da ardência bucal e no controle da ansiedade. Dentre as técnicas utilizadas, destacam-se a acupuntura, eletroacupuntura, laser acupuntura e a acupuntura microssistêmica (FERNANDES NJA, et al., 2019; MELO GAA, et al., 2020).

Porém, apesar de ser não invasiva e com benefícios aos tratamentos odontológicos convencionais, a acupuntura na odontologia ainda é pouco utilizada e estudada. Seus resultados variam consideravelmente de nenhum efeito a uma melhora significativa (FERNANDES NJA, et al., 2017).

\section{CONSIDERAÇÕES FINAIS}

Apesar da acupuntura ser considerada na literatura uma importante terapia complementar na prática odontológica, poucos estudos foram desenvolvidos visando um conhecimento mais aprofundado para sua utilização. Assim, sugere-se que sejam realizadas mais pesquisas a fim de se obter um maior conhecimento acerca da aplicação dessa terapia na odontologia.

\section{REFERÊNCIAS}

FERNANDES NJA, et al. A Pesquisa Científica Brasileira Sobre Acupuntura na Odontologia: Análise Bibliométrica dos Trabalhos Apresentados nas Reuniões da SBPqO. Journal of Health Sciences, 2019; $21(4): 348-351$.

FERNANDES NJA, et al. Habilitação em acupuntura para cirurgiões-dentistas no Brasil: uma análise por estados e regiões. Archives of health investigation, 2017; 6(4):181-184.

MELO GAA, et al. Efeitos da acupuntura em pacientes com insuficiência renal crônica: revisão sistemática. Revista Brasileira de Enfermagem, 2020; 73(4):e20180784. 
094 | RESUMOS SIMPLES: Revisão Bibliográfica

\section{O acolhimento na rede de atenção primária}

Autor/coautores: Luana dos Santos Fonseca Peixoto, Carolina Pereira da Silva, Heitor Tavares de Araújo, lasmin Fares Menezes de Lima, Rosa Rayanne Lins de Souza.

Instituição: Faculdade de Odontologia da Universidade de Pernambuco (FOP/UPE), Camaragibe PE. Hospital da Restauração Governador Paulo Guerra, Recife - PE.

Palavras-chave: Humanização da assistência, Acolhimento, Saúde Pública.

\section{INTRODUÇÃO}

No ano de 2000, com a XI Conferência Nacional de Saúde, o debate acerca do tema acolhimento, apontou algumas dificuldades enfrentadas pelo SUS. Em 2003, na XII Conferência Nacional de Saúde, retornou-se ao debate sobre o acesso ao sistema, desde a valorização dos usuários e dos trabalhadores, até a participação e na gestão do SUS. Neste mesmo ano surge a Política Nacional de Humanização da Atenção e Gestão do SUS- Humaniza SUS (PNH), a qual fomenta mudanças na atenção e na gestão ao convidar os sujeitos envolvidos a (re)pensar e intervir no cotidiano da saúde pública brasileira. (FERMINO JM, et al., 2015; MARTINS CP e LUZIO FA, 2016).

\section{OBJETIVO}

Apresentar uma revisão bibliográfica sobre a definição do acolhimento e a sua aplicação como uma importante ferramenta na rede de atenção primária em resposta às necessidades dos cidadãos que procuram os serviços de saúde.

\section{REVISÃO BIBLIOGRÁFICA}

O acolhimento se configura com uma das diretrizes da Política Nacional de Humanização (HumanizaSus), que propõe o protagonismo de todos os sujeitos envolvidos no processo de produção de saúde, ou seja, os profissionais atuantes na área da saúde, bem como, a reorganização dos serviços a partir de uma problematização dos processos de trabalho (MOREIRA MADM, et al., 2015).

Envolve uma postura ética e de cuidado, uma abertura humana, empática e respeitosa ao paciente e implica em uma avaliação de riscos e vulnerabilidades, eleição de prioridades, percepção de necessidades clínico-biológicas, epidemiológicas e psicossociais. Deve-se permitir hierarquizar as necessidades quanto ao tempo do cuidado, e ainda, distinguir entre necessidades desiguais e 
tratá-las conforme suas características. É uma proposta voltada para a melhoria das relações dos serviços de saúde com os usuários (MARTINS CP e LUZIO FA, 2016; FERMINO JM, et al., 2015).

\section{CONSIDERAÇÕES FINAIS}

O acolhimento baseia-se no encontro do usuário que procura o serviço espontaneamente com os profissionais de saúde, em que há uma escuta, um processamento de sua demanda e a busca da resolução, se possível. Implica compartilhamento de saberes, angústias e invenções, buscando "abrigar" aqueles que procuram o serviço, com responsabilidade.

\section{REFERÊNCIAS}

FERMINO JM, et al. Potencialidades e dificuldades nas práticas de acolhimento na rede de atenção básica conforme a política nacional de humanização. Saúde \& Transformação Social, 2015; 6(2): 54-69.

MARTINS CP, LUZIO FA. Política Humaniza SUS: ancorar um navio no espaço. InterfaceComunicação, Saúde, Educação, 2016; 21(60): 13-22.

MOREIRA MADM, et al. Public humanization policies: integrative literature review. Ciência \& saúde coletiva, 2015; 20(10): 3231-3242. 
095 | RESUMOS SIMPLES: Revisão Bibliográfica

\section{O impacto da pandemia da COVID-19 na saúde mental}

Autor/coautores: Maria Vitória Freire Silva; Henry Jonhson Passos de Oliveira²; Iracema da Silva Frazão3; Raphael Alves da Silva ${ }^{4}$; Felicialle Pereira da Silva¹.

Instituição: 1. Universidade de Pernambuco, Recife-PE; 2. Instituto Aggeu Magalhães, Recife-PE; 3. Universidade Federal de Pernambuco, Recife-PE; Centro Universitário Maurício de Nassau, Recife-PE.

Palavras-chave: Saúde Mental, Saúde Coletiva, COVID-19.

\section{INTRODUÇÃO}

O primeiro caso de infecção pelo novo coronavírus foi reportado na China em dezembro de 2019, e a rápida disseminação do vírus ao nível global fez com que a doença COVID-19 fosse considerada uma pandemia (ZHOU F, et al., 2020). Nesse sentido, medidas como o distanciamento social e o uso de máscaras foram adotadas como principais recomendações para o combate da ameaça à saúde mundial (RIBEIRO IAP, et al., 2020). Além disso, a pandemia da COVID-19 acarretou nos indivíduos sentimentos de ansiedade, medo, insegurança e constantes preocupações. Portanto, torna-se imperiosa a preocupação com a saúde mental devido a esse contexto (LIMA SO, et al., 2020).

\section{OBJETIVO}

Descrever os principais impactos da pandemia causada pela COVID-19, as mudanças no comportamento e os fatores de risco que podem afetar a saúde mental das pessoas de modo geral na atualidade.

\section{REVISÃO BIBLIOGRÁFICA}

Os impactos à saúde mental estão relacionados a vários fatores, principalmente à ansiedade e ao medo, tanto do adoecimento, como o da transmissão para pessoas em casa. O sentimento de impotência, de tédio, angústia e estresse estão presentes no cotidiano das pessoas, pois além das consequências para saúde, houve impacto econômico com o fechamento dos estabelecimentos comerciais (SILVA HGN, et al., 2020). As pessoas passaram a ter medo uma das outras, medidas de limpeza outrora consideradas excessivas hoje são recomendadas, como lavar as mãos frequentemente ao tocar objetos e superfícies. As relações interpessoais passaram a ser afetadas pela situação, uma vez que ninguém pode mais apertar às mãos, ou visitar alguém, quer seja em 
casa, ou mesmo no hospital (AFONSO P e FIGUEIRA ML, 2020). Para pessoas que perderam familiares e amigos, sem poder realizar um funeral conforme sua cultura e crença, torna esse período enlutado com etapas não concluídas. Assim, a atenção à saúde mental é prioritária para população, pois as pessoas necessitam de aconselhamento e suporte para superar os impactos emanados pela COVID-19 (SCHMIDT B, et al., 2020).

\section{CONSIDERAÇÕES FINAIS}

A pandemia da COVID-19 trouxe importante impacto para saúde mental devido às incertezas sobre o futuro e a possibilidade em agravar transtornos mentais preexistentes. $\mathrm{O}$ luto e o isolamento são realidades que requerem estratégias de promoção e cuidado à saúde mental efetivas e direcionadas a população geral.

\section{REFERÊNCIAS}

AFONSO P, FIGUEIRA ML. Pandemia COVID-19: Quais são os Riscos para a Saúde Mental? Revista Portuguesa de Psiquiatria e Saúde Mental, 2020 6(1) 2-3.

LIMA SO, et al. Impactos no comportamento e na saúde mental de grupos vulneráveis em época de enfrentamento da infecção COVID-19: revisão narrativa. Revista Eletrônica Acervo Saúde, 2020: 46: e4006-e4006.

RIBEIRO IAP, et al. Isolamento social em tempos de pandemia por COVID-19: impactos na saúde mental da população. Revista Enfermagem Atual in Derme, 2020 92(30).

SCHMIDT B, et al. Saúde mental e intervenções psicológicas diante da pandemia do novo coronavírus (COVID-19). Estudos de Psicologia (Campinas), 2020: 37.

SILVA HGN, et al. Efeitos da pandemia do novo Coronavírus na saúde mental de indivíduos e coletividades. Journal of Nursing and Health, 2020; 10(4).

ZHOU F, et al. Clinical course and risk factors for mortality of adult inpatients with COVID-19 in Wuhan, China: a retrospective cohort study. Lancet 2020: 395(10229): 1054-1062. 
096| RESUMOS SIMPLES: Revisão Bibliográfica

\section{Ferramenta tecnológica para a implementação da sistematização da assistência de enfermagem}

Autor/coautores: ${ }^{1}$ Cryshna Leticia Kirchesch; ${ }^{1}$ Andre Lacerda Lawinscky de Andrade; ${ }^{1}$ Daniel Antônio Borsari Kirchesch; ${ }^{2}$ João Pedro Borsari Kirchesch.

Instituição: ${ }^{1}$ Universidade Federal de Pelotas (UFPel), Pelotas - Rio Grande do Sul; ${ }^{2}$ Faculdade de Ilhéus CESUPI, Ilhéus - Bahia.

Palavras-chave: Processo de Enfermagem, Serviços de Saúde, SAE.

\section{INTRODUÇÃO}

A implementação da Sistematização da Assistência de Enfermagem (SAE) promove organização das ações realizadas pela equipe e fornece maior segurança ao enfermeiro, uma vez que os registros são documentos que possuem respaldo legal e técnico. No entanto, mesmo sendo uma prática obrigatória e exclusiva do enfermeiro, ainda se evidenciam instituições de saúde que não conseguiram realizar a sua implementação (SILVA MC, et al., 2020). Diante disso, as inovações tecnológicas podem auxiliar na aceleração desse processo. Devido ao tempo escasso e sobrecarga de trabalho, o uso de ferramentas como o prontuário eletrônico vieram para somar na otimização da assistência prestada na área da saúde (CORDEIRO TLR, et al., 2019).

\section{OBJETIVO}

Compreender o funcionamento de uma ferramenta tecnológica para a implementação da Sistematização da Assistência de Enfermagem, de modo a otimizar o tempo dos profissionais e possibilitar que a SAE seja aplicada integralmente em todos os espaços de saúde.

\section{REVISÃO BIBLIOGRÁFICA}

A SAE envolve etapas nas quais acontecem a coleta de dados, levantamento dos diagnósticos de enfermagem, planejamento, implementação e avaliação dos cuidados elencados. Esse processo demanda tempo para execução, e o uso do computador facilita não só o registro, mas a comunicação entre os demais profissionais, que facilmente conseguem acesso ao histórico do paciente por meio do prontuário eletrônico. No entanto, alguns profissionais apresentam dificuldades para manusear as máquinas, o que pode ser sanado com capacitações. Os sistemas de informação, surgiram inicialmente, para suprir as necessidades administrativas e burocráticas dos serviços de saúde, então é comum que ainda precisem de melhorias para se adaptar à realidade 
da assistência. Mesmo com vieses, a ferramenta do prontuário eletrônico auxilia na implementação da SAE, pois a otimização do tempo que ela proporciona é uma característica que lhe beneficia e agrada aos enfermeiros assistenciais, tornando-se assim, uma possibilidade para que mais instituições adotem a SAE como processo de trabalho, conforme determinam os conselhos de classes (CORDEIRO TLR, et al., 2019).

\section{CONSIDERAÇÕES FINAIS}

Os enfermeiros reconhecem o prontuário eletrônico como uma ferramenta que facilita a implementação da SAE nas instituições, porém, trazem que é preciso fazer ajustes para a melhoria da programação. Essa ferramenta permite que as informações registradas sejam acessadas a qualquer momento, facilitando a comunicação dentre os profissionais e trazendo respaldo legal aos enfermeiros.

\section{REFERÊNCIAS}

CORDEIRO TLR, et al. Prontuário eletrônico como ferramenta para a sistematização da assistência de enfermagem no serviço de urgência/emergência: percepção dos enfermeiros. Revista Espaço para a Saúde, 2019;20(2):30-41.

SILVA MC, et al. A implementação da sistematização da assistência de enfermagem no ambiente hospitalar. Braz. J. of Develop., 2020;6(6):33293- 33306. 
097 | RESUMOS SIMPLES: Revisão Bibliográfica

\section{Toxina botulínica como uma ferramenta terapêutica no tratamento da disfunção temporomandibular}

Autores/coautores: Luiza Fernanda Correia Molina Cabral, Anna Carolina Vidal Moura, Júlia Vanessa Bezerra Lima, Juliana Darling Bezerra de Lima, Fernanda Cardoso Machado. Instituição: Universidade de Pernambuco (UPE), Recife - Pernambuco.

Palavras-chave: Toxinas Botulínicas, Músculos da Mastigação, Transtornos da Articulação Temporomandibular.

\section{INTRODUÇÃO}

As Disfunções Temporomandibulares (DTMs) têm levantado grande interesse pela sua crescente incidência na população e pelas suas implicações na qualidade de vida dos indivíduos acometidos. Trata-se de um conjunto de distúrbios que afeta os músculos mastigatórios, a articulação temporomandibular (ATM) e estruturas associadas, causando limitação e dor em seu movimento. Além disso, outros sintomas relatados são manifestações otológicas como zumbido, plenitude auricular e vertigem (NAKED S, et al., 2017). À vista disso, diversos métodos de tratamento são sugeridos como terapia, dentre eles, a toxina botulínica (TB) vem emergindo como uma ferramenta clínica com potencial de agir na diminuição da dor em indivíduos portadores de DTM (FASSINA MT, et al., 2016).

\section{OBJETIVO}

Revisar o uso da toxina botulínica como medida alternativa no tratamento de disfunções temporomandibulares, visando compreender o seu mecanismo de ação, os seus principais efeitos adversos, seus resultados e benefícios.

\section{REVISÃO BIBLIOGRÁFICA}

A TB foi introduzida como método terapêutico para DTM por ser um relaxante muscular específico para os músculos mastigatórios. O seu efeito local é bloquear a inervação da musculatura esquelética através da sua ligação nos terminais nervosos colinérgicos, impedindo a liberação de acetilcolina na junção neuromuscular, diminuindo a contratilidade do músculo alvo (NAKED S, et al., 2017). Com o relaxamento muscular, a função mandibular será restabelecida, ocorrendo diminuição da dor, visto que essas dores são causadas por espasmos musculares derivados da distensão ou contração do músculo. Estes por sua vez, geralmente são causados pela 
hiperatividade muscular, possuindo como principal fator etiológico os hábitos parafuncionais (FASSINA MT, et al., 2016). Ademais, seu uso reverte a hipertrofia massetérica com melhora dos contornos faciais e restaura a cinética normal da ATM. Em contrapartida, os potenciais efeitos adversos da toxina botulínica incluem paralisia do nervo facial, dor no local injetado, fraqueza muscular, disfagia, hematoma, difusão da toxina e paralisia de músculos adjacentes. Contudo, o tratamento com TB possui resultados satisfatórios, sendo minimamente invasivo, sutil e de rápida recuperação (ALVAREZ-PINZON N, et al., 2018).

\section{CONSIDERAÇÕES FINAIS}

A TB apresenta-se como uma alternativa terapêutica eficaz para pacientes portadores da DTM. Entretanto, mais estudos clínicos são necessários a fim de aprimorar a compreensão dos mecanismos de segurança e eficácia de aplicação da TB a longo prazo, e da fisiopatologia desses distúrbios com a finalidade de definir os melhores protocolos de utilização da TB.

\section{REFERÊNCIAS}

ALVAREZ-PINZON N, et al. Toxina Botulínica para el Tratamiento de los Desórdenes Temporomandibulares. Int. J. Odontostomat, 2018; 12(2): 103-109.

FASSINA MT, et al. Toxina botulínica tipo A nas DTM musculares: há eficácia?. Portal Metodista de Periódicos Científicos e Acadêmicos, 2016; 24(48): 1-13.

NAKED S, et al. Toxina botulínica tipo a na disfunção temporomandibular. Revista Fluminense de Odontologia, 2017; 1(47): 1-10. 
098 | RESUMOS SIMPLES: Revisão Bibliográfica

\section{Presença de manifestações orais em pacientes portadores da Síndrome da Imunodeficiência Adquirida}

Autores/coautores: Anna Carolina Vidal Moura, Júlia Vanessa Bezerra Lima, Luiza Fernanda Correia Molina Cabral, Pedro Agra Celestino, Juliana Darling Bezerra de Lima.

Instituição: Universidade de Pernambuco (UPE), Recife - PE e Faculdade Pernambucana de Saúde (FPS), Recife - PE.

Palavras-chave: Síndrome de Imunodeficiência Adquirida, Manifestações Bucais, Infecções Oportunistas Relacionadas com a AIDS.

\section{INTRODUÇÃO}

A AIDS ou Síndrome da Imunodeficiência Adquirida é uma patologia infectocontagiosa causada pelo vírus HIV (Human Immunodeficiency Virus). A transmissão ocorre através de relações sexuais, sangue, agulhas e seringas contaminadas e da mãe infectada para seu filho. A apresentação do HIV no organismo é caracterizada pela degradação das células de defesa do hospedeiro (PAULIQUE NC, et al., 2017). Logo, o sistema imunológico do indivíduo será acometido, deixandoo mais suscetível a outras doenças de origem sistêmica, como as lesões bucais. Assim, é importante que o cirurgião-dentista tenha conhecimento das manifestações orais relacionadas ao vírus para o controle da patologia encontrada (MARÇAL CS, et al., 2018).

\section{OBJETIVO}

Revisar a relação entre síndrome da imunodeficiência adquirida a e as manifestações orais que comumente afetam a cavidade bucal em pacientes portadores da doença, visando alertar o cirurgião-dentista da sua imprescindível função no diagnóstico preciso e precoce destas lesões.

\section{REVISÃO BIBLIOGRÁFICA}

O vírus HIV não tem capacidade de se reproduzir sozinho, por isso, age infectando toda célula do hospedeiro que expresse na superfície o receptor CD4, com maior afinidade pelos linfócitos T. Conforme o vírus se replica, causa depleção dessas células, diminuindo a resistência orgânica contra infecções oportunistas, afetando, também, a atividade imune da mucosa oral (PAULIQUE NC, et al., 2017). 
As manifestações orais podem ser determinantes no diagnóstico da doença em sua fase inicial ou estágio mais avançado. Estas podem ter origem fúngica, bacteriana e viral, além de processos neoplásicos e lesões de natureza desconhecida. Dentre estas manifestações, as mais frequentes são: Candidíase, Gengivite Ulcerativa Necrosante, Periodontite Ulcerativa Necrosante, Leucoplasia Pilosa, Herpes Simples e Sarcoma de Kaposi (DE ARAÚJO JF, et al., 2018).

O papel do cirurgião-dentista é a prevenção e diagnóstico precoce da AIDS. Portanto, estes profissionais devem possuir conhecimentos sobre os processos da doença, suas manifestações bucais, modo de transmissão e como o vírus age no organismo, para assim orientar o paciente e propor o melhor tratamento (MARÇAL CS, et al., 2018).

\section{CONSIDERAÇÕES FINAIS}

Mesmo com os tratamentos atuais que elevam a expectativa de vida dos pacientes soropositivos, a suscetibilidade a lesões bucais ainda é alta. Diante disso, é notória a importância da descoberta dessas manifestações orais precocemente pelo cirurgião-dentista, o qual poderá indicar os primeiros sintomas da doença e auxiliar no tratamento, melhorando a qualidade de vida dos portadores do vírus HIV.

\section{REFERÊNCIAS}

DE ARAÚJO JF, et al. Principais manifestações bucais em pacientes pediátricos HIV positivos e o efeito da terapia antirretroviral altamente ativa. Ciênc. e saúde coletiva, 2018; 23(1): 115-122.

PAULIQUE NC, et al. Manifestações bucais de pacientes soropositivos para HIV/AIDS. Arch Health Invest, 2017; 6(6): 240-244.

MARÇAL CS, et al. Síndrome da imunodeficiência adquirida na criança e no adolescente: conduta odontológica. Revista da Faculdade de Odontologia de Porto Alegre, 2018; 59(2): 72-82. 
099 | RESUMOS SIMPLES: Revisão Bibliográfica

\section{Depressão e suicídio na terceira idade: uma revisão de literatura}

Autor/coautores: Henrique Guimarães Vasconcelos, Fernanda Odete Souza Rodrigues, Daiane Guimarães da Silveira.

Instituição: Universidade de Itaúna (UIT), Itaúna - Minas Gerais; Universidade Federal de Lavras (UFLA), Lavras - Minas Gerais.

Palavras-chave: Suicídio, Idoso, Depressão.

\section{INTRODUÇÃO}

No Brasil, o crescimento da população idosa é cada vez mais expressivo e as taxas de suicídio registradas entre esse grupo são o dobro das que a população em geral apresenta, o que pode indicar que o aumento da idade se relaciona com processos biológicos e psicológicos que podem induzir à decisão de se autodestruir (RAMOS FP, et al., 2019). Dessa forma, a prevenção do suicídio entre os idosos caracteriza-se como um obstáculo importante a ser enfrentado por profissionais de saúde (SANTOS MC e SANTOS MAM, 2019; SANTOS EDG, et al., 2019).

\section{OBJETIVO}

Realizar uma revisão da literatura científica atual a respeito da depressão como um dos fatores de risco para ocorrência de suicídio entre a população idosa.

\section{REVISÃO BIBLIOGRÁFICA}

O Brasil, apesar de não apresentar taxas elevadas de suicídio quando comparado a outros países, demonstra taxas de suicídio entre idosos superiores à média, sendo uma fatalidade mais comum em homens (SANTOS MC e SANTOS MAM, 2019).

O processo de envelhecimento, por si só, apresenta características que se assemelham aos sintomas depressivos, trazendo confusão para seu diagnóstico adequado. Por vezes, o idoso com distúrbio depressivo relata aos seus familiares, antes de alcançar o ápice de seu adoecimento, seu desejo de morrer, fortemente associado a fatores como infelicidade e falta de sentido para a vida (SANTOS EDG, et al., 2019; RAMOS FP, et al., 2019).

Conforme relatado pelos estudos de SANTOS EDG, et al. (2019), é possível que àqueles que convivam com o idoso não façam a correta interpretação de seu comportamento, o que impede a 
busca por ajuda psiquiátrica. Todavia, quando a ajuda profissional é encontrada, o fato de este ser um transtorno complexo, com graus variados de manifestação, torna o idoso mais suscetível à perpetuação do quadro e ao sofrimento psíquico (SANTOS EDG, et al., 2019).

\section{CONSIDERAÇÕES FINAIS}

O diagnóstico e o tratamento precoce da depressão são ferramentas fundamentais para minimizarem a ocorrência desse desfecho, o que ressalta a importância do preparo dos médicos da atenção básica para intervirem nesses casos precocemente. Além disso, é fundamental que a família do idoso busque esclarecimento sobre o assunto e esteja atenta aos sinais que ele possa fornecer (RAMOS FP, et al., 2019).

\section{REFERÊNCIAS}

RAMOS FP, et al. Fatores associados à depressão em idoso. REAS. 2019; (19): e239.

SANTOS MC, SANTOS MAM. Depressão em idosos. Revista de Saúde da ReAGES. 2019; 4(2): 40-45.

SANTOS EDG, et al. Suicídio entre idosos no Brasil: uma revisão de literatura nos últimos 10 anos. Psicología, Conocimiento y Sociedad. 2019; 9(1): 258-282. 
100 | RESUMOS SIMPLES: Revisão Bibliográfica

\section{Síndrome do pânico: grupos de risco e aspectos neurofisiológicos}

Autor/coautores: Fernanda Odete Souza Rodrigues, Henrique Guimarães Vasconcelos, Daiane Guimarães da Silveira.

Instituição: Universidade de Itaúna (UIT), Itaúna - Minas Gerais; Universidade Federal de Lavras (UFLA), Lavras - Minas Gerais.

Palavras-chave: Transtorno do pânico, Mecanismo neural do medo, Neurologia.

\section{INTRODUÇÃO}

Transtornos mentais das mais diversas naturezas têm se tornado cada vez mais comum nos dias atuais, tendo sido relatado na literatura mais de 450 milhões de pessoas com algum destes agravos. Dentre eles, ressalta-se o transtorno do pânico (TP), que é caracterizado pela presença de ataques súbitos de ansiedade, acompanhados por pelo menos quatro entre treze sintomas somáticos ou cognitivos, tais como taquicardia, sudorese, tremores, sufocamento, entre outros. O quadro é, frequentemente, progressivo, com impactos de ordem econômica e com perda da qualidade de vida (KIM YK, 2019; COSTA CO, et al., 2019).

\section{OBJETIVO}

Elucidar e descrever o possível circuito cerebral que leva ao desencadeamento do transtorno do pânico, bem como apresentar os grupos de risco suscetíveis ao desenvolvimento deste quadro patológico.

\section{REVISÃO BIBLIOGRÁFICA}

O TP é cerca de duas vezes mais comum em mulheres e, geralmente, apresenta aumento gradual durante a adolescência, possivelmente associado às alterações hormonais e corticais que marcam esse período (COSTA CO, et al., 2019).

A teoria mais aceita sobre o mecanismo neural desse transtorno postula que, dada uma combinação de fatores genéticos, de desenvolvimento, hormonais e ambientes, ocorre formação de sinapses inibitórias no córtex pré-frontal ventromedial e, assim, este se torna hipoativo. Tal hipoativação resulta em tônus inibitório diminuído e, consequentemente, em maior atividade de estruturas como a amigdala, o hipotálamo, ínsula e a substância cinzenta periaquedutal. A 
hipersensibilidade da ínsula aos estímulos interoceptivos produz uma reação de falso alarme, ativando áreas geradoras do pânico, como o hipotálamo e a substância cinzenta periaquedutal. $\mathrm{A}$ repetição desse circuito aumenta a vulnerabilidade aos ataques de pânico desencadeado por associações comportamentais e ambientais (ZUARDI AW, 2017).

\section{CONSIDERAÇÕES FINAIS}

A síndrome do pânico se desenvolve predominantemente em mulheres a partir da adolescência, o que exige o desenvolvimento de estratégias de saúde específicas para esse o grupo. Em relação ao mecanismo neural, a hipersensibilidade da ínsula aos estímulos interoceptivos assume importante papel no desencadeamento do TP.

\section{REFERÊNCIAS}

KIM YK. Panic disorder: Current research and management approaches. Psychiatry Investigation. 2019; 16(1): 1-3.

ZUARDI AW. Características básicas do transtorno do pânico. Revista Medicina Ribeirão Preto. 2017; 50(1): 56-63.

COSTA CO, et al. Prevalência de ansiedade e fatores associados em adultos. Jornal Brasileiro de Psiquiatria. 2019; 68(2): 92-100. 
101 | RESUMOS SIMPLES: Revisão Bibliográfica

\section{Influência da pandemia de COVID-19 na automedicação}

Autor/coautores: Camila da Silva Moura'; Maria Eduarda Bezerra Coutinho²; Vivian Farias Fortuna ${ }^{1}$; Maria Eduarda Alves Zuppardo"; Heytor Victor Pereira da Costa Neco'.

Instituição: ${ }^{1}$ Centro Universitário Maurício de Nassau (UNINASSAU), Recife-PE; ${ }^{2}$ Universidade Federal Rural de Pernambuco (UFRPE), Recife-PE.

Palavras-chave: Automedicação, Coronavírus, Pandemia.

\section{INTRODUÇÃO}

Com a declaração da Organização Mundial de Saúde (OMS) de que a COVID-19, doença causada pelo vírus SARS-CoV-2, se tratava de uma pandemia, as autoridades de saúde de diversos países estimularam o isolamento social e decretaram o fechamento de estabelecimentos públicos a fim de reduzir a possibilidade de infecção (SPINELLI A e PELLING G, 2020). Além disso, a prevenção consiste na utilização de máscaras, bem como higienização das mãos com água e sabão ou álcool em gel. Porém, apesar de vários estudos desenvolvidos, não há tratamento eficaz contra o vírus SARS-CoV-2, nem consenso sobre os medicamentos estudados. Ainda assim, a busca por medicamentos que amenizassem os sintomas da doença cresceu, assim como a automedicação.

\section{OBJETIVO}

Relatar a influência da pandemia de COVID-19 na automedicação.

\section{MÉTODO}

Esse resumo incluiu como base de estudo artigos da plataforma Google Acadêmico e Pubmed baseado no critério de avaliação à seleção de trabalhos dos anos 2019 e 2020 com foco na automedicação no período da pandemia do Covid-19 e que relata exemplos dos medicamentos mais automedicados na pandemia.

\section{RESULTADOS E DISCUSSÃO}

Diante da pandemia do Covid-19, a automedicação, que é o uso de medicamento sem o conhecimento prévio de um profissional de saúde, está ainda mais evidente no período de isolamento social, pois o indivíduo busca resolver os sintomas da doença. Dessa forma, houve um aumento no consumo de medicamentos como Azitromicina, Ivermectina, Paracetamol, Ibuprofeno, Vitamina $\mathrm{C}$ e Cloroquina ou Hidroxicloroquina. Porém, nenhum desses medicamentos citados têm 
eficácia comprovada em pacientes infectados por Covid-19, e alguns mostraram-se tóxicos e letais como a Hidroxicloroquina que tem seus efeitos negativos ao coração. Ela é propensa a causar prolongamento do intervalo QT e arritmia cardíaca potencialmente letal em certos pacientes (KAPOOR A, et al., 2020). Outro perigo de automedicação também foi descrito onde a toxicidade é observada como uma forma mais grave relatada assim em um caso de uma mulher de 42 anos infectada com a Covid-19 que se automedicou com hidroxicloroquina e desenvolveu a síndrome de Steves-Johnson que é a necrólise epidérmica tóxica que são causadas por medicamentos ou infecções (DAVOODI L, et al., 2020).

\section{CONSIDERAÇÕES FINAIS}

Dados os fatos propostos nesse resumo, constatou-se um grande aumento de automedicação durante a pandemia. Sendo assim, é relevante salientar que nenhum medicamento é usado no momento para combater a Covid-19. Por isso, é de extrema importância consultar um profissional de saúde para ter acesso a um tratamento eficaz e supervisionado.

\section{REFERÊNCIAS}

BARROS SC, et al. Indicações na terapia adjuvante das formas graves. Nota informativa do Ministério da Saúde, 2020.

DAVOODI L, et al. Hydroxychloroquine-induced Stevens-Johnson syndrome in COVID-19: a rare case report. Oxford Medical Case Reports, 2020; 6,193-195.

HENNIGEN AW, et al. Informações para profissionais da APS. Revista Telecondutas №28(Covid19), 2020.

KAPOOR A, et al. Cardiovascular risks of hydroxychloroquine in treatment andprophylaxis of COVID-19 patients: A scientific statement from thelndian Heart Rhythm Society. Indian Pacing and Electrophysiology Journal, 2020.

LUCCHETTA RC, DE CARVALHO MASTROIANNI P. Rational use of chloroquine and hydroxychloroquine in times of COVID-19. Journal of Basic and Applied Pharmaceutical Sciences, 2019.

SPINELLI A, PELLINO G. Pandemia de COVID-19: perspectivas de uma crise que se desenrola. $\mathrm{Br}$ J Surg, 2020; 107 (7): 785-787. 


\section{AGRADECIMENTOS}
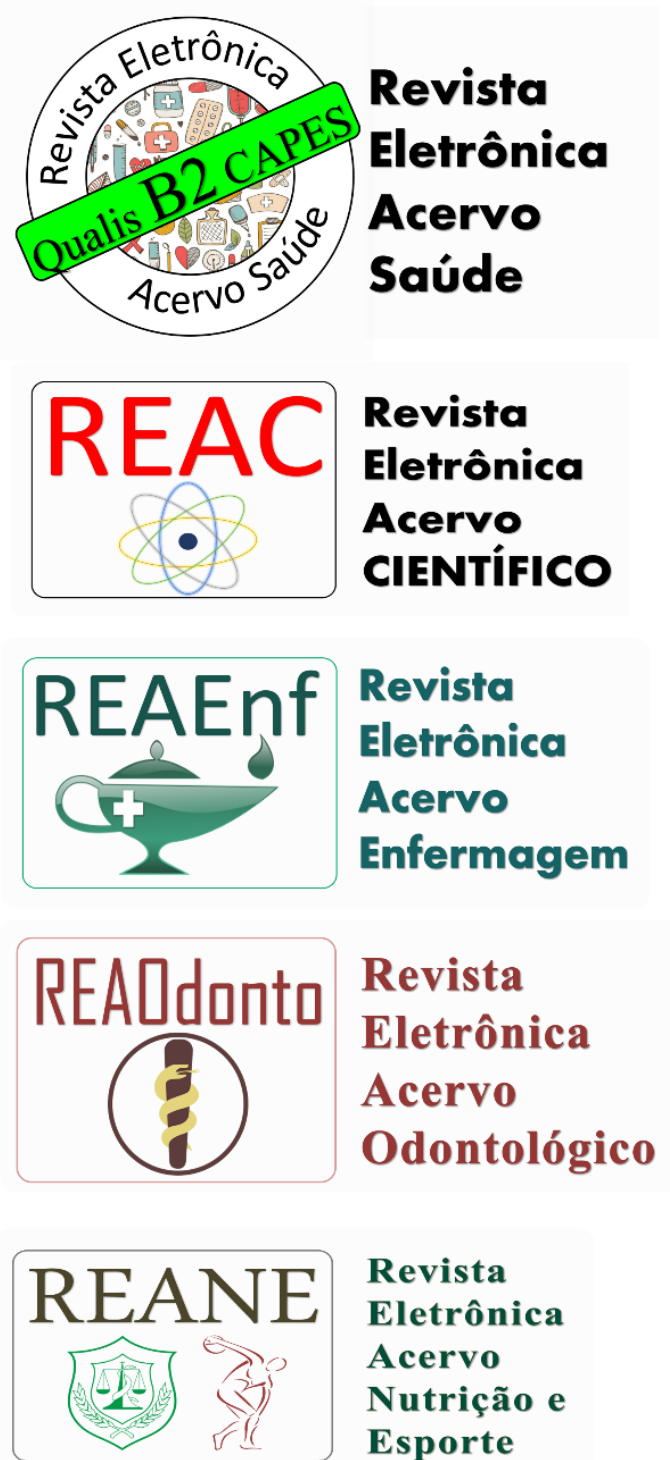

\section{Revista}

Eletrônica

Acervo

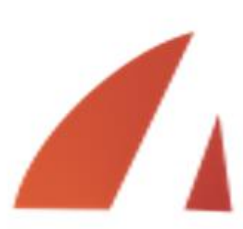

Nutrição e

Esporte

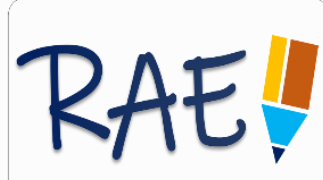

Revista

Acervo

Educacional

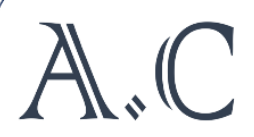

Revista

Artigos.

Com 